\title{
SÍNTESE, CARACTERIZAÇÃO E ESTUDO DO DESEMPENHO DE CATALISADORES DE PtRuMo/C TOLERANTES A CO
}

Dissertação apresentada ao Instituto de Química de São Carlos da Universidade de São Paulo como requisito para a obtenção do título de mestre em ciências.

Área de concentração: Físico-Química.

Orientadora: Prof. ${ }^{a}$ Dr. ${ }^{\text {a }}$ Joelma Perez

São Carlos - SP 
DEDICATÓRIA

Dedico este trabalho à memória do meu Pai, José Vicente González, de quem tive a melhor herança, seu exemplo; a minha Mãe Blanca Inês Hernandez, e toda minha família que sempre está presente, apesar da distância. 


\section{AGRADECIMENTOS}

- À República Federativa do Brasil, pela oportunidade de realizar meu estudo de mestrado;

- Ao meu pai José Vicente González e minha mãe Blanca Inés Hernandez, por me dar a vida, o amor, exemplo e força suficientes para me desenvolver tanto pessoal como profissionalmente em cada aspecto da minha vida. Agradeço também aos meus irmãos Adriana, Sandra, Claudia, Dora e Vicente por compartilhar sua vida, dedicação e estar sempre juntos nos momentos mais difíceis;

- À Prof. Dra. Joelma Perez, por permitir o desenvolvimento do meu projeto de mestrado no seu grupo de pesquisa, pelo apoio constante e ajuda tanto profissional como pessoal durante minha permanência;

- Ao Dr. Valdecir Paganin, pela constante ajuda e disposição para resolver assuntos tanto experimentais como teóricos, pela amizade e pela paciência mostrada durante o desenvolvimento de cada experimento;

- Ao Gabriel Christiano da Silva, pela amizade, ajuda e disposição profissional que teve em cada momento tanto no laboratório como fora dele;

- À Nathalia Abe Santos, pela confiança tanto pessoal como profissional, pela constante e paciente ajuda em cada duvida que se apresentou no desenvolvimento do meu projeto;

- Aos meus colegas do laboratório, Patrícia Corradini, Felipe Ibanhi, Claudia Nuñez, Guilherme Saglietti, Ayaz Hassam, Graziela Alves Ferreira, Jessica Alves, Juliana Jacob por seu profissionalismo como químicos e como pessoas;

- Aos meus amigos Colombianos, Cristian Camilo, Mônica Soto, Richard D'vries, Cristina , Felipe Rodriguez, Erica Meñaca, Irwin Patiño, Jorge Unas, Claudia Marín, por me receber e me aguentar dentro de suas vidas;

- Aos meus amigos Brasileiros Graziela, Gabriel, Rafael, Fernanda, Pedro, Nathalia, Guilherme, Patrícia, Juliana, os quais sempre estiveram disponíveis para me ajudar em qualquer momento do meu mestrado;

- Aos técnicos de Laboratório Jonas Ferreira e Paulo, encargados do equipamento de XDR pela ajuda concedida oportunamente na medida dos espectros, e Márcio de Paula, Pelas medidas de EDX; 
- Aos professores Germano Tremiliosi Filho, Hamilton Varela, Edson Ticianelli, Fabio Henrique Barros, pelos conhecimentos ministrado em cada aula recebida.

- Ao Instituto de Química de São Carlos (IQSC), por me aceitar e permitir desenvolver meu mestrado e por permitir a utilização de suas instalações e equipamentos;

- Ao Laboratório Nacional de Luz de Síncrotron (LNLS), por permitir as medidas de XPS relacionadas com meu projeto de pesquisa;

- A Coordenação de Aperfeiçoamento de Pessoal de Nível Superior (CAPES), por me outorgar a bolsa para realizar meu mestrado. 


\section{RESUMO}

Monóxido de carbono é a impureza mais comum encontrada em hidrogênio obtido a partir da reforma catalítica ou via hidrocarbonetos. Hidrogênio contaminado com CO diminui drasticamente o desempenho dos ânodos de células a combustível tipo PEM, especialmente quando Pt é utilizada, diminuindo assim os sítios disponíveis para a oxidação de $\mathrm{H}_{2}$. Neste trabalho catalisadores bimetálicos (PtRu e PtMo) e trimetálicos (PtRuMo) suportados em carbono de alta área superficial foram sintetizados através de duas rotas de síntese: impregnação e poliol. Os materiais foram caracterizados através das técnicas de difração de Raios X (DRX), Energia Dispersiva de Raios X (EDX), Microscopia Eletrônica de Transmissão (TEM) e Espectroscopia Fotoeletrônica de Raios X (XPS), e avaliados frente a reação de oxidação de hidrogênio, utilizando $\mathrm{H}_{2}$ puro e $\mathrm{H}_{2}$ contaminado com $\mathrm{CO}$, através de medidas em célula unitária, como ânodos de PEMFC. Os catalisadores ternários apresentaram o melhor desempenho frente a $\mathrm{ROH}$, e os catalisadores tratados a $600{ }^{\circ} \mathrm{C}$ em atmosfera redutora e obtido utilizando o método do poliol com segundo agente redutor apresentaram melhor tolerância a CO. Através dos testes de envelhecimento acelerado (TEA), constatouse uma menor perda de desempenho para o catalisador PtRuMo/C tratado a $600{ }^{\circ} \mathrm{C}$ em atmosfera redutora. A espectrometria de massa permitiu identificar $\mathrm{CO}_{2}$ e $\mathrm{CH}_{4}$ como produtos da oxidação.

Palavras chaves: células a combustível, monóxido de carbono, $\mathrm{PtRu} / \mathrm{C}, \mathrm{PtMo} / \mathrm{C}$ e PtRuMo/C. 


\begin{abstract}
Carbon monoxide is one of the most common impurities in hydrogen fuel obtained from the catalytic reforming of hydrocarbons. CO-contaminated hydrogen drastically decreases the performance of the anodes of PEM fuel cell type, especially when $\mathrm{Pt}$ is used, by $\mathrm{CO}$ adsorption, reducing the available sites for oxidation $\mathrm{H}_{2}$. In this work bimetallic catalysts (PtRu and PtMo) and trimetallic (PtRuMo) supported on high surface area carbon were synthesized via two synthetic routes: impregnation and polyol. The materials were characterized by X-ray diffraction, energy dispersive X-ray analysis, transmission electron microscopy and X-ray photoelectron spectroscopy, and evaluated towards hydrogen oxidation reaction ( $\mathrm{HOR}$ ), using pure $\mathrm{H}_{2}$ and $\mathrm{H}_{2}$ contaminated with $\mathrm{CO}$, through measurements in the unit cell, as anode of PEMFC. Ternary catalysts showed better performance to $\mathrm{HOR}$, while the catalysts treated at $600^{\circ} \mathrm{C}$ in a reducing atmosphere and the one obtained using the polyol method using a second reducing agent had the best $\mathrm{CO}$ tolerance. Accelerated Aging Tests (AGT) evidenced a minor loss of performance for the PtRuMo catalyst treated at $600{ }^{\circ} \mathrm{C}$. Mass spectrometry permitted the identification of $\mathrm{CO}_{2}$ and $\mathrm{CH}_{4}$ as oxidation products.
\end{abstract}

Keywords: Fuel Cells, carbon monoxide, PtRu/C, PtMo/C, PtRuMo/C. 


\section{LISTA DE FIGURAS}

Figura 1. Projeção de consumo mundial de energia até o ano 2060 e suas fontes [1].

Figura 2. Esquema de uma célula a combustível, adaptado de [8]. 18

Figura 3. Esquema dos tipos de ligação entre $\mathrm{CO}$ e Pt a) Tipo linear e b) tipo ponte. .20

Figura 4. Mecanismos de oxidação de CO para a liga bimetálica PtRu/C considerando: i) mecanismo bifuncional e ii) efeito eletrônico. Adaptado de [11].

Figura 5. Exemplo do conjunto dos eletrodos e membrana MEA (membrane electrode assembly) [4].

Figura 6. Difratograma dos catalisadores: (a) bimetálicos: PtRu/C e PtMo/C, comparados com Pt Etek e (b) trimetálicos PtRuMo submetidos a diferentes tratamentos térmicos.

Figura 7. Micrografias dos catalisadores trimetálicos PtRuMo/C: a)PtRuMo-P; b)PtRuMo-P300, c)PtRuMo-P600, d)PtRuMo-PSH.

Figura 8. Espectros de XPS para Pt 4f, Ru 3p e Mo 3d para os diferentes compostos trimetálicos de a) PtRuMo-P, b) PtRuMo-P300, c) PtRoMu-P600 e d) PtRuMoPSH.

Figura 9. (a) Curva de polarização em estado estacionário e (b) curvas de densidade de potência e (c) curva de sobrepotencial $\left(\eta \mathrm{H}_{2} / C O=E H_{2}-E H_{2} / C O\right.$ ) vs. densidade de corrente j $\left(\mathrm{A} \mathrm{cm}^{-2}\right)$. Para os catalisadores bimetálicos (ânodos) de PtRu e PtMo/C. e cátodo de Pt/C ao 20\%. Nafion $\AA^{\circledR} 115$, T. cátodo $=95^{\circ} \mathrm{C}, \mathrm{T}$. ânodo $=105^{\circ} \mathrm{C}, \mathrm{T}$. Célula $85^{\circ} \mathrm{C}$. Alimentados no ânodo com $\mathrm{H}_{2}$ e $\mathrm{H}_{2}+100$ ppm de CO. 
Figura 10. (a) Curva de polarização em estado estacionário e (b) curvas de densidade de potência e (c) Curva de sobrepotencial ( $\eta \mathrm{H}_{2} / \mathrm{CO}=E \mathrm{H}_{2}-E$ $\left.\mathrm{H}_{2} / \mathrm{CO}\right)$ vs. densidade de corrente j $\left(\mathrm{A} \mathrm{cm}^{-2}\right)$. Para os catalisadores tribimetálicos (ânodos) de PtRutMo/C. e cátodo de Pt/C ao 20\% . Nafion ${ }^{\circledR} 115$, T. cátodo $=95^{\circ} \mathrm{C}, \mathrm{T}$. ânodo $=105^{\circ} \mathrm{C}, \mathrm{T}$. Célula $85^{\circ} \mathrm{C}$. Alimentados no ânodo com $\mathrm{H}_{2}$ e $\mathrm{H}_{2}+100$ ppm de CO.

Figura 11. Curvas de polarização em estado estacionário e curvas de densidade se potencia para catalisadores trimetálicos de PtRuMo/C antes e depois de 1000 ciclos, com $\mathrm{H}_{2}$ puro e 100 ppm de CO (a-b) PtRuMo-P300, (c-d) PtRuMo-P600 e (e-f) PtRuMo-PSH.

Figura 12. (a) Densidade de potência máxima para catalisadores trimetálicos de PtRuMo/C antes e depois de 1000 ciclos e (b) Sobrepotenciais da célula unitária em $0,5 \mathrm{~A} \mathrm{~cm}^{-2}$ para catalisadores trimetálicos de PtRuMo/C antes e depois de 1000 ciclos, com $\mathrm{H}_{2}$ puro e 100 ppm de $\mathrm{CO}$.

Figura 13. Voltametria cíclica para os catalisadores PtRuMo (P300, P600 e PSH), entre $0,1 \mathrm{~V}-0,7 \mathrm{~V}$ a $20 \mathrm{mV} \mathrm{s}^{-1}$ vs. $\mathrm{ERH}, \mathrm{T}=25^{\circ} \mathrm{C}$, ante e após 1000 ciclos. ....58

Figura 14. Stripping de CO para os catalisadores trimetálicos PtRuMo/C , v $=10 \mathrm{mV}$ $\mathrm{s}^{-1}$, atmosfera de argônio (a) e Curvas obtidas da subtração do $1^{\circ}$ ciclo (b)......59

Figura 15. Comparação das curvas obtidas da subtração do $1^{\circ}$ ciclo do stripping de CO para os catalisadores trimetálicos PtRuMo/C, antes e após o TEA , v $=10$ $\mathrm{mV} \mathrm{s}^{-1}$, atmosfera de argônio: (a) PtRuMo-P300, (b) PtRuMoP-600 e (c) PtRuMo-PSH.

Figura 16. Áreas ativas dos catalisadores PtRuMo antes e após o TEA. 62

Figura 17 (a) Produção de $\mathrm{CO}_{2}$ em termos de corrente relativa $(\Delta \mathrm{l})$ vs. sobrepotencial $\eta$ para os catalisadores PtRuMO-P e (b) Densidade de corrente $\left(\mathrm{Acm}^{-2}\right)$ vs. sobrepotencial $(\eta)$ 
Figura 18. Intensidade iônica via EM, obtida para a produção de $\mathrm{CH}_{4}(\mathrm{~m} / \mathrm{z}=15)$ e $\mathrm{CO}_{2}(\mathrm{~m} / \mathrm{z}=44)$ com relação a troca de $\mathrm{H}_{2}$ por $\mathrm{H}_{2}+100 \mathrm{ppm}$ de $\mathrm{CO}$ alimentando o cátodo com $\mathrm{O}_{2}$ para o catalisador de PtRuMo-P, nas condições estabelecidas para as curvas de polarização em função do tempo. Trocas indicadas na figura.

Figura 19. Intensidade iônica Via EM, obtida para a produção de $\mathrm{CH}_{4}(\mathrm{~m} / \mathrm{z}=15), \mathrm{CO}$ $(\mathrm{m} / \mathrm{z}=28)$ e $\mathrm{CO}_{2}(\mathrm{~m} / \mathrm{z}=44)$ com relação a troca de $\mathrm{H}_{2}$ por $\mathrm{H}_{2}+100 \mathrm{ppm}$ de $\mathrm{CO}$ alimentando o cátodo com $\mathrm{O}_{2}$ para o catalisador de PtRuMo-PSH, nas condições estabelecidas para as curvas de polarização. Trocas indicadas na figura 


\section{LISTA DE TABELAS}

Tabela 1. Lista de catalisadores da literatura desenvolvidos para avaliar sua tolerância ao CO Adaptado da referência [21].

Tabela 2. Composição atômica nos catalisadores PtRu-P, PtRu-I e PtMo-P via EDX, tamanho de cristalito, parâmetro de rede e grau de liga determinado por XDR.39

Tabela 3. Composição atômica presentes nos catalisadores PtRuMo/C via EDX, tamanho de cristalito (DRX), tamanho de partícula (TEM) e parâmetro de rede (A) obtidos por DRX

Tabela 4. Energia de Ligação dos componentes Pt 4f, Ru 3p e Mo 3d para os catalisadores PtRuMo/C

Tabela 5. Porcentagem atômica de cada elemento em cada catalisador PtRuMo/C de acordo aos seus estados de oxidação para Pt 4f, Ru 3p e Mo 3d.

Tabela 6. Áreas eletroativas dos catalisadores trimetálicos de PtRuMo antes e após o TEA. .60 


\section{LISTA DE ABREVIAÇÕES}

PEMFC "Proton exchange membrane fuel cell"

PEM "Polymer electrolyte membrane"

MEA "Membrane elctrode assembly"

DFT "Density functional theory"

ERH "Eletrodo Reversível de hidrogênio".

VC "Voltametría cícila"

MS "Mass espectrommetry"

SCO "Stripping de CO"

TEM "Transmission electronic microscopy"

XDR "X-Ray difraction"

EDX "Energy dispersive X-ray analysis"

XPS "X-ray photoelectron spectroscopy"

EM "Espectroscopia de massas"

CFC "Estrutura cúbica de face centrada"

Eph "Energia do fotón"

TEA "Teste de envelhecimento acelerado" 


\section{LISTA DE SÍMBOLOS}

jL Corrente limite

j Densidade de corrente $\left(\mathrm{A} \mathrm{cm}^{-2}\right)$

E Potencial (V)

$\rho \quad$ Densidade de potência $\left(\mathrm{W} \mathrm{cm}^{-2}\right)$

d Tamanho médio de cristalito $(\mathrm{nm})$

a Parâmetro de rede $(\AA)$

$a_{\mathrm{Pt}} \quad$ Parâmetro de rede da Pt Pura ( $\AA$ )

$a_{\mathrm{L}} \quad$ Parâmetro de rede teórico para catalisadores bimetálicos $(\AA ̊ \AA)$

$a_{\text {ex }} \quad$ Parâmetro de rede experimental para catalisadores bimetálicos $(\AA ̊)$

$\theta \quad$ Ângulo de difração

$\lambda \quad$ Comprimento de onda $(\mathrm{nm})$

$X_{\text {liga }} \quad$ Fração molar do segundo metal na liga

$\eta_{\mathrm{H} 2 / \mathrm{CO}}$ Sobrepotencial (V) obtido entre a diferença de potenciais de $\mathrm{H}_{2}$ puro e $\mathrm{H}_{2} / \mathrm{CO}$

$E_{H 2} \quad$ Potencial (V) do ânodo alimentado com $\mathrm{H}_{2}$

$E_{\text {H2/CO }}$ Potencial (V) do ânodo contaminado com 100 ppm de CO

$\Delta \mathrm{I}_{44} \quad$ Corrente de normalização para produção de $\mathrm{CO}_{2}$ com relação à $\mathrm{H}_{2}$ 


\section{SUMÁRIO}

1. INTRODUÇÃO 15

1.1 Relevância dos recursos energéticos ............................................ 15

1.2 Descrição das células a combustível.............................................17

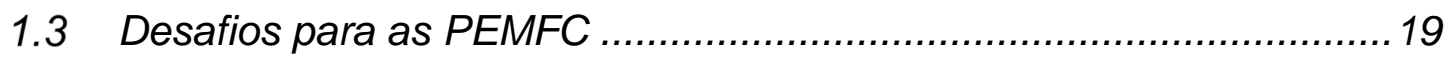

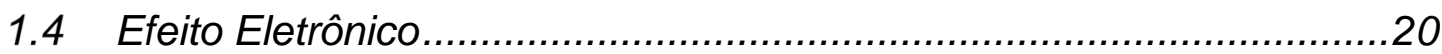

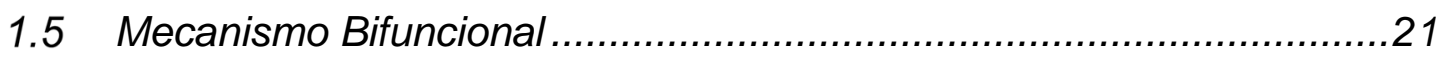

1.6 Estado da arte dos catalisadores tolerantes a CO...........................22

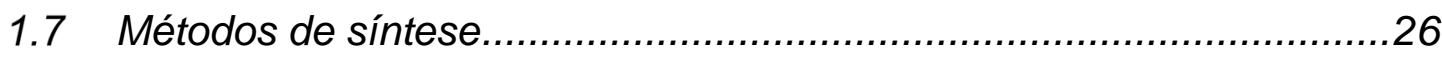

2. OBJETIVOS

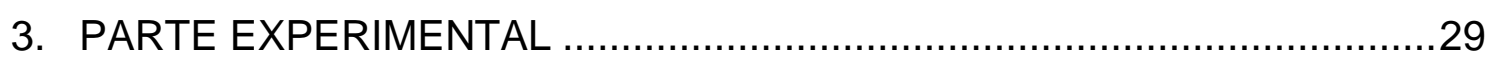

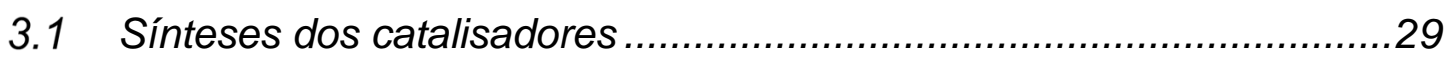

3.1.1 Síntese pelo método de Impregnação..........................................29

3.1.2 Síntese pelo método de poliol modificado …..................................30

3.1.3 Tratamentos térmicos dos catalisadores .....................................30

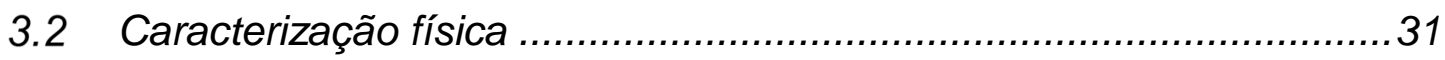

3.2.1 Difração de raios X (DRX) ……..................................................

3.2.2 Espectroscopia de raios $\mathrm{X}$ por energia dispersiva (EDX) ................32

3.2.3 Microscopia eletrônica de transmissão (TEM)................................32

3.2.4 Espectroscopia de fotoelétrons excitados por raios X (XPS) ….......32 
3.3.1 Testes em célula unitária. .34

4. RESULTADOS E DISCUSSÃO .39

4.1 Caracterização Física 39

4.2 Espectroscopia de raios $X$ por energia dispersiva 39

4.2.1 Difração de raios $X$. 40

4.2.2 Microscopia eletrônica de transmissão 43

4.2.3 Espectroscopia de Fotoelétrons Excitados por Raios X. .44

4.3 Medidas em Célula Unitária. 48

4.3.1 Curvas de polarização 48

4.3.2 Testes de Envelhecimento Acelerado (TEA)..... .53

4.3.3 Voltametria cíclica e stripping de CO 57

4.4 Espectroscopia de Massa on-line 62

5. CONCLUSÃO 67

6. REFERÊNCIAS BIBLIOGRÁFICAS 69 


\section{INTRODUÇÃO}

\subsection{Relevância dos recursos energéticos}

As diversas fontes energéticas aproveitadas pelo homem são, até nosso tempo, a base de desenvolvimento ao redor do mundo, razão pela qual a humanidade depende diretamente destas para desenvolver suas atividades mais comuns, desde movimentar-se, trabalhar e até o entretenimento. Neste sentido, o consumo excessivo de matéria prima implica, desde a etapa de extração até a etapa de descarte, na deterioração do meio ambiente. Como exemplo, podemos citar a extração e refino de petróleo e uso dos seus derivados, as baterias que ao terminar sua vida útil são descartadas, tornando-se poluentes para o meio ambiente e também as fontes de energia hídricas que transformam o entorno e muitas vezes destroem a flora e fauna do local da construção [1].

A combustão de hidrocarbonetos fósseis é também uma fonte de contaminação ambiental, pois gera óxidos poluentes como dióxido de carbono e monóxido de carbono $\left(\mathrm{CO}_{2}, \mathrm{CO}\right)$, dióxido de enxofre $\left(\mathrm{SO}_{2}\right)$ e óxido nitroso $\left(\mathrm{NO}_{2}\right)$, que destroem a camada de ozônio, ocasionando o aquecimento global, a chuva ácida, a destruição do ecossistema e a diminuição na qualidade de vida da população [2].

Além disso, o consumo destes combustíveis e das diversas fontes energéticas vem se elevando com o aumento da população [1], o que gera relevância suficiente para encontrar formas que promovam o uso de novas fontes de energia, diminuindo o efeito da poluição na sociedade, o impacto ambiental e, ao mesmo tempo, desenvolvimento sustentável.

A Figura 1 ilustra as projeções que se tem para o consumo de energia e suas fontes, na qual os combustíveis fósseis tem uma importante relevância na atualidade, e, consequentemente, seu efeito poluente. No entanto, estas fontes são limitadas e sua diminuição está prevista após do ano 2030, razão pela qual, devem ser complementadas por fontes energéticas limpas e renováveis. 
Figura 1. Projeção de consumo mundial de energia até o ano 2060 e suas fontes [1].

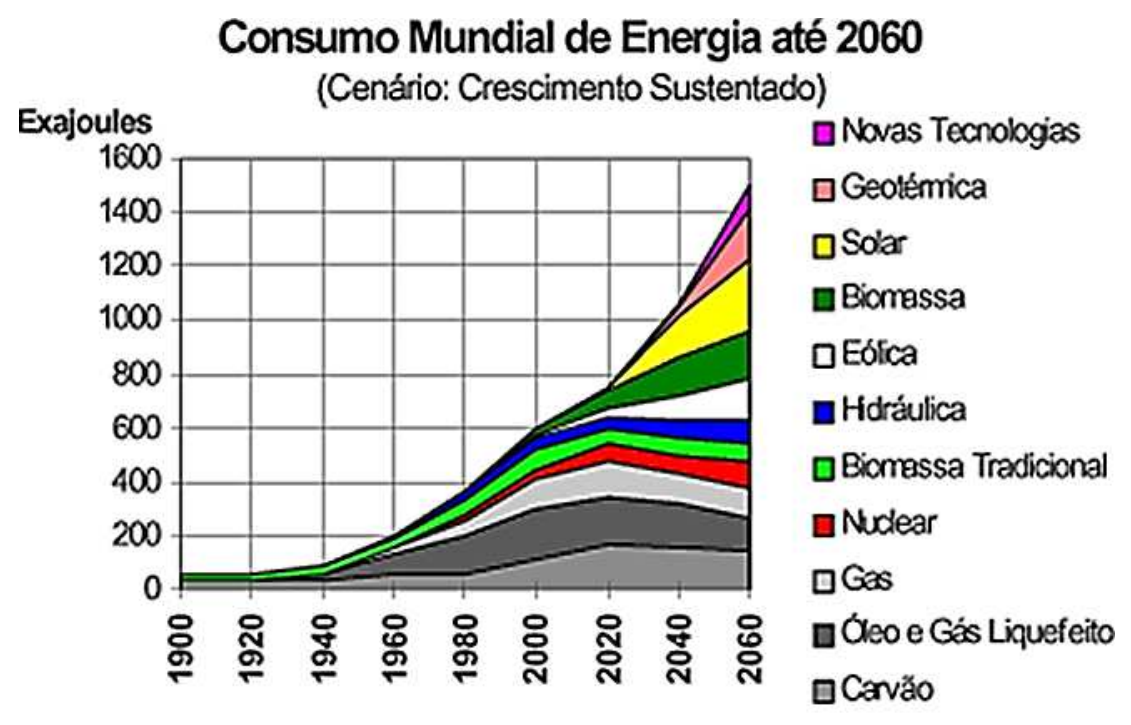

Neste sentido, as tecnologias limpas para o futuro serão fundamentais como opções viáveis, reduzindo os níveis de poluentes, melhorando o meio ambiente e, consequentemente, a qualidade de vida das pessoas na sociedade.

Existem várias opções de energias alternativas, que compreendem a energia solar, eólica, maremotriz, geotérmica e as células a combustível. As células a combustível são dispositivos que utilizam, geralmente, hidrogênio, etanol ou outros álcoois de baixo peso molecular como combustível [3,4]. Elas se dividem em dois grupos, as que operam em baixa e as que operam em alta temperatura, sendo que as primeiras trabalham até $470 \mathrm{~K}$, como, por exemplo, as células de hidrogênio e álcoois de baixo peso molecular [5]. A implementação deste tipo de célula está crescendo devido a sua operação em baixas temperaturas e eficiência entre $60 \%$ e $70 \%$, quando hidrogênio é utilizado como combustível $[5,6]$. Até o ano 2000, a capacidade instalada foi ao redor de $400 \mathrm{MW}$, que segue elevando-se. Portanto, a pesquisa neste tópico é muito ativa, sendo estimulada pelos governos e empresas privadas, especificamente no desenvolvimento de células a combustível de membrana de troca protônica (Proton Exchange membran fuel cell - PEMFC) [3,4]. 


\subsection{Descrição das células a combustível}

As células a combustível têm o mesmo princípio que as baterias e as pilhas convencionais, compostas de um ânodo e um cátodo, cujo processo de oxidação e redução, respectivamente, permitem a passagem de elétrons desde o ânodo até o cátodo e, portanto, a produção de energia. A diferença entre as células a combustível e as pilhas é que, as pilhas contêm seus reagentes em um sistema fechado, razão pela qual são descartadas após seu uso, além de apresentarem corrosão e líquidos que limitam a sua durabilidade. No entanto, as células a combustível podem funcionar continuamente com a adição de seus reagentes em um sistema aberto [5-7].

O desenvolvimento da pesquisa nesta área pode representar uma mudança na economia, favorecendo um ciclo de energia menos poluente em comparação com os já mencionados. Nas células a combustível tipo PEMFC, ocorre a redução do oxigênio no cátodo e a oxidação do hidrogênio no ânodo, transformando a energia diretamente do "combustível" ou reagente em energia elétrica através de um processo redox, sem ocorrer uma reação de combustão, atingindo uma eficiência real entre $50 \%-65 \%$ que aumenta com o aumento da temperatura de funcionamento da célula. [6].

A estrutura da célula a combustível é relativamente simples, está constituída por dois eletrodos, o cátodo e o ânodo, separados por um eletrólito, que permite a passagem dos prótons $\left(\mathrm{H}^{+}\right)$. No ânodo ocorre a oxidação do combustível $\left(\mathrm{H}_{2}\right)$ e no cátodo, ocorre a redução de oxigênio $\mathrm{O}_{2}$ procedente do ar como ilustrado na Figura 2. 
Figura 2. Esquema de uma célula a combustível, adaptado de [8].

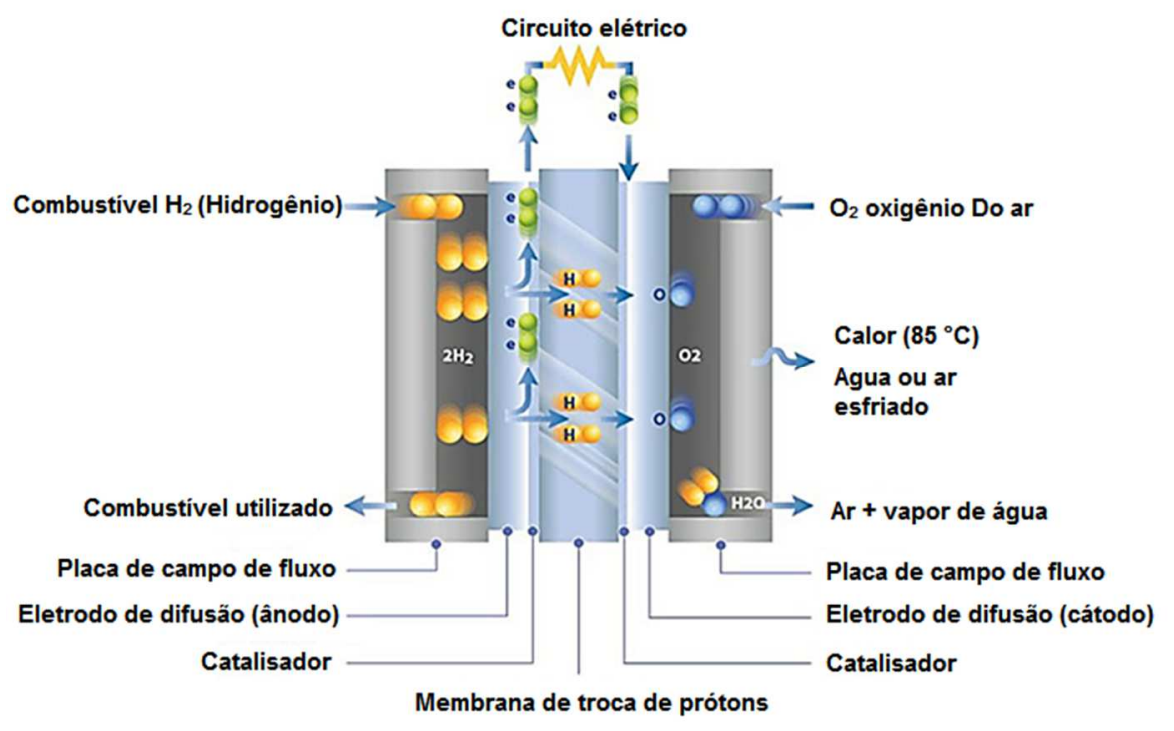

As células a combustível são classificadas pela temperatura de funcionamento e, consequentemente, pela composição do eletrólito utilizado na célula. No caso das células de baixas temperaturas $\left(<200{ }^{\circ} \mathrm{C}\right)$, geralmente são utilizados eletrólitos poliméricos aquosos, como os eletrodos de membrana polimérica PEM (Polymer electrolyte membrane) baseadas em Náfion ${ }^{\circledR}$ como eletrólito. Enquanto que, nas células de alta temperatura são utilizadas membranas não aquosas $\left(>200^{\circ} \mathrm{C}\right)$, como as membranas de ácido fosfórico [4,7].

A importância das membranas poliméricas de Nafion ${ }^{\circledR}$, utilizada nas PEMFC, consiste na troca de prótons que ocorre na reação de oxidação em baixas temperaturas (até $105^{\circ} \mathrm{C}$ ), permitindo passagem de ions $\mathrm{H}^{+}$até o cátodo, onde ocorre a redução do oxigênio, tendo água como produto. A eficiência da membrana consiste em permitir a passagem de íons $\mathrm{H}^{+}$até o cátodo por meio de íons sulfeto $\left(\mathrm{SO}_{3}{ }^{2-}\right)$, que fazem parte da estrutura do $\mathrm{Nafion}^{\circledR}$ e estão ligados a uma cadeia hidrofóbica que bloqueia a passagem de moléculas de água, permitindo unicamente a passagem de íons $\mathrm{H}^{+}[9]$.

Até o momento, as células PEM mais eficientes na conversão de energia são as que utilizam gás hidrogênio $\left(\mathrm{H}_{2}\right)$ como combustível, oxidando $\mathrm{H}_{2}$ no ânodo, enquanto o oxigênio é reduzido no cátodo. Entretanto, a presença de monóxido de carbono 
(CO), que é a impureza mais comum encontrada em hidrogênio, obtido a partir da reforma catalítica ou via hidrocarbonetos [10], diminui drasticamente o desempenho dos ânodos, especialmente quando Pt é utilizada, reduzindo a atividade catalítica do catalisador anódico pela adsorção de $\mathrm{CO}$, diminuindo os sítios disponíveis para a oxidação de $\mathrm{H}_{2}$. O estudo dos catalisadores tolerantes a $\mathrm{CO}$ é uma das vertentes mais pesquisadas no campo das células a combustível [10-12]

\subsection{Desafios para as PEMFC}

Um dos principais desafios para as células a combustível que utilizam $\mathrm{H}_{2}$ como combustível contaminados com $\mathrm{CO}$ consiste em reduzir a atividade do $\mathrm{CO}_{a d s}$ na superfície do eletrodo. Os elétrons do orbital $5 \sigma$ do $\mathrm{CO}$ são doados a banda $5 \mathrm{~d} d a \mathrm{Pt}$ por retro-doação, preenchendo o orbital $2 \pi^{\star}$ do metal, gerando uma forte adsorção do $\mathrm{CO}$ na $\mathrm{Pt}$, muito maior do que $\mathrm{H}_{2}$, portanto observa-se uma diminuição: I) dos sítios ativos disponíveis da Pt para a oxidação de $\mathrm{H}_{2}$, ii) da transferência protônica e iii) na geração de corrente [12].

A adsorção de CO sobre a Pt acontece de 2 formas como apresentado na Figura 3. A Figura 3(a) ilustra a adsorção na Pt de forma linear, entre um sítio ativo da Pt e uma molécula de $\mathrm{CO}$ formando uma ligação entre o orbital $5 \mathrm{p} \sigma$ da Pt e o orbital $\sigma$ do $C$ pertencente ao $\mathrm{CO}$. Na Figura 3 (b) observa-se a adsorção tipo ponte entre 2 sítios ativos da Pt e uma molécula de $\mathrm{CO}$, na qual se formam 2 ligações entre a Pt e CO mediante os orbitais $5 \mathrm{~d} \pi$ e os orbitais $2 \mathrm{p} \pi$ do carbono $\mathrm{C}$ ligado ao CO. A forma predominante de adsorção na Pt depende do grau de recobrimento, sendo a adsorção linear dominante em altos recobrimentos [13].

Uma das principais formas propostas para diminuir o efeito do envenenamento catalítico por CO adsorvido na superfície da platina no ânodo é a síntese de catalisadores bimetálicos suportados em carbono $(\mathrm{Pt}-\mathrm{M} / \mathrm{C})$, onde o segundo metal $\mathrm{M}$ corresponde a metais de transição tais como: $\mathrm{Ru}, \mathrm{Mo}, \mathrm{Fe}, \mathrm{Sn}, \mathrm{Ni}$. A maior tolerância dos catalisadores bimetálicos (PtM) é atribuída ao efeito eletrônico, ao mecanismo bifuncional ou por uma combinação dos mesmos. 
Figura 3. Esquema dos tipos de ligação entre $\mathrm{CO}$ e Pt a) Tipo linear e b) tipo ponte.

a)
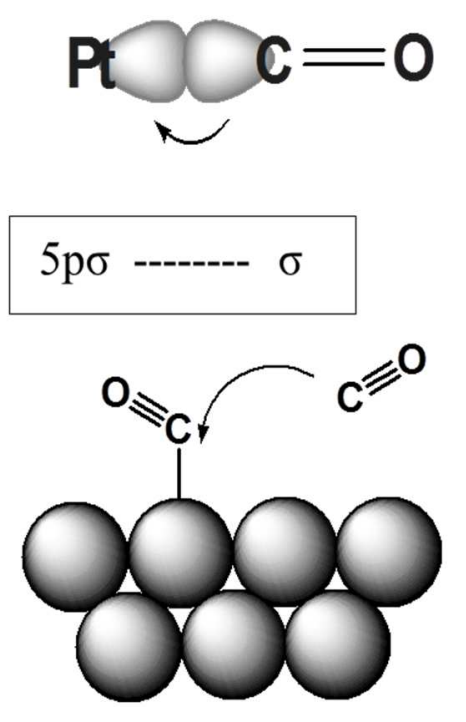

b)
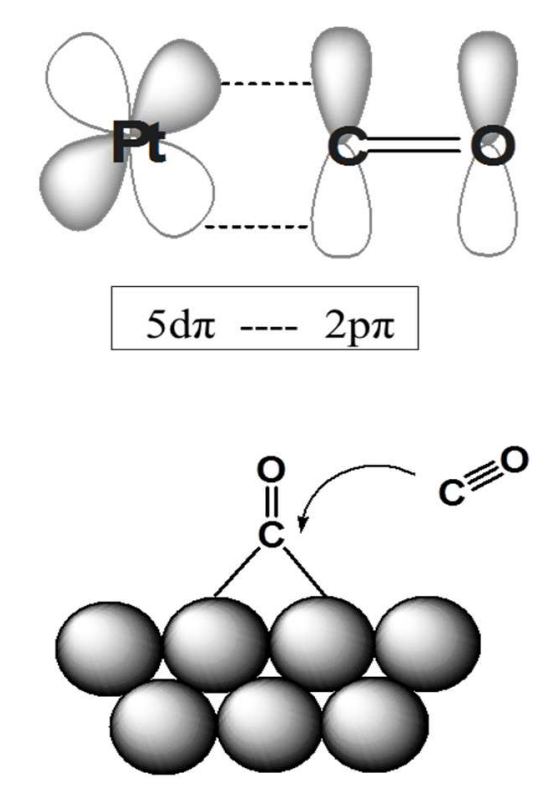

\subsection{Efeito Eletrônico}

O efeito eletrônico baseia-se no fato que a presença de um segundo metal na liga com Pt, tais como Ru, Mo, Rh, Sn ou outros metais de transição, aumenta a vacância $5 \mathrm{~d}$ da Pt. Esta observação foi apontada por Norskov et al. [14,15] baseados em estudos de DFT (teoria da densidade funcional). Ao mudar a estrutura eletrônica da Pt pela adição de um segundo metal, a energia de adsorção de CO nos catalisadores bimetálicos diminui, decrescendo o recobrimento superficial de $\mathrm{CO}$ e enfraquecendo a ligação deste com a Pt e, consequentemente, aumentando a adsorção de $\mathrm{H}_{2}$, e a cinética da reação de oxidação de hidrogênio $(\mathrm{ROH})$. O efeito eletrônico foi demonstrado por estudos experimentais utilizando espectroscopia de absorção de raios $\mathrm{X}$, indicando que o segundo metal desloca a banda eletrônica $5 d$ da $\mathrm{Pt}$, diminuindo seu potencial de oxidação, conseguindo uma dessorção de $\mathrm{CO}$ a potenciais inferiores $[11,16,17]$. 


\subsection{Mecanismo Bifuncional}

No mecanismo bifuncional, o segundo metal ligado à Pt tem a finalidade de formar espécies oxigenadas em potenciais inferiores ao dos catalisadores de Pt. Este mecanismo ocorre por uma reação tipo Langmuir-Hinshelwood com espécies oxihidróxi formadas na superfície do eletrodo. Os íons $\mathrm{OH}^{-}$(provenientes das moléculas de $\mathrm{H}_{2} \mathrm{O}$ presentes no meio), como intermediários adsorvidos no segundo metal, favorecem a oxidação de $\mathrm{CO}$ a $\mathrm{CO}_{2}$. Com isto, a adição do segundo metal leva a dessorção de $\mathrm{CO}$ no catalisador a potenciais inferiores a $0,5 \mathrm{~V}$ vs. ERH (eletrodo reversível de hidrogênio) comparado ao catalisadores de $\mathrm{Pt} / \mathrm{C}(0,7 \vee$ vs. $\mathrm{ERH})$, liberando mais sítios ativos de Pt para a adsorção de $\mathrm{H}_{2}$ na superfície do eletrodo, melhorando assim a eficiência com respeito à conversão de energia $[10,11,14,16$, $18]$.

A Figura 4 apresenta a influência de um catalisador de PtRu/C sobre a reação de oxidação de $\mathrm{CO}$. Nos mecanismos de adsorção e dessorção de $\mathrm{CO}$ no catalisador de $\mathrm{PtRu}$, observa-se uma corrente limite, $\mathrm{jL}$, que representa o número de sítios superficiais livres, e para que exista dessorção a densidade de corrente tem que ser maior do que a densidade de corrente em fase estacionária. No mecanismo bifuncional $(I)$ as correntes superiores a jL não suprem o recobrimento por $\mathrm{H}^{*}$ para manter a taxa de oxidação, razão pela qual são adsorvidos os íons hidroxila $\mathrm{OH}^{-}$que contribuem para a oxidação de $\mathrm{CO}$ a $\mathrm{CO}_{2}$; e no mecanismo eletrônico (ii) jL é superior a $\mathrm{j}$ e, portanto, aumenta a área livre de recobrimento de $\mathrm{CO}$, aumentando $\mathrm{O}$ desempenho do ânodo. 
Figura 4. Mecanismos de oxidação de $C O$ para a liga bimetálica PtRu/C considerando: i) mecanismo bifuncional e ii) efeito eletrônico. Adaptado de [11].

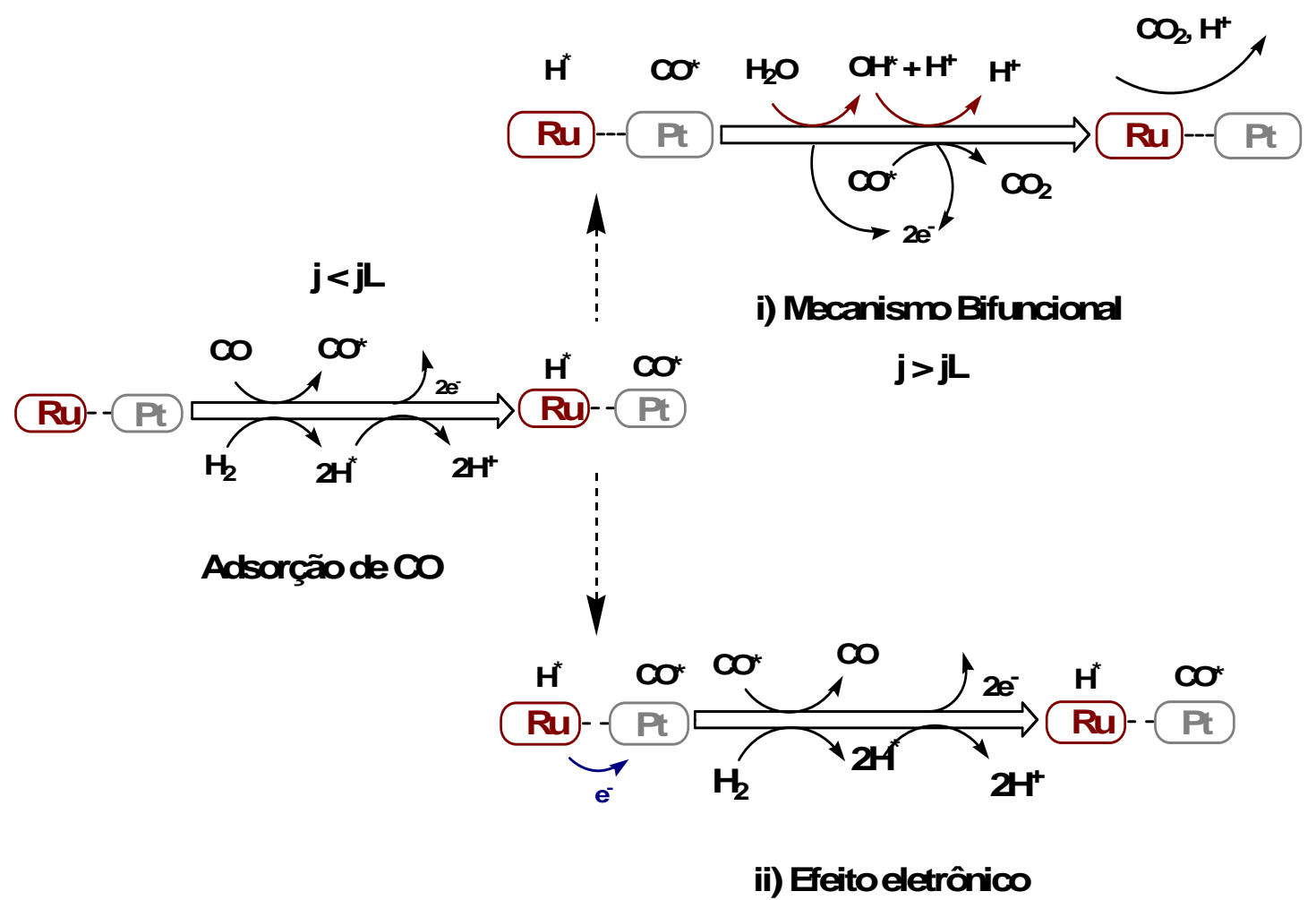

jL superior

\subsection{Estado da arte dos catalisadores tolerantes a CO}

Estudos prévios mostram que catalisadores bimetálicos de Pt com metais de transição suportados em carbono evidenciam uma melhor tolerância ao $\mathrm{CO}$, justificada com base no efeito eletrônico e/ou mecanismo bifuncional, aumentando a cinética da $\mathrm{ROH}$ (reação de oxidação de hidrogênio). Estudos com catalisadores bimetálicos como PtCo/C e PtNi/C apresentam uma discreta melhora na atividade catalítica de oxidação de $\mathrm{CO}$, obtendo densidades de correntes superiores em potencial entre 50 e $150 \mathrm{mV}$ vs. ERH, respectivamente, com relação à Pt/C [19-21]. Estudos com catalisadores de PtSn/C comparados a Pt/C, com o Sn na forma de óxido, indicam uma tolerância discretamente superior, justificado pela combinação entre o mecanismo bifuncional e efeitos eletrônicos [22]. Ligas de PtFe tipo core-shell suportado em carbono apresentam uma melhor atividade catalítica em potenciais 
superiores a 200 mV vs. ERH com relação aos catalisadores PtCo, PtNi, PtSn, PtPb. PtW e Pt suportados em carbono, devido as propriedades da cobertura de Fe sobre a Pt (core-shell), aumentando, como consequência, o efeito eletrônico [23]. Ligas de $\mathrm{PtCe} / \mathrm{C}$ também apresentam alta atividade eletrocatalítica na forma de $\mathrm{PtCe}$ e $\mathrm{PtCeO}_{2}$, devido ao efeito de spill-over e pelo mecanismo bifuncional evidenciando pela produção de $\mathrm{CO}_{2}$ na catálise [24].

Os catalisadores de PtRu/C são considerados os catalisadores mais promissores no sentido de diminuir o efeito do envenenamento no ânodo das células PEM, ao oxidar de maneira eficiente o $\mathrm{CO}$ a $\mathrm{CO}_{2}$, aliado a sua maior estabilidade [10, 21, 25]. Os estudos envolvendo catalisadores de PtRu apresentam várias rotas justificando a tolerância. Por exemplo, estudos de espetroscopia de absorção de raios $X(X A S)$ [10, 26] mostram que a presença de Ru em contato com a platina aumenta a vacância na banda $5 \mathrm{~d}$ da $\mathrm{Pt}$, sendo a ligação $\mathrm{Pt}-\mathrm{CO}$ mais fraca, diminuindo, portanto, o envenenamento da superfície. Além do efeito eletrônico pode-se ainda observar o mecanismo bi-funcional $[14,27,28]$. Os catalisadores de PtRu/C são apontados como estáveis na célula operando em condições normais (0,5 V vs. ERH), apresentando dissolução somente após longos tempos de operação da célula, consequência de altos sobrepotenciais que ocorrem durante o liga-desliga das células [29].

Recentemente, catalisadores de PtMo/C tem ganhado destaque por apresentarem atividade superior aos catalisadores de PtRu/C na mesma composição e condições de operação da célula. Entretanto, apesar do catalisador de PtMo/C ser apontado como mais tolerante a $\mathrm{CO}$, alguns destes estudos apresentam como principal problema a falta de estabilidade e durabilidade destes materiais [30-33]. Os eletrodos de PtMo em geral são aparentemente instáveis porque o Mo se desprende gradualmente da liga ternária [29,34].

Tem sido difícil encontrar catalisadores cuja estabilidade e tolerância ao CO sejam superiores de maneira simultânea em comparação com as ligas bimetálicas já estudadas. Uma forma de aliar essas duas características está no desenvolvimento de catalisadores trimetálicos de $\mathrm{PtM}_{1} \mathrm{M}_{2}$, que permitam obter propriedades tanto de tolerância como de estabilidade. Alguns estudos com materiais trimetálicos de 
PtCoSn/C e PtRuPd/C indicam melhor atividade catalítica em comparação com ligas $\mathrm{PtRu}$, no entanto, apresentam pouca estabilidade [35].

Estudos com catalisadores trimetálicos de Pt e Ru combinados com terceiro metal como Co, Ni, W, Pd, Mo e Ir apresentam maior tolerância ao monóxido de carbono em comparação com os catalisadores de $\mathrm{PtRu} / \mathrm{C}$, entretanto, estes estudos não apresentam dados sobre a estabilidade destes materiais. Entre os catalisadores trimetálicos PtRulr e PtRuMo são os que apresentam maiores densidades de corrente, razão pela qual são opções viáveis de estudo [36].

Para catalisadores de PtRuMo/C o desempenho pode variar de acordo com o suporte utilizado na liga, como mostra Lin e colaboradores [37], onde utilizando nanotubos de carbono como suporte, melhorou a atividade catalítica dos materiais em comparação com os suportados em carbono. A quantidade de Mo é outro fator que influencia na atividade catalítica, estudos realizados por Martínez e Stevens [38, 39], indicam um aumento do desempenho da liga PtRuMo/C com relação a quantidade de Mo no catalisador. Com base no desempenho, vários estudos afirmam que o método de síntese também influencia no desempenho do catalisador trimetálico, conseguindo uma maior atividade de acordo como o menor tamanho de partícula obtido. Pastor e colaboradores [40] afirmam que o desempenho do catalisador depende do controle na obtenção das nanopartículas incorporando Ru e Pt em duas etapas no suporte de $\mathrm{MoO}_{\times} / \mathrm{C}$. Estes estudos avaliam a estabilidade nestes catalisadores mostrando uma diminuição de Mo na liga trimetálica com o tempo.

Com base nestes resultados é interessante desenvolver novos catalisadores de PtRuMo/C cujas propriedades físicas e eletroquímicas permitam melhorar o seu desempenho, estabilidade e atividade catalítica. A Tabela 1 apresenta um panorama geral e atual de vários catalisadores bimetálicos e trimetálicos estudados na literatura para esta reação e as suas principais conclusões resumidas [21]. 
Tabela 1. Lista de catalisadores da literatura desenvolvidos para avaliar sua tolerância ao CO Adaptado da referência [21].

\begin{tabular}{|c|c|c|c|c|}
\hline Estrutura & Catalisador & $\begin{array}{l}\text { Teste eletroquímico } \\
\text { realizado }\end{array}$ & Resultado e mecanismos & Ref. \\
\hline \multirow[t]{9}{*}{$\begin{array}{l}\text { Catalisadores } \\
\text { binários de } \\
\text { Pt-M/C }\end{array}$} & $\mathrm{Pt}-\mathrm{Ru} / \mathrm{C}$ & $\begin{array}{l}\text { PEMFC a } 85^{\circ} \mathrm{C} \text { e } \mathrm{H}_{2} / x \\
\text { ppm CO }\end{array}$ & $\begin{array}{l}\text { Pt-Ru apresenta maior tolerância } \\
\text { ao } \mathrm{CO} \text { e } \mathrm{CO}_{2} \text { do que } \mathrm{PtCo} / \mathrm{C} \text { devido aos } \\
\text { mecanismos eletrônicos e bifuncionais }\end{array}$ & $\begin{array}{l}{[10,41-} \\
43]\end{array}$ \\
\hline & $\mathrm{Pt}-\mathrm{Mo} / \mathrm{C}$ & $\begin{array}{l}\text { Teste em } \mathrm{H}_{2} \mathrm{SO}_{4} 1 \mathrm{M} \\
\text { com baixo fluxo de } \\
\mathrm{H}_{2} / \text { xpm Co }\end{array}$ & $\begin{array}{l}\text { Pt-Mo/C apresenta maior } \\
\text { eficiência que Pt-Ru/C, predominando o } \\
\text { mecanismo bifuncional. Sua estabilidade } \\
\text { é incerta. }\end{array}$ & [30-33] \\
\hline & $\mathrm{Pt}-\mathrm{Sn} / \mathrm{C}$ & $\begin{array}{l}\text { Teste em } \mathrm{H}_{2} \mathrm{SO}_{4} 1 \mathrm{M} \\
\text { com fluxo de } \mathrm{H}_{2} / x \mathrm{ppm} \\
\mathrm{CO}\end{array}$ & $\begin{array}{l}\text { Pt-Sn/C apresenta maior } \\
\text { tolerância ao CO com relação ao } \mathrm{Pt}-\mathrm{Ru} / \mathrm{C} \\
\text { devido aos mecanismos bifuncionais e } \\
\text { eletrônicos. Sua estabilidade é incerta. }\end{array}$ & $\begin{array}{l}{[16,22,} \\
44,45]\end{array}$ \\
\hline & $\mathrm{Pt}-\mathrm{Fe} / \mathrm{C}$ & $\begin{array}{l}\text { Teste em } \mathrm{H}_{2} \mathrm{SO}_{4} 0,5 \mathrm{M} \\
\text { em fluxo de } \mathrm{H}_{2} / x \text { ppm } \\
\text { CO }\end{array}$ & $\begin{array}{l}\text { Superior tolerância ao CO } \\
\text { comparada a } \mathrm{Pt}-\mathrm{Ni} / \mathrm{C} \text {, devido à formação } \\
\text { da camada de } \mathrm{Pt} \text { no } \mathrm{Fe} \text { e por efeitos } \\
\text { eletrônicos. }\end{array}$ & $\begin{array}{ll}{[10,} & 17, \\
23] & \end{array}$ \\
\hline & $\mathrm{Pt}-\mathrm{Ni} / \mathrm{C}$ & $\begin{array}{l}\text { Teste em } \mathrm{H}_{2} \mathrm{SO}_{4} \quad 0,5 \mathrm{M} \\
\text { em fluxo de } \mathrm{H}_{2} / x \text { ppm } \\
\text { CO }\end{array}$ & $\begin{array}{l}\text { Maior tolerância observada em } \\
\text { comparação com } \mathrm{Pt} / \mathrm{C} \text {. }\end{array}$ & {$[21,35]$} \\
\hline & $\mathrm{Pt}-\mathrm{W} / \mathrm{C}$ & $\begin{array}{l}\text { PEMFC a } 85{ }^{\circ} \mathrm{C} \text { e } \\
\mathrm{H}_{2} / 100 \text { ppm CO }\end{array}$ & $\begin{array}{c}\text { W apresenta atividade co- } \\
\text { catalítica na oxidação de } \mathrm{H}_{2} \text { em presença } \\
\text { de } \mathrm{CO} \text {, mas não é tão efetivo como o } \mathrm{Ru} \text {. }\end{array}$ & $\begin{array}{l}{[10,32,} \\
46]\end{array}$ \\
\hline & $\mathrm{Pt}-\mathrm{Co} / \mathrm{C}$ & $\begin{array}{l}\text { PEMFC a } 85^{\circ} \mathrm{C} \text { e } \mathrm{H}_{2} / \mathrm{x} \\
\text { ppm CO. }\end{array}$ & $\begin{array}{l}\text { Co diminui o potencial de início da } \\
\text { oxidação de CO, mas é maior do que } \\
\text { PtFe. Sua estabilidade é incerta. }\end{array}$ & $\begin{array}{l}{[21,47,} \\
48]\end{array}$ \\
\hline & $\mathrm{Pt}-\mathrm{Ce} / \mathrm{C}$ & $\begin{array}{l}\text { Teste em } 0,5 \quad \mathrm{M} \\
\mathrm{H}_{2} \mathrm{SO}_{4} / \mathrm{LiClO}_{4} \quad 0,1 \mathrm{M} \\
\text { em fluxo de } \mathrm{H}_{2} / \mathrm{x} \text { ppm } \\
\mathrm{CO} \text { a } 80{ }^{\circ} \mathrm{C} \text { e célula } \\
\text { eletroquímica }(0,5 \mathrm{M} \\
\left.\mathrm{H}_{2} \mathrm{SO}_{4}\right) \text { utilizada. }\end{array}$ & $\begin{array}{l}\text { Apresenta uma alta atividade } \\
\text { tolerante ao CO comparado com } \mathrm{Pt} / \mathrm{C} \text {. }\end{array}$ & {$[24]$} \\
\hline & $\mathrm{Pt}-\mathrm{Pb} / \mathrm{C}$ & $\begin{array}{l}\text { Teste em solução } 0,1 \\
\mathrm{M} \text { de } \mathrm{H}_{2} \mathrm{SO}_{4}\end{array}$ & $\begin{array}{l}\text { Pt-Pb apresenta menor potencial } \\
\text { de inicio da oxidação e alta tolerância ao } \\
\mathrm{CO} \text { em comparação com a Pt }\end{array}$ & {$[49,50]$} \\
\hline \multirow{8}{*}{$\begin{array}{l}\text { Catalisadores } \\
\text { ternários } \\
\mathrm{Pt}_{-} \mathrm{M}_{1}-\mathrm{M}_{2} / \mathrm{C}\end{array}$} & Pt-Ru-Mo/C & $\begin{array}{l}\text { Operação do PEMFC } \\
\text { a } 80^{\circ} \mathrm{C}\end{array}$ & $\begin{array}{l}\text { Este catalisador é ligeiramente } \\
\text { maior do que } \mathrm{Pt}-\mathrm{Ru}\end{array}$ & {$[39,51]$} \\
\hline & $\mathrm{Pt}-\mathrm{Ru}-\mathrm{Co} / \mathrm{C}$ & $\begin{array}{l}\text { Operação do PEMFC } \\
\text { a } 75^{\circ} \mathrm{C} .\end{array}$ & $\begin{array}{l}\text { Este catalisador apresenta melhor } \\
\text { tolerância ao CO do que PtRuMo/C }\end{array}$ & {$[52]$} \\
\hline & Pt-Ru-Ni/C & $\begin{array}{l}\text { Teste em } \mathrm{H}_{2} \mathrm{SO}_{4} \quad 0,5 \mathrm{M} \\
\text { e PEMFC }\end{array}$ & $\begin{array}{l}\text { Superior tolerância ao } \mathrm{CO} \\
\text { comparado com } \mathrm{Pt}-\mathrm{Ru} / \mathrm{C}\end{array}$ & [35] \\
\hline & Pt-Ru-W/C & $\begin{array}{l}\text { Operação do PEMFC } \\
\text { a } 75^{\circ} \mathrm{C} .\end{array}$ & $\begin{array}{l}\text { O catalisador obtido pelo método } \\
\text { coloidal apresenta uma superior } \\
\text { tolerância ao CO em comparação com } \\
\text { Pt-Ru comercial Etek }\end{array}$ & [32] \\
\hline & $\mathrm{Pt}-\mathrm{Ru}-\mathrm{Pd} / \mathrm{C}$ & $\begin{array}{l}\text { Teste em } \mathrm{H}_{3} \mathrm{PO}_{4} \text { a } 180 \\
{ }^{\circ} \mathrm{C}\end{array}$ & $\begin{array}{l}\text { Apresenta uma maior tolerância } \\
\text { ao CO em comparação com Pt-Ru/C }\end{array}$ & [53] \\
\hline & $\mathrm{Pt}-\mathrm{Co}-\mathrm{Sn} / \mathrm{C}$ & $\begin{array}{l}\text { Operação do PEMFC } \\
\text { a } 75^{\circ} \mathrm{C} .\end{array}$ & $\begin{array}{l}\text { Apresenta maior tolerância ao CO } \\
\text { em comparação com Pt-Ru/C }\end{array}$ & {$[54]$} \\
\hline & Pt-Ru-Mo/C & $\begin{array}{l}\text { Teste em } \mathrm{H}_{2} \mathrm{SO}_{4} \\
\text { Operação do PEMFC } \\
\text { a } 85^{\circ} \mathrm{C} \text {. }\end{array}$ & $\begin{array}{l}\text { Superior tolerância ao } \mathrm{CO} \\
\text { comparado com Pt-Ru/C }\end{array}$ & [21] \\
\hline & Pt-Ru-Ir/C & $\begin{array}{l}\text { Teste em } \mathrm{H}_{2} \mathrm{SO}_{4} 0,5 \mathrm{M} \\
\text { e PEMFC } 80^{\circ} \mathrm{C} .\end{array}$ & $\begin{array}{l}\text { Apresenta excelente tolerância ao } \\
\text { CO em comparação com Pt-Ru/C }\end{array}$ & {$[36]$} \\
\hline
\end{tabular}




\subsection{Métodos de síntese}

Em síntese, em meio a esse panorama sobre os catalisadores tolerantes a $\mathrm{CO}$, muitos esforços continuam voltados para o desenvolvimento de catalisadores eficientes para oxidação de hidrogênio, especialmente na presença de $\mathrm{CO}$. Todos com objetivo comum de aumentar a eficiência das reações envolvidas e entender o motivo das variações na atividade catalítica, somado a análise da estabilidade dos materiais.

Dentro deste contexto, os métodos de sínteses têm um papel de destaque pois a utilização de métodos que conferem maior controle na preparação permite, por exemplo, o estudo da variação do tamanho de partícula mantendo fixas outras propriedades frente uma reação eletroquímica [55,56], ou manter um tamanho de partícula fixo e estudar outras propriedades, tais como o grau de liga e a quantidade de óxidos presentes no catalisador.

O método de impregnação é o método mais comum de preparação de catalisadores metálicos suportados em carbono [10,25], consiste na impregnação dos sais de metais no suporte e posterior redução dos íons metálicos. A redução dos catalisadores pode ser química ou eletroquímica. Os redutores químicos mais comuns são a hidrazina, o boroidreto e o hidrogênio, sendo que para este último, é necessário o uso de altas temperaturas [25] [10] [57]. Ticianelli et al. [2, 10, 58] utilizam o método de impregnação e o método de ácido fórmico, o primeiro consiste na implementação de reagentes em suspensão cuja a vantagem consiste na simplicidade de reagir em condições do ambiente $\left(90^{\circ} \mathrm{C}\right)$, e posterior tratamento em atmosfera redutora de hidrogênio a $550^{\circ} \mathrm{C}$ por 3 horas com ótimos resultados. No entanto, a exposição do catalisador a altas temperaturas implica aumento do tamanho da partícula ao redor de $4 \mathrm{~nm}[10,26]$, diminuindo o sobrepotencial do catalisador para $\mathrm{ROH}$. No método de ácido fórmico os sais dos metais são dissolvidos de acordo as proporções requeridas em água, em uma mistura com o carbono Vulcan em ácido fórmico $2 \mathrm{molL}^{-1}\left(80^{\circ} \mathrm{C}\right)$, obtendo partículas com um tamanho menor do que com o método de impregnação (em torno de $3 \mathrm{~nm}$ ) [10,58]. 
Alguns autores utilizam o método de microemulssão que consiste de uma mistura aquosa e oleosa com o fim de obter partículas com uma distribuição mais uniforme, utilizando hidrazina com agente redutor, obtendo partículas trimetálicas $\mathrm{PtRuM}_{2}$ com um tamanho ao redor de 2,5 nm. [59] O método de poliol modificado, onde a síntese ocorre em fase oleosa, utilizando octileter como solvente e 1,2-hexadecanodiol como redutor em altas temperaturas $\left(298^{\circ} \mathrm{C}\right)$, apresenta melhores resultados com relação ao tamanho de partícula e distribuição no suporte, fornecendo tamanhos de partícula ao redor de 2-3 nm [44, 60, 61]. Takeguchi e Wang [62] sintetizaram compostos bimetálicos de PtRu/C obtendo partículas bimetálidas de PtRu com melhor distribuição e tamanho de partícula da ordem de $2,5 \mathrm{~nm}$ e eficiente atividade eletrocatalítica para $\mathrm{ROH}$ na presença de $\mathrm{CO}$. Zhou e colaboradores sintetizaram catalisadores trimetálicos a base de PtRuMo também utilizando o método de poliol modificado [63, 64], variando a metodologia de síntese, tratamento térmico e a quantidade dos metais, mostrando melhor eficiência a partir do tamanho médio de partícula $(2,4 \mathrm{~nm})$. Outros estudos envolvendo catalisadores de PtRuMo/CNTs realizados por Lin [37] mostraram tamanhos de partícula da ordem de 2,4 nm e uma melhor eficiência frente $\mathrm{ROH}[65$, 66].

Estas metodologias de síntese podem estar sujeitas a modificações na rota e/ou modificações dos precursores ou alteração dos agentes redutores, no sentido de alterar as propriedades físico química dos materiais, tais como: grau de liga entre os metais, tamanho de partícula, dispersão no suporte, etc. e consequentemente variar sua atividade catalítica. Também no sentido de alterar as propriedades físico químicas dos materiais, tratamentos térmicos em diferentes atmosferas podem ser realizados.

Com base nestes resultados é interessante desenvolver novos catalisadores cujas propriedades físico químicas permitam melhorar o seu desempenho, estabilidade e atividade catalítica frente a $\mathrm{ROH}$, utilizando hidrogênio contaminado com $\mathrm{CO}$. 


\section{OBJETIVOS}

O principal objetivo deste trabalho é sintetizar e caracterizar compostos de Pt$\mathrm{Ru} / \mathrm{C}, \mathrm{Pt}-\mathrm{Mo} / \mathrm{C}$ e Pt-Ru-Mo/C e avaliar na reação de oxidação de hidrogênio em presença de monóxido de carbono em PEMFC, visando a obtenção de catalisadores eficientes, estáveis e tolerantes na presença de CO.

Para tal, foram realizadas as seguintes etapas:

i) Otimização do método de síntese para a obtenção de catalisadores de Pt$\mathrm{Ru} / \mathrm{C}, \mathrm{Pt}-\mathrm{Mo} / \mathrm{C}$ e $\mathrm{Pt}-\mathrm{Ru}-\mathrm{Mo} / \mathrm{C}$, os dois métodos utilizados são de impregnação e poliol;

ii) Caracterização física dos materiais obtidos com técnicas como: difratometria de raios-X (DRX), microscopia eletrônica de transmissão (TEM); espectroscopia de raios $X$ por energia dispersiva (EDX); espectroscopia fotoeletrônica de raios X (XPS);

iii) Avaliação da atividade eletrocatalítica dos catalisadores para a reação de oxidação de hidrogênio em células a combustível tipo PEM utilizando como combustível hidrogênio contaminado com monóxido de carbono, envolvendo experimentos eletroquímicos em estado estacionário e Espectroscopia de Massa (EM) on-line acoplado;

iv) Correlação entre as propriedades físicas e químicas (tamanho, composição, cristalinidade) com a atividade eletrocatalítica frente à reação de oxidação de hidrogênio contaminado com $\mathrm{CO}$ dos catalisadores sintetizados. 


\section{PARTE EXPERIMENTAL}

Neste tópico apresentamos as metodologias de sínteses utilizadas nos catalisadores: PtRu/C e PtMo/C e PtRuMo/C, com 20\% em massa de metais com relação ao carbono (Vulcan® $\mathrm{XC72R}$ ). As caracterizações eletroquímicas em célula unitária foram feitas para medir o desempenho dos catalisadores em condições reais das PEMFC. Estas medidas foram feitas com base na literatura da carga metálica e temperatura no ânodo e cátodo, temperatura e pressão da célula, fluxo e composição dos gases.

\subsection{Sínteses dos catalisadores}

A síntese dos catalisadores propostos $\mathrm{Pt}-\mathrm{Ru} / \mathrm{C}, \mathrm{Pt}-\mathrm{Mo} / \mathrm{C}$ com relação metálica 1:1 e Pt-Ru-Mo/C 2:1:1, com 20\% em massa de metal, depositado em carbono (Vulcan® $\mathrm{XC72R}$ ) (80\%) foram preparados pelos métodos de impregnação (para $\mathrm{PtRu} / \mathrm{C}$ ) e pelo método de poliol modificado para os demais catalisadores.

\subsubsection{Síntese pelo método de Impregnação}

A massa necessária de carbono (Vulcan® XC72R) como suporte foi pesada em um becker ( $80 \%$ em massa com relação a quantidade dos metais), e adicionada as massas necessárias de sais de platina como ácido hexacloroplatínico $\left(\mathrm{H}_{2} \mathrm{PtCl}_{6} 6 \mathrm{H}_{2} \mathrm{O}\right)$ em tricloreto de rutênio $\left(\mathrm{RuCl}_{3} .3 \mathrm{H}_{2} \mathrm{O}\right)$, com relação nominal 1:1, adicionando etanol como solvente. A mistura foi homogeneizada com um bastão de vidro e colocada por uma hora no ultrassom.

Posteriormente, colocou-se o becker sobre uma chapa, aquecendo até aproximadamente a $80^{\circ} \mathrm{C}$. A mistura foi agitada até evaporar todo o solvente. Em seguida, o catalisador foi colocado em uma barca de alumina e levado ao forno por uma hora, passando simultaneamente o gás argônio a $100{ }^{\circ} \mathrm{C}$. Após esse processo, colocou-se em fluxo de hidrogênio durante três horas a $550{ }^{\circ} \mathrm{C}$. 


\subsubsection{Síntese pelo método de poliol modificado}

O método do poliol foi utilizado para a síntese de nanopartículas de PtRu/C, $\mathrm{PtMo} / \mathrm{C}$ e PtRuMo/C. Foram utilizados como agentes estabilizantes o ácido oleico e a oleilamina. Os precursores metálicos são os correspondentes acetilacetonatos. As nanopartículas foram sintetizadas em um sistema de refluxo em atmosfera inerte de argônio. Os precursores de Ru e/ou Mo são dissolvidos em uma mistura de 1,2hexadecanodiol e dioctiléter como solvente, esta mistura foi aquecida a uma taxa de $5^{\circ} \mathrm{C} / \mathrm{min}$, até aproximadamente $110^{\circ} \mathrm{C}$ por 20 minutos. Os protetores ácido oleico e oleilamina foram adicionados à mistura anterior e aquecida sob o refluxo até $298^{\circ} \mathrm{C} e$ agitada por 30 minutos à mesma temperatura. As nanopartículas obtidas foram redispersas em hexano/etanol e depois centrifugadas várias vezes, este processo foi repetido 5 vezes para remoção dos resíduos nas nanopartículas.

A ancoragem das nanopartículas sobre o suporte de carbono de alta área superficial (Vulcan ${ }^{\circledR} \mathrm{XC72R}$ ) foi efetuada pela adição do mesmo à dispersão na composição nominal metal:carbono $20: 80 \%$ (em massa). Na etapa final da preparação, os catalisadores suportados são filtrados e lavados com água, acetona e álcool. Após esse procedimento, redispersou-se em acetona e centrifugou-se e assim foram lavados com água e secados a $80 \stackrel{\circ}{C}$ por 2 horas.

\subsubsection{Tratamentos térmicos dos catalisadores}

Os compostos sintetizados, tanto bimetálicos como trimetálicos foram tratados termicamente a diferentes temperaturas (identificados abaixo). Todos os catalisadores foram preparados com $20 \%$ em massa de metais com relação ao carbono e foram nomeados da seguinte maneira:

PtRu-I: Catalisador PtRu/C 1:1, sintetizado pelo método de impregnação.

PtRu-P: Catalisador PtRu/C 1:1 atômico dos metais, sintetizado pelo método de poliol modificado, tratamento térmico a $200{ }^{\circ} \mathrm{C}$ por $5 \mathrm{~min}$ em ar. 
PtMo-P: Catalisador PtMo/C 1:1 atômico dos metais, sintetizado pelo método de poliol modificado, tratamento térmico a $200^{\circ} \mathrm{C}$ por 5 min em ar.

PtRuMo-P: Catalisador PtRuMo/C 2:1:1 atômico, sintetizado pelo método de poliol modificado,, tratamento térmico a $200^{\circ} \mathrm{C}$ por 5 min em ar.

PtRuMo-P300: Catalisador PtRuMo/C 2:1:1 atômico dos metais, sintetizado pelo método de poliol modificado a $300^{\circ} \mathrm{C}$ por 30 min em $\mathrm{H}_{2}$.

PtRuMo-P600: Catalisador PtRuMo/C 2:1:1 atômico dos metais, sintetizado pelo método de poliol modificado tratado a $600^{\circ} \mathrm{C}$ por $60 \mathrm{~min} \mathrm{em} \mathrm{H}_{2}$.

PtRuMo-PSH: Catalisador PtRuMo/C 2:1:1 atômico dos metais, sintetizado pelo método de poliol modificado com superhidreto, tratado a $230^{\circ} \mathrm{C}$ por 5 minutos em ar.

\subsection{Caracterização física}

A caracterização física dos catalisadores sintetizados Pt-Ru/C, Pt-Mo/C e Pt-RuMo/C é fundamental para determinar a proporção atômica e de massa entre os catalisadores sintetizados, seu tamanho de partícula e a distribuição no suporte carbono, o grau de liga entre os metais e sua estrutura eletrônica. Estes testes foram realizados por meio de difração de raios $X(D R X)$, espectroscopia por energia dispersiva (EDX), microscopia eletrônica de transmissão (TEM), espectroscopia de fotoelétrons excitados por raios X (XPS). Estas análises contribuíram com a determinação das propiedades física e eletrônica, composição e distribuição dos componentes do catalisador, com o objetivo de entender o comportamento eletroquímico no desempenho de cada um deles.

\subsubsection{Difração de raios X (DRX)}

A técnica de difração de raios $X$ em pó foi utilizada para a determinação estrutural dos compostos em estudo, tais como a presença de óxidos, tamanho de cristalito nos catalisadores $(d)$, parâmetro de rede $(a)$, estrutura cristalográfica CFC da platina e grau 
de liga entre metais que compõem os catalisadores. Para isso utilizou-se um difratômetro Rigaku ${ }^{\circledR}$ - ULTIMA IV, uma radiação de tipo KaCu 40 kV e 20 mA, com varreduras de $1^{\circ} / \mathrm{min}$, entre um intervalo de $2 \theta$ na faixa de $10^{\circ}$ a $100^{\circ}$.

\subsubsection{Espectroscopia de raios $\mathrm{X}$ por energia dispersiva (EDX)}

A técnica de EDX consiste na identificação da composição elementar e porcentual em uma amostra, mediante a incidência de raios $X$. A radiação emitida por cada elemento corresponde à energia caraterística dos seus orbitais nos seus átomos mediante a relaxação dos elétrons presentes, caraterístico para cada elemento na amostra.

Esta técnica foi utilizada para determinar a relação atômica dos metais nos catalisadores. Cada amostra foi preparada em pastilhas de 1,6 mm de diâmetro previamente misturadas em solução de Teflon ${ }^{\circledR}$ a $5 \%$, e colocada em um suporte para sua análise. O equipamento utilizado para realizar este procedimento foi um espectrômetro Leziss-Leica ${ }^{\circledR} 440$ com um detector de SiLi.

\subsubsection{Microscopia eletrônica de transmissão (TEM).}

Esta técnica foi utilizada para determinar o tamanho médio de partícula, morfologia e distribuição de tamanho nos catalisadores trimetálicos sintetizados de PtRuMo, utilizando um microscópio JEOL 2100200 kV, com filamento hexaboreto de lantânio (LaB6) do Instituto de Química de São Carlos - USP. Esta técnica consiste na geração de um feixe de elétrons transmitidos através da amostra, usando detectores os quais integram o feixe da amostra sendo coletados e processados como imagem. A amostra a ser analisada foi dissolvida em isopropanol, dispersa em ultrassom e depositada sobre uma porta amostra de cobre recoberto com carbono. Após a obtenção da imagem se faz a contagem de aproximadamente 200 partículas espalhadas na imagem para determinar o tamanho médio de partícula.

\subsubsection{Espectroscopia de fotoelétrons excitados por raios X (XPS)}


Os dados de XPS fornecem informações sobre a densidade de estados eletrônicos dos catalisadores trimetálicos de PtRuMo/C, de maneira individual para Pt, Ru e Mo. A estrutura eletrônica dos catalisadores, na estrutura de Pt, é modificada pela adição de outros metais, pois estes alteram a tensão do retículo cristalino e permitem a transferência de carga entre os componentes da liga. Alterações na posição central da banda ligante podem acarretar mudanças na energia de ligação dos elétrons dos níveis internos. A técnica pode ser usada como uma ferramenta analítica, porque as informações das alturas e áreas de pico, em relação às energias de ligação, permitem a identificação dos compostos presentes e fornece estimativas de sua concentração para $\mathrm{Pt}, \mathrm{Ru}$ e Mo. Este análise foi realizada na linha de luz SXS do Laboratório Nacional de Luz Sincrotron (LNLS).

Os espetros de XPS foram coletados utilizando uma energia de fóton (Eph) incidente de $1840 \mathrm{eV}$, fornecida pelo monocromador de cristal duplo de InSb (111). O analisador hemisférico de elétrons (Specs - phoibos 150) foi programado para passagens de $20 \mathrm{eV}$, com passo de energia de 0,2 eV e tempo de aquisição de 200 ms.

A resolução energética global alcançada foi cerca de 0,3 eV a Eph $=1840$ eV. A pressão de base de câmara de análise foi 1,3 x 10-9 mBar. A calibração da energia dos fótons do monocromador foi realizada na borda K do Si (1839 eV) uma calibração adicional do analisador de energia foi a realizando uma folha de Au padrão (Au 4f). Todas as medidas de XPS foram realizadas a temperatura ambiente. Os espectros foram analisados por deconvolução dos picos através de ajustes de funções gaussianas e lorentzianas. A contribuição dos elétrons espalhados inelasticamente foi suprimida através da utilização do método de Shirley. 


\subsection{Caracterização eletroquímica}

\subsubsection{Testes em célula unitária.}

As medidas realizadas na célula unitária determinam o desempenho e estabilidade de cada catalisador em células a combustível, operando em condições reais. A célula unitária consiste ânodo e o cátodo, que são preparados sobre camadas difusoras de tecido de carbono (PBW-3 pamex) recoberto por carbono em pó (Vulcan XC-72), e Teflon ${ }^{\circledR}$ cuja área para cada camada é de $4,62 \mathrm{~cm}^{2}$ e a carga de catalisador foi de 0,4 $\mathrm{mg} \mathrm{cm}^{-2}$, segundo procedimento estabelecido na literatura $[2,58,67]$.

A elaboração da camada catalítica do ânodo e do cátodo, foi feita com uma porcentagem de $35,5 \% \mathrm{~m} / \mathrm{m}$ Nafion DuPont ${ }^{\circledR}$, com uma carga metálica de $0,4 \mathrm{mg} \mathrm{cm}^{-}$ ${ }^{2}$ de $\mathrm{Pt}$ (Pt/C - 20\% em massa de Pt) para o caso do cátodo e $0,4 \mathrm{mg} \mathrm{cm}^{-2}$ de metal dos catalisadores sintetizados (PtRu, PtMo ou PtRuMo) para o ânodo. Os catalisadores foram dissolvidos e misturados em isopropanol e levados a ultrassom por $20 \mathrm{~min}$, depois secos na capela. Posteriormente, a amostra é redissolvida em isopropanol, distribuindo o conteúdo da amostra em sua totalidade sobre o tecido de carbono com auxílio de um pincel. O eletrodo foi seco a $80^{\circ} \mathrm{C}$ por 1 hora.

Para realizar a montagem do ânodo e cátodo e viabilizar a troca de prótons, foi utilizada uma membrana de Nafion ${ }^{\circledR} 115$ de $125 \mu \mathrm{m}$ de espessura previamente tratada com $\mathrm{H}_{2} \mathrm{O}_{2}$ ao $3 \% \mathrm{v} / \mathrm{v}$ por uma hora a $80^{\circ} \mathrm{C}$. Esta montagem ânodo/membrana /cátodo (MEA), colocada em uma placa metálica de aço, levada a $125^{\circ} \mathrm{C}$ e 50 Ton de pressão por 60 segundos, com a finalidade de diminuir os espaçamentos na célula [58], conforme ilustrado na Figura 5. 
Figura 5. Exemplo do conjunto dos eletrodos e membrana MEA (membrane electrode assembly) [4].

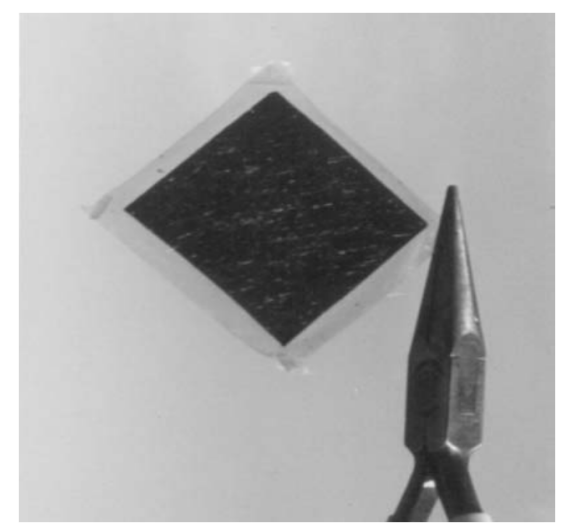

Finalmente, o MEA foi montado em uma célula unitária, para serem realizadas as medidas de voltametria cíclica, stripping de CO curvas de polarização em estado estacionário e a espectrometria de massas, descritas a seguir.

\subsubsection{Voltametria cíclica}

Esta técnica consiste na determinação eletroquímica dos perfis voltamétricos para cada um dos catalisadores utilizados na configuração da célula unitária. O ânodo da célula foi o eletrodo de trabalho, alimentado com argônio e o cátodo foi alimentado com $\mathrm{H}_{2}$ atuando também como eletrodo de referência. Os voltamogramas cíclicos foram obtidos na faixa de 0,05 e 0,8 V vs. ERH com velocidades de varredura de 10, 20 e $50 \mathrm{mV} \mathrm{s}^{-1}$ Estas medidas foram realizadas com um potenciostato/galvanostato Solartron 1285, conectado a um microcomputador.

\subsubsection{2 "Stripping" de CO}

A voltametria de varredura linear de $\mathrm{CO}$, denominada comumente stripping de $\mathrm{CO}$, consiste em analisar a adsorção e, principalmente a dessorção de $\mathrm{CO}$, determinando a carga obtida, estabelecendo-se a relação entre a carga de dessorção de CO e a 
área ativa para cada eletrodo (sítios ativos do eletrodo ocupados por CO). Cada catalisador foi submetido a um pré-tratamento de borbulhamento de CO por 1200 segundos, e em sequência, 2400 segundos com gás argônio, mantendo a célula em modo potenciostático em $0,10 \mathrm{~V} v \mathrm{v}$. ERH. Foram realizados três ciclos a $10 \mathrm{mV} \mathrm{s}^{-1}$ entre 0,1 a $0,9 \vee v s$. ERH, de acordo com a metodologia descrita na literatura [68].

\subsubsection{Curvas de Polarização}

As curvas de polarização para a avaliação do desempenho das PEMFC foram obtidas na forma galvanostática, em uma estação de trabalho (Fuel Cell Tecnologies Inc), que permite o controle da temperatura, pressão e fluxo dos gases. As condições iniciais de trabalho da célula foram sob fluxo constante de $\mathrm{H}_{2}\left(1,02\right.$ bar e $\left.100{ }^{\circ} \mathrm{C}\right)$ no ânodo, utilizando catalisadores bimetálicos de $\mathrm{PtRu} / \mathrm{C}$ e $\mathrm{PtMo} / \mathrm{C}$, e trimetálicos de $\mathrm{PtRuMo/C}$. No cátodo foi utilizado $\mathrm{O}_{2}$ puro $\left(0,72\right.$ bar e $\left.90^{\circ} \mathrm{C}\right)$. Após a montagem, a célula foi estabilizada por 2 horas sob um potencial fixo de $0,7 \mathrm{~V}$, a $80^{\circ} \mathrm{C}$, com o fim de acondicionar a célula, umidificando o sistema com vapor de água para garantir a condutividade da membrana de Nafion ${ }^{\circledR}$. Em seguida, foi feita uma curva de potencial $E(\mathrm{~V})$ vs. corrente I (A), primeiro a $50 \mathrm{mV} \mathrm{s}^{-1}$ e depois a $20 \mathrm{mV} \mathrm{s}^{-1} \mathrm{em}$ um intervalo de 0,0 até $1,4 \mathrm{~A} \mathrm{~cm}^{-2}$ de acordo com estudos prévios [2].

Todas as medidas foram realizadas com hidrogênio, ou hidrogênio contaminado com 100 ppm de CO no ânodo para avaliar a eficiência da célula nas condições de trabalho reais estabelecidas na literatura com relação a tolerância de CO [69]. Os resultados obtidos foram expressos em termos de densidade de corrente vs. potencial ( $j$ vs. E) ou em termos de densidade de corrente vs. sobrepotencial ( $j$ vs. $\eta$ ), o sobrepotencial representa a diferença entre os potencias da célula a combustível de $\mathrm{H}_{2}$ puro e $\mathrm{H}_{2} / \mathrm{CO}$.

\subsubsection{Espectroscopia de Massa on line acoplado}

Os experimentos de Espectrometria de Massas (EM) on line foram realizados em conjunto com as curvas de polarização, com o espectrômetro de massas acoplado na saída dos gases do compartimento anódico da célula unitária. $O$ acoplamento foi 
efetuado introduzindo o capilar de admissão dos gases à câmara de alto-vácuo até um dos canais de difusão do gás na placa de grafite da célula unitária. Para monitorar a variação das espécies produzidas ou consumidas no ânodo como um todo, o capilar foi fixado perto da tubulação de saída dos gases. As medidas foram efetuadas em um espectrômetro de massas OmniStar ${ }^{\circledR}$ (GSD 301Pfeiffer Vaccum, Prisma QMS 200) com energia de ionização em $70 \mathrm{eV}$ e corrente de emissão de $1 \mathrm{~mA}$. A deteç̧ão dos íons foi efetuada por meio de uma unidade multiplicadora de elétrons (voltagem comum $=1000 \mathrm{~V}$ ) no equipamento.

Os experimentos monitoram as correntes iônicas para as espécies produzidas e consumidas no ânodo na PEMFC, e algumas espécies que são difundidas desde o cátodo até o ânodo, mediante a relação entre massa/carga para cada produto, as quais são bem definidas para cada sobrepotencial anódico em estado estacionário. As razões massa/carga medidas foram as de $28(\mathrm{CO}), 44\left(\mathrm{CO}_{2}\right), 15\left(\mathrm{CH}_{4}\right.$ na forma de $\mathrm{CH}_{3}{ }^{+}$); para o monitoramento do consumo de $\mathrm{CO}$, produção de $\mathrm{CO}_{2}$, produção de $\mathrm{CH}_{4}$ e a verificação das variações nas demais massas observadas pelo monitoramento do carbono. Após obter as curvas de polarização em estado estacionário para cada catalisador anódico, foi utilizado o método de cascata, que consiste em fixar o potencial desde o circuito aberto entre valores que começam em $900 \mathrm{mV}$ até $100 \mathrm{mV}$, em intervalos de $100 \mathrm{mV}$, a medida foi efetuada durante 200 ciclos [11]. O sistema foi estabilizado por 5 minutos com passagem de $\mathrm{H}_{2} / \mathrm{CO}$ antes de cada medida.

Cada resultado foi normalizado e expresso em termos da corrente relativa de íons de acordo com a massa carga de interesse, onde $1 \mathrm{~m}$ corresponde à relação massa carga ( $m$ é a razão massa/carga). Para a obtenção da corrente de normalização para a produção de $\mathrm{CO}_{2} \mathrm{I}_{44}$ ao ser alimentado o ânodo com $\mathrm{H}_{2}+\mathrm{CO}$, esta foi normalizada com base na corrente do ânodo alimentado $\mathrm{com} \mathrm{H}_{2}$ puro $1^{\circ} 44$, obtendo-se os incrementos de corrente de maneira adimensional com relação a corrente $0 \mathrm{de}_{2}$ puro, equação 1, estabelecendo uma relação qualitativa entre a quantidade da amostra detectada ( $\mathrm{CO}_{2}$ produzido) no espectrômetro, e assim determinar os fatores cinéticos em cada catalisador. 


$$
\Delta \mathrm{I} 44=\frac{\mathrm{I} 44-\mathrm{I}^{\circ} 44}{\mathrm{I}^{\circ} 44}
$$

\subsubsection{Testes de envelhecimento acelerado (TEA) em célula unitária}

Os testes de envelhecimento acelerado permitem estimar o tempo de vida útil dos catalisadores. Estes são importantes para conhecer a estabilidade dos catalisadores $\mathrm{PtRu} / \mathrm{C}, \mathrm{PtMo} / \mathrm{C}$ e PtRuMo/C em função de imposição de condições similares às de operação da célula, de acordo com variáveis tais como tempo (durabilidade), temperatura, quantidade de CO na célula, e composição do catalisador.

Para O TEA realizou-se o seguinte protocolo: os materiais sintetizados foram submetidos a um total de 1000 ciclos, entre os potencias de $70 \mathrm{mV}$ e $700 \mathrm{mV}$ vs. ERH com velocidade de varredura de $50 \mathrm{mV} \mathrm{s}^{-1}$. Foram realizadas voltametrias cíclicas $(0,1$ $-0,7 \mathrm{~V}$ vs. ERH, $20 \mathrm{mV} \mathrm{s}^{-1}$ ), stripping de $\mathrm{CO}$ e curvas de polarização, antes e após 0 TEA. 


\section{RESULTADOS E DISCUSSÃO}

Compreender a influência das propriedades físico-químicas no desempenho eletrocatalítico dos catalisadores sintetizados para a $\mathrm{ROH}$ contaminado com monóxido de carbono é parte fundamental deste trabalho. A seguir apresentaremos a descrição e análise das propriedades físico químicas e comportamento eletroquímico apresentado pelos catalisadores bimetálicos e trimetálicos de PtRu/C, PtMo/C e PtRuMo/C.

\subsection{Caracterização Física}

\subsection{Espectroscopia de raios $\mathrm{X}$ por energia dispersiva}

A técnica de EDX confirmou a presença dos metais platina, rutênio e molibdênio nos catalisadores preparados pelos métodos de poliol e impregnação: PtRu/C, PtMo/C e PtRuMo/C, como pode ser observado nas Tabelas 2 e 3, para os catalisadores binários e ternários, respectivamente. Os resultados de proporção atômica entre os metais foram muito próximos aos nominais, com exceção do catalisador bimetálico PtMo-P onde foi obtida uma relação atômica 75:25 ao invés 1:1, este resultado está relacionado à perda de Mo na mistura dos precursores de Pt e Mo durante a síntese, sendo que este problema ainda não foi solucionado.

Tabela 2. Composição atômica nos catalisadores PtRu-P, PtRu-I e PtMo-P via EDX, tamanho de cristalito, parâmetro de rede e grau de liga determinado por XDR.

\begin{tabular}{|c|c|c|c|c|c|c|}
\hline \multirow[t]{2}{*}{ Catalisador } & \multicolumn{2}{|c|}{$\begin{array}{c}\% \\
\text { Elemento }\end{array}$} & \multirow{2}{*}{$\begin{array}{c}\text { Tamanho } \\
\text { Cristalito } \\
\text { (nm) } \\
\text { XDR } \\
\end{array}$} & \multirow{2}{*}{$\begin{array}{l}\text { Parâmetro } \\
\text { de rede } \\
\text { (A) }\end{array}$} & \multirow{2}{*}{$\begin{array}{c}\text { Distância } \\
\text { interatômica } \\
\text { (A) }\end{array}$} & \multirow{2}{*}{$\begin{array}{c}\text { Grau de } \\
\text { Liga } \\
\text { (Fração) }\end{array}$} \\
\hline & Pt & $\mathbf{M}$ & & & & \\
\hline PtMo-P & 74,0 & 26,0 & 3,9 & 3,913 & 2,77 & 38,2 \\
\hline PtRu-I & 49,8 & 50,2 & 5,4 & 3,847 & 2,72 & 65,5 \\
\hline PtRu-P & 52,8 & 47,2 & 2,0 & 3,922 & 2,77 & 4,1 \\
\hline
\end{tabular}


Tabela 3. Composição atômica presentes nos catalisadores PtRuMo/C via EDX, tamanho de cristalito (DRX), tamanho de partícula (TEM) e parâmetro de rede (A) obtidos por DRX.

\begin{tabular}{|c|c|c|c|c|}
\hline Catalisador & PtRuMo-P & PtRuMo-P300 & PtRuMo-P600 & PtRuMo-PSH \\
\hline \multicolumn{5}{|l|}{ Análise } \\
\hline Pt:Ru:Mo \% & $54: 22: 24$ & $54: 22: 24$ & $54: 22: 24$ & $46: 27: 27$ \\
\hline \multicolumn{5}{|l|}{ Tamanho } \\
\hline Cristalito (nm) & 2,8 & 3,7 & - & 2,9 \\
\hline \multicolumn{5}{|l|}{ Tamanho de } \\
\hline Partícula (nm) & 2,4 & 2,9 & 4,9 & 2,4 \\
\hline \multicolumn{5}{|l|}{ Parâmetro de } \\
\hline rede $(\AA)$ & 3,922 & 3,916 & - & 3,923 \\
\hline \multicolumn{5}{|l|}{ Distância } \\
\hline interatômica (Å) & 2,774 & 2,769 & - & 2,77 \\
\hline
\end{tabular}

\subsubsection{Difração de raios $X$}

Os difratogramas dos materiais sintetizados estão representados na Figura 6. Os picos correspondentes aos planos cristalográficos característicos da Pt se encontram nos seguintes valores de ângulo de difração $2 \theta$ : a $40^{\circ}$ o plano [111], $46^{\circ}$ o [200], $67^{\circ}$ o [220], $81^{\circ}$ o [311] e $85^{\circ}$ o plano [222]. Estes picos são observados tanto para os catalisadores bimetálicos quanto para os trimetálicos. Para obter informações da liga composta pelos metais a partir dos parâmetros cristalográficos, leva-se em consideração a rede da Pt, e toma-se como referência o plano cristalográfico [220] a $67^{\circ}$. 
Figura 6. Difratograma dos catalisadores: (a) bimetálicos: PtRu/C e PtMo/C, comparados com Pt Etek e (b) trimetálicos PtRuMo submetidos a diferentes tratamentos térmicos.
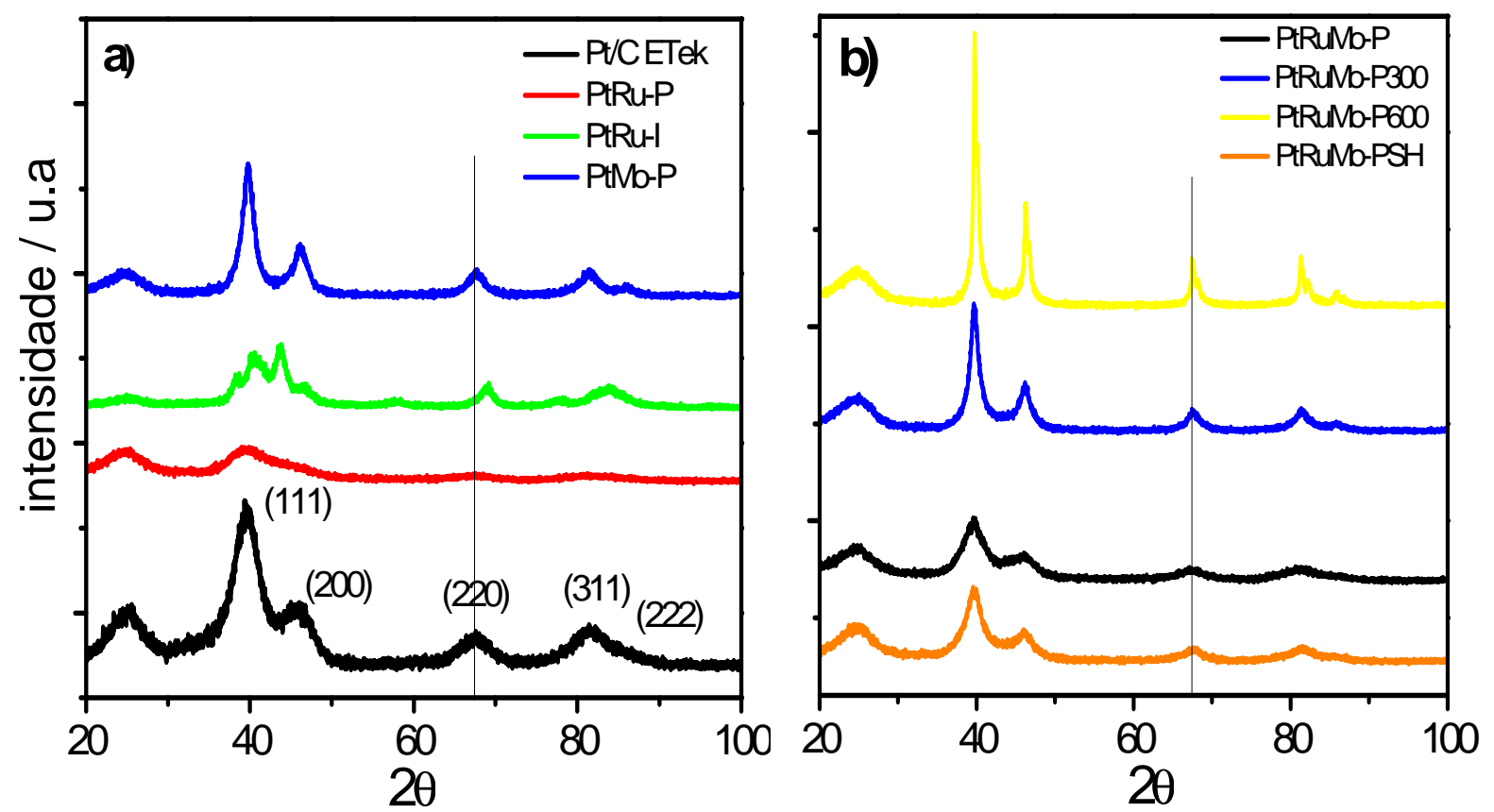

Para determinar o tamanho médio de cristalito $(d)$ foi necessário determinar a largura à meia altura do pico no plano estrutural [220] da platina, que sofre uma distorção pela agregação atômica do segundo ou terceiro metal na liga [26], utilizandose a equação de Scherrer:

$$
d=\frac{(K \lambda)}{\beta \cos \theta}
$$

$K$ é a constante de proporcionalidade, que tem um valor de 0,9 devido a configuração esférica assumida dos cristalitos no catalisador, $\lambda$ corresponde ao cumprimento de onda da radiação incidente, $\theta$ é o ângulo de difração do pico observado e $\beta$ a largura média da altura do pico de difração, aproximado mediante uma função de deconvolução de Voigt. Para determinar o parâmetro de rede $(a)$, foi utilizada a equação 3 , na qual: 


$$
a=\frac{\lambda \sqrt{h^{2}+l^{2}+k^{2}}}{2 \operatorname{sen} \theta}
$$

A distância interatômica $\left(d_{\mathrm{cfc}}\right)$ entre dois átomos de platina foi obtida através da equação 4:

$$
d_{\mathrm{cfc}}=\frac{\sqrt{2} \sin \theta}{2}
$$

O grau de liga em catalisadores bimetálicos de PtRu e PtMo foi estimado mediante a lei de Vegard, na qual é calculada a quantidade do segundo metal inserido na rede de Pt, com relação aos parâmetros de rede obtidos experimentalmente, e teóricos [70] de acordo com a equação 5 :

$$
X=X_{\text {liga }} \frac{a \mathrm{Pt}-a \mathrm{ex}}{a \mathrm{Pt}-a \mathrm{~L}}
$$

$X_{\text {liga }}$ representa a fração molar do segundo metal na liga, $a_{\mathrm{Pt}}$ representa 0 parâmetro de rede da platina suportada no carbono e tem um valor de 3,927 $\AA$ [71], $a_{\text {ex }}$ relaciona o parâmetro de rede experimental da liga bimetálica, e $a_{\mathrm{L}}$ é o parâmetro de rede do catalisador bimetálico teórico.

Foi possível determinar, de esta maneira, para cada catalisador: o tamanho médio de cristalito $(d)$, parâmetro de rede $(A)$, distância interatômica e o grau de liga, neste último caso, apenas para os catalisadores bimetálicos. Os resultados estão apresentados nas tabelas 2 e 3 para os catalisadores bimetálicos e trimetálicos, respectivamente. Os catalisadores bimetálicos sintetizados pelo método do poliol possuem tamanho de cristalito da ordem de 3,9 nm para o PtMo e 2,0 para PtRu, enquanto que o catalisador preparado pelo método de impregnação possui o maior valor de 5,4 nm. No caso dos catalisadores trimetálicos observa-se um aumento do tamanho de cristalito apenas com o aumento da temperatura de tratamento térmico, e não com a alteração no método de síntese, onde um segundo redutor foi adicionado (PtRuMo-PSH), como esperado. Observa-se uma pequena contração nos parâmetros 
de rede $(A)$ para os catalisadores bimetálicos e trimetálicos, mostrados nas tabelas 2 e 3. Esta diminuição é causada por mudanças na estrutura cúbica de face centrada da platina $[10,21,58]$, o que implica a inclusão do segundo e/ou terceiro metal na rede da Pt. Para os catalisadores bimetálicos obteve-se o maior grau de liga para o catalisador PtRu sintetizado por impregnação, onde método de síntese inclui o tratamento em atmosfera redutora de hidrogênio durante três horas a $550^{\circ} \mathrm{C}$. No caso dos catalisadores trimetálicos não é possível determinar ou grau de liga uma vez que não é possível separar as contribuições do Mo e Ru. Mas é possível observar decréscimo no parâmetro de rede $(A)$ com o aumento da temperatura de tratamento em atmosfera redutora, comparando-se o catalisador PtRuMo-P com o PtRuMo-P300, como pode se observar na tabela 3 , indicando uma maior inclusão dos metais na liga ternária. Já no caso do catalisador PtRuMo-600 não foi possível obter os valores uma vez que os picos apresentaram desmembrados.

\subsubsection{Microscopia eletrônica de transmissão}

A técnica de microscopia eletrônica de transmissão foi utilizada para determinar as faixas de distribuição de tamanho das partículas e avaliar a dispersão destas no suporte de carbono. As Figuras 7(a-d) representam as micrografias e os histogramas obtidos para os catalisadores trimetálicos, PtRuMo. Pode-se observar que todos os catalisadores possuem forma esférica e ocorreu deposição do material no suporte de maneira homogênea. $O$ tamanho médio da partícula foi determinado por uma curva gaussiana ajustada ao histograma obtido, com os resultados estão apresentados na Tabela 3. Os tamanhos médios de cristalito encontrados foram próximos aos valores de tamanhos médios de cristalito (d) obtidos por DRX. Os tamanhos das partículas obtidas neste trabalho para os catalisadores ternários foram inferiores em relação a literatura $[10,21,58]$, os quais mostram tamanhos por acima de $2,8 \mathrm{~nm}$.

Para os catalisadores trimetálicos quando submetidos a tratamento térmico ocorre um aumento do tamanho de partícula com a temperatura e com o tempo de exposição em atmosfera redutora. Este aumento de tamanho corresponde a uma maior aglomeração de partículas como consequência da exposição térmica, sendo 
comparável com estudos prévios que indicam esta tendência de crescimento em maiores temperaturas [26,62].

Figura 7. Micrografias dos catalisadores trimetálicos PtRuMo/C: a)PtRuMo-P; b)PtRuMo-P300, c)PtRuMo-P600, d)PtRuMo-PSH.
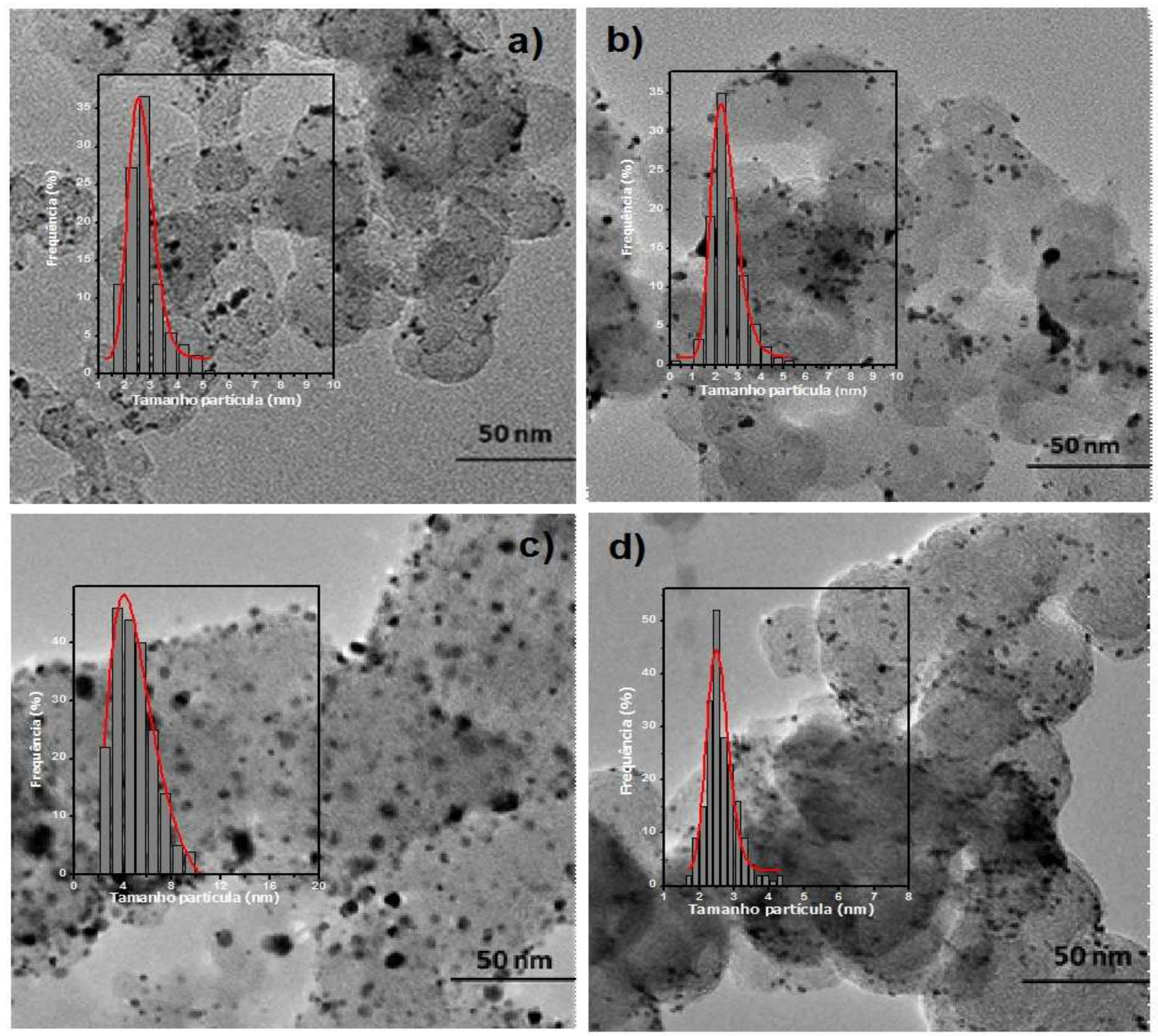

\subsubsection{Espectroscopia de Fotoelétrons Excitados por Raios X}

A técnica de XPS permite obter informações sobre a densidade de estados eletrônicos do catalisador metálico. Os espectros XPS dos orbitais $4 f$ para Pt dos catalisadores ternários estão apresentados na Figura 8, e foram deconvoluídos em três dubletos, que correspondem a diferentes estados de oxidação da Pt $4 f_{7 / 2}$ e da Pt 
4t5/2. A linha com maior intensidade corresponde a Pt de valência zero, no estado metálico, o valor da literatura corresponde a 71,2 eV [72]. A energia de ligação dos componentes $\mathrm{Pt} 4 f_{5 / 2}$ centrado em 72,5 eV e 74,2 eV pode ser atribuído às espécies $\mathrm{Pt}^{2+} \mathrm{e} \mathrm{Pt}^{4+}$, respectivamente [72]. As energias de ligação obtidas para os componentes da Pt $4 f$ estão apresentadas na Tabela 4.

Para a análise do Ru foram determinadas a energia de ligação dos componentes $\mathrm{Ru} 3 p_{3 / 2}$. Os espectros do $\mathrm{Ru} 3 p$ foram deconvoluídos em três singletos que correspondem aos diferentes estados de oxidação: $R u^{0}, R u^{4+}$ e $R u^{6+}$. Para análise do Mo foram determinadas a energia de ligação dos componentes Mo $3 d$. Os espectros de Mo $3 d$ foram deconvoluídos em três dubletos, que correspondem a diferentes estados de oxidação do $3 d_{5 / 2}$ e $3 d_{3 / 2}$, que pertencem aos estados $\mathrm{Mo}^{0}, \mathrm{Mo}^{4+}$ $\mathrm{Mo}^{6+}$. As energias de ligação obtidas para os componentes do Ru $3 p$ e Mo $3 d$ estão apresentadas na Tabela 4. A energia de ligação obtidas para os dubletos do Mo $3 d$ correspondem a valores muito próximos descritos na literatura [37,70]. Para o Ru 3d observa-se deslocamentos para os catalisadores trimetálicos de: $460,9 \mathrm{eV}$ para $\mathrm{Ru}^{0}$, 462,9 eV para $\mathrm{Ru}^{4+}$ e 465,2 eV para $R u^{6+}$. Estes dados estão perto com os valores da literatura, comparado com 459,2 eV e 462,2 eV [72] para $\mathrm{Ru}^{0} \mathrm{e} \mathrm{Ru}^{2+}$, respectivamente.

$\mathrm{Na}$ Tabela 5 são apresentadas as porcentagens dos espectros de XPS deconvoluídos, mostrando a relação entre as áreas e sua respectiva porcentagem de acordo com o estado de oxidação para Pt, Ru e Mo. 
Figura 8. Espectros de XPS para Pt $4 f$, Ru $3 p$ e Mo $3 d$ para os diferentes compostos trimetálicos de a) PtRuMo-P, b) PtRuMo-P300, c) PtRoMu-P600 e d) PtRuMo-PSH.
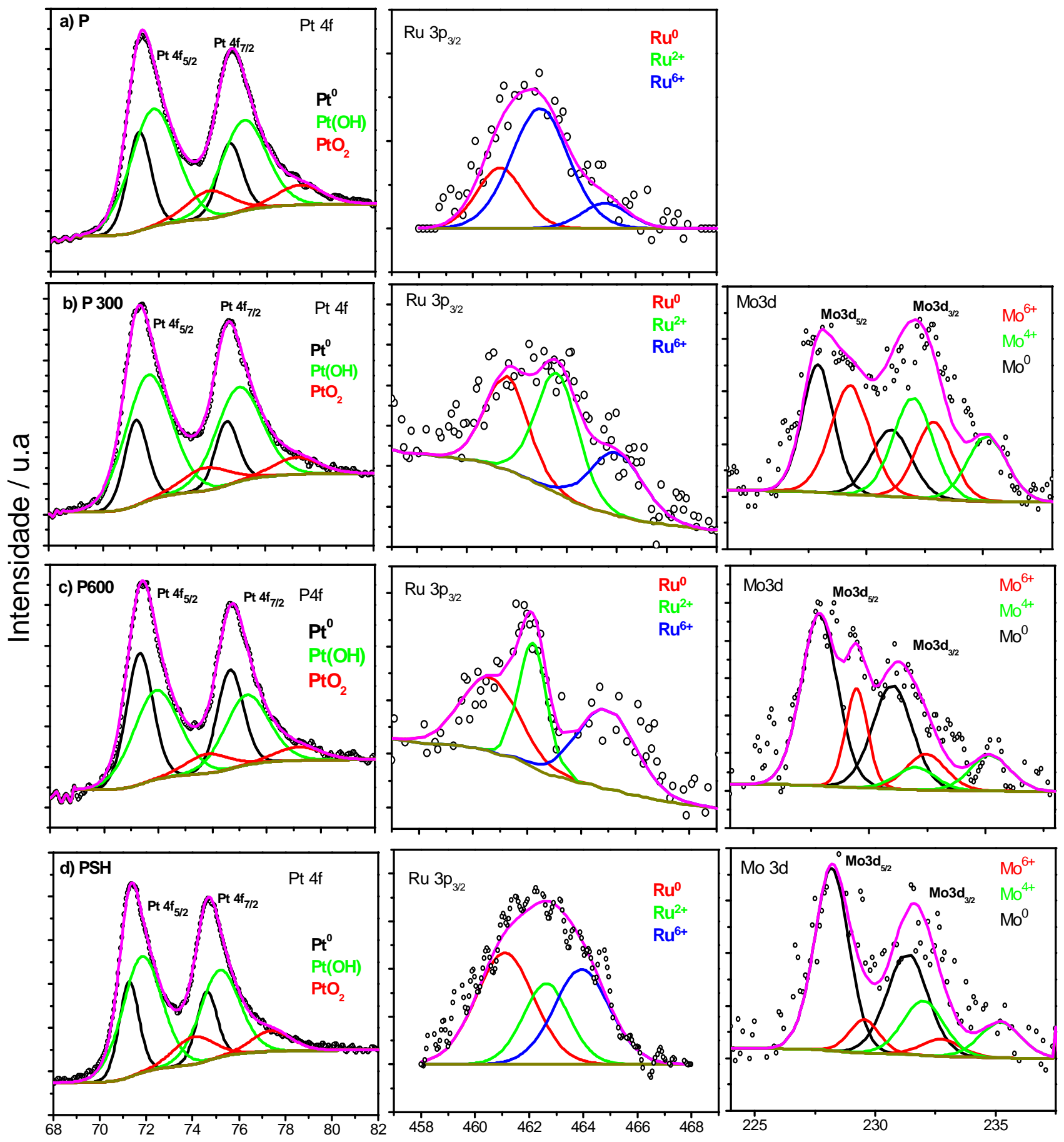

Energia de Ligaçao / eV 
Tabela 4. Energia de Ligação dos componentes $\mathrm{Pt} 4 \mathrm{f}, \mathrm{Ru} 3 \mathrm{p}$ e Mo $3 \mathrm{~d}$ para os catalisadores PtRuMo/C.

\begin{tabular}{|c|c|c|c|c|c|c|c|c|c|c|c|c|c|c|c|}
\hline \multirow[b]{2}{*}{ Catalisador } & \multicolumn{3}{|c|}{ Pt 4f $f_{5 / 2}$} & \multicolumn{3}{|c|}{ Pt 4f $7 / 2$} & \multicolumn{3}{|c|}{ Ru 3p } & \multicolumn{3}{|c|}{ Mo 3d $_{5 / 2}$} & \multicolumn{3}{|c|}{ Mo 3d $_{3 / 2}$} \\
\hline & $\mathbf{P t}^{0}$ & $\mathrm{Pt}^{2+}$ & $\mathrm{Pt}^{4+}$ & $\mathbf{P t}^{0}$ & $\mathrm{Pt}^{2+}$ & $\mathrm{Pt}^{4+}$ & $\mathbf{R u}^{\mathbf{0}}$ & $\mathbf{R u}^{2+}$ & $\mathbf{R u}^{6+}$ & $\mathrm{Mo}^{0}$ & $\mathrm{Mo}^{4+}$ & $\mathrm{Mo}^{6+}$ & $\mathrm{Mo}^{0}$ & $\mathrm{Mo}^{4+}$ & $\mathrm{M}^{6+}$ \\
\hline PtRuMo-P & 74,6 & 75,2 & 77,2 & 71,3 & 71,8 & 73,9 & 461 & 462,7 & 464,8 & & & & & & \\
\hline PtRuMo-P300 & 74,6 & 75 & 77,2 & 71,2 & 71,7 & 73,8 & 461 & 463 & 465,2 & 227,9 & 229,3 & 232,0 & 231,1 & 232,9 & 235,2 \\
\hline PtRuMo-P600 & 74,7 & 75,3 & 77,2 & 71,3 & 71,9 & 73,8 & 459,2 & 462,2 & 465,4 & 227,8 & 229,5 & 232 & 231,0 & 232,7 & 235,2 \\
\hline PtRuMo-PSH & 74,6 & 75,2 & 77,4 & 71,3 & 71,8 & 74 & 461,1 & 462,7 & 464 & 228,2 & 229,5 & 232,0 & 231,3 & 232,7 & 232,5 \\
\hline
\end{tabular}

Tabela 5. Porcentagem atômica de cada elemento em cada catalisador PtRuMo/C de acordo aos seus estados de oxidação para Pt 4f, Ru 3p e Mo 3d.

\begin{tabular}{l|ccc|ccc|cccc}
\hline & \multicolumn{3}{|c|}{ Pt 4f } & \multicolumn{3}{c|}{ Ru 3p } & \multicolumn{3}{c}{ Mo 3d } \\
\hline Catalisador & $\mathrm{Pt}^{0}$ & $\mathrm{Pt}^{2+}$ & $\mathrm{Pt}^{4+}$ & $\mathrm{Ru}^{0}$ & $\mathrm{Ru}^{2+}$ & $\mathrm{Ru}^{6+}$ & $\mathrm{Mo}^{0}$ & $\mathrm{Mo}^{4+}$ & $\mathrm{Mo}^{+6}$ \\
\hline PtRuMo-P & 26,0 & 60,5 & 13,5 & 27,4 & 51,2 & 20,4 & & & \\
PtRuMo-P300 & 22,4 & 65,8 & 11,8 & 31,1 & 38,9 & 30,0 & 32,7 & 35,1 & 32,2 \\
PtRuMo-P600 & 41,2 & 49,0 & 9,8 & 34,5 & 28,2 & 37,3 & 63,6 & 22,1 & 14,3 \\
PtRuMo-SH & 25,0 & 60,7 & 14,4 & 42,9 & 24,2 & 32,9 & 66,0 & 10,5 & 23,5 \\
\hline
\end{tabular}

Com o tratamento térmico com atmosfera redutora, como esperado, se consegue obter maior quantidade de material na forma metálica corroborando com os resultados de DRX que apresentaram deslocamentos significativos dos picos de difração. Estas mudanças da porcentagem nos estados de oxidação são devidas à exposição térmica em atmosfera redutora dos compostos, que variam sua composição eletrônica com relação às mudanças na sua estrutura [38]. No caso do catalisador PtRuMo-SH, onde a síntese foi realizada utilizando um redutor adicional, o super hidreto, também observa-se maior quantidade de Ru e Mo no estado metálico. Neste caso foi possível obter uma maior quantidade de $\mathrm{Mo}^{0} \mathrm{em}$ estado metálico comparado com a literatura, que apresenta estes picos majoritariamente $\mathrm{Mo}^{6+} \mathrm{em}$ forma de óxidos como $\mathrm{MoO}_{3}$ [37]. Os estados de oxidação da $\mathrm{Pt}^{0}$ se encontram com percentuais entre 
22 e $26 \%$ na maioria dos compostos trimetálicos com exceção do catalisador tratado a $600{ }^{\circ} \mathrm{C}$, onde esta porcentagem aumentou para $41 \%$ de $\mathrm{Pt}^{0}$ na superfície, considerando também maior quantidade de $\mathrm{Ru}^{0} \mathrm{e} \mathrm{Mo}^{0}$, a formação de uma superfície rica em Pt e em PtRuMo ligado.

\subsection{Medidas em Célula Unitária}

As curvas de polarização obtidas para os catalisadores na presença e na ausência de CO permitem avaliar o desempenho do catalisador em condições reais e determinar sua tolerância ao CO. Posteriormente, a estabilidade destes materiais foi avaliada através do TEA, determinando-se a área eletroativa, antes e após do TEA. Por último, a espectrometria de massas on-line foi utilizada para determinar parâmetros de catálise em tempo real.

\subsubsection{Curvas de polarização}

A Figura 9(a) apresenta os resultados das curvas de potencial em função da densidade de corrente para os catalisadores bimetálicos para a $\mathrm{ROH}$ utilizando $\mathrm{H}_{2}$ puro e $\mathrm{H}_{2}$ contaminado com 100 ppm CO no ânodo, sendo que o catalisador Pt Etek comercial foi utilizado para comparação. Cada catalisador foi avaliado sob condições de temperatura no ânodo de $105^{\circ} \mathrm{C}$, temperatura do cátodo a $95^{\circ} \mathrm{C}$, e temperatura da célula de $85^{\circ} \mathrm{C}$, entre uma faixa de densidade de corrente (J) de 0 e $2,0 \mathrm{~A} \mathrm{~cm}^{-2}$, e um potencial $(E)$ entre 0 e $1,0 \mathrm{~V}$. Os materiais bimetálicos apresentaram atividade oxidante comparável a $\mathrm{Pt}$ quando expostos a $\mathrm{H}_{2}$ puro, apresentando potenciais eficientes em altas densidades de corrente. Quando os catalisadores estão na presença de $\mathrm{CO}$, sofrem uma queda de potencial devido à ocupação de sítios ativos por parte do $\mathrm{CO}$, que impedem a oxidação direta de $\mathrm{H}_{2}$, e, portanto, apresentam menores potenciais a maiores densidades de corrente. No caso dos catalisadores bimetálicos preparados por poliol observou uma discreta melhora na tolerância ao CO em relação ao catalisador de $\mathrm{Pt}$. 
Figura 9. (a) Curva de polarização em estado estacionário e (b) curvas de densidade de potência e (c) curva de sobrepotencial $\left(\eta \mathrm{H}_{2} / \mathrm{CO}=\mathrm{E} \mathrm{H}_{2}-E \mathrm{H}_{2} / \mathrm{CO}\right)$ vs. densidade de corrente j $\left(\mathrm{A} \mathrm{cm}^{-2}\right)$. Para os catalisadores bimetálicos (ânodos) de PtRu e PtMo/C. e cátodo de $\mathrm{Pt} / \mathrm{C}$ ao $20 \%$. Nafion ${ }^{\circledR} 115$, T. cátodo $=95^{\circ} \mathrm{C}$, T. ânodo $=105^{\circ} \mathrm{C}, \mathrm{T}$. Célula $85^{\circ} \mathrm{C}$. Alimentados no ânodo com $\mathrm{H}_{2}$ e $\mathrm{H}_{2}+100$ ppm de $\mathrm{CO}$.
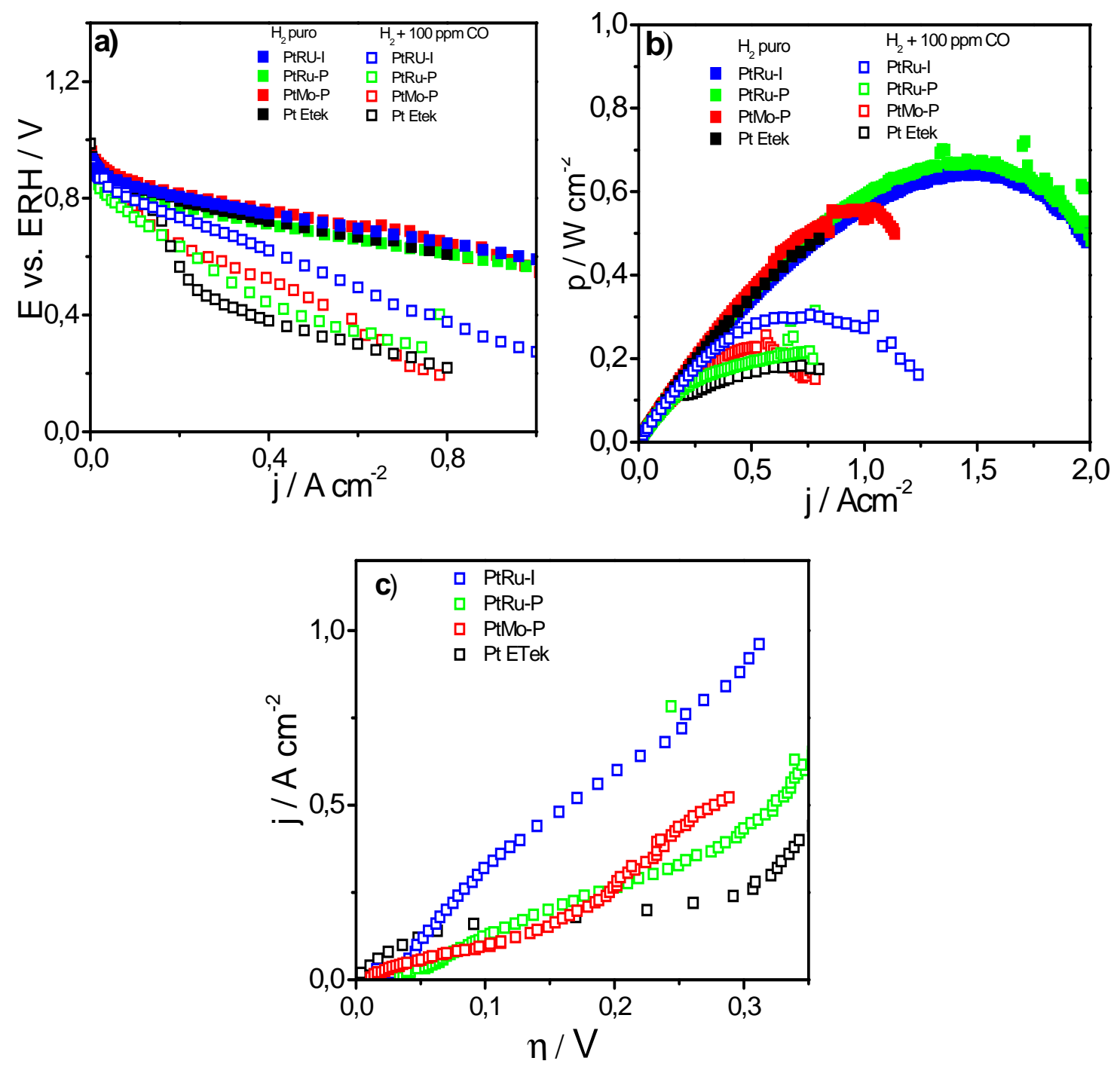

Na Figura 9 (b) observa-se as curvas de densidades de potência $\left(\mathrm{W} \mathrm{cm}^{-2}\right)$ em função da densidade de corrente (j). Para os catalisadores bimetálicos é possível observar em $\mathrm{H}_{2}$ puro maiores densidades máximas de potência para os catalisadores de PtRu/C sintetizados pelo método de impregnação e poliol, obtendo $0,67 \mathrm{~W} \mathrm{~cm}^{-2} \mathrm{e}$ $0,64 \mathrm{~W} \mathrm{~cm}^{-2}$, respectivamente. O catalisador PtMo-P apresenta um pico máximo de potência em $0,55 \mathrm{~W} \mathrm{~cm}^{-2}$. As densidades de potência para os catalisadores contaminados com CO, apresentaram para PtRu-I o valor de $0,30 \mathrm{~W} \mathrm{~cm}^{-2}$, seguido 
pelo catalisador de PtRu-P, a $0,230 \mathrm{~W} \mathrm{~cm}^{-2}$, e finalmente pelo catalisador de PtMo/C que tem um máximo de densidade de potência, perto de $\mathrm{Pt} / \mathrm{C}, \mathrm{a} \pm 0,19 \mathrm{~W} \mathrm{\textrm {cm } ^ { - 2 }}$. A maior tolerância foi observada para o catalisador PtRu-I, seguida pelo catalisador PtRu-P, e finalmente por PtMo-P, o qual teve pouco desempenho na catálise de CO. Estudos mostram maior tolerância para o PtMo/C, comparado com $\mathrm{PtRu} / \mathrm{C}$, com mesma proporção atômica (1:1) [73,74], enquanto no presente trabalho, esta proporção foi menor para Pt:Mo (74:26). O grau de liga pode explicar o comportamento para os catalisadores $\mathrm{PtRu} / \mathrm{C}$, os resultados de DRX indicam um elevado grau de liga para 0 catalisador PtRu-I (66\%) em comparação ao catalisador PtRu-P (4,1\%).

A Figura 9 (c) apresenta as curvas de sobrepotencial para os catalisadores bimetálicos de PtRu/C e PtMo/C. As curvas de sobrepotencais permitem medir a eficiência da célula em fase anódica para cada catalisador na presença de $\mathrm{CO}$, mediante a diferença dos potenciais entre a oxidação de $\mathrm{H}_{2}$ puro e o potencial do catalisador contaminado com 100 ppm $\mathrm{H}_{2} / \mathrm{CO}$, calculadas pela utilização da equação 6:

$$
\eta \mathrm{H}_{2} / \mathrm{CO}=\mathrm{EH}_{2}-\mathrm{EH}_{2} / \mathrm{CO}
$$

onde $\eta \mathrm{H}_{2} / \mathrm{CO}$ corresponde a diferença de potencial, $E \mathrm{H}_{2}$ ao potencial do ânodo alimentado com $\mathrm{H}_{2}$ e $E \mathrm{H}_{2} / \mathrm{CO}$ corresponde ao potencial do ânodo contaminado com 100 ppm de CO.

Na Figura 9 (c) observa-se o desempenho dos catalisadores bimetálicos de PtRu/C e PtMo/C sintetizados pelo método de poliol, sendo possível identificar uma maior atividade catalítica do que PtRu/C sintetizado pelo método de impregnação, e portanto, maior densidade de corrente a um menor sobrepotencial. Todos os catalisadores bimetálicos apresentam uma discreta melhora em comparação com $\mathrm{Pt} / \mathrm{C}$. Este resultado está relacionado pela maior atividade do mecanismo bifuncional para a Pt como consequência da inclusão de $\mathrm{Ru}$ e/ou Mo, oxidando $\mathrm{CO}$ a $\mathrm{CO}_{2} \mathrm{e}$ liberando mais sítios ativos na Pt para a oxidação de $\mathrm{H}_{2}$, como afirmam estudos prévios apresentados na literatura $[18,21,75]$. 
Na Figura 10 (a) observa-se a curva de polarização para os compostos trimetálicos de PtRuMo/C 2:1:1 sintetizados vía poliol e poliol com super hidreto, tratados termicamente, na oxidação de $\mathrm{H}_{2}$ puro em comparação com $\mathrm{Pt} / \mathrm{C}$ comercial, conseguindo uma maior eficiência para os compostos trimetálicos. A oxidação do hidrogênio na presença de $\mathrm{CO}$ indica uma diminuição do potencial com relação ao $\mathrm{H}_{2}$ puro, o qual foi explicado previamente. Observa-se para os catalisadores trimetálicos uma melhora na tolerância ao $\mathrm{CO}$ com relação aos catalisadores bimetáicos. O catalisador PtRuMo tratado a $600^{\circ} \mathrm{C}$ e o catalisador preparado pelo método do poliol utilizando um segundo agente redutor, o super hidreto, apresentam os melhores resultados com relação a tolerância a $\mathrm{CO}$. Estes dois materiais apresentaram maior quantidade superficial de Ru e Mo na forma metálica determinada por XPS. Com relação ao tamanho médio de partícula, o catalisador tratado a $600^{\circ} \mathrm{C}$ apresentou um valor 4,9 nm muito superior ao obtido para o catalisador PtRuMo-PSH, 2,4 nm. Apesar do tratamento térmico causar aglomeração no catalisador e aumento no tamanho médio da partícula, não afetou a tolerância a $\mathrm{CO}$, parecendo que o fator mais importante neste caso é quantidade de Ru e Mo ligadas à Pt.

Na Figura 10 (b), podemos observar as curvas de densidade de potência para os catalisadores trimetálicos comparados a Pt comercial. Estas curvas de densidade de potência apresentam um máximo valor na catálise de $\mathrm{H}_{2}$, indicando para o catalisador PtRuMo-P e PtRuMo-P300 as maiores densidades de potência de 0,754 e 0,763 W $\mathrm{cm}^{-2}$, respectivamente. Estes valores são seguidos pelos catalisadores P600 e PSH, apresentando valores máximos a 0,651 e $0,653 \mathrm{~W} \mathrm{~cm}^{-2}$. Enquanto para a $\mathrm{ROH}$ contaminado com CO, estas curvas são superiores para os catalisadores P600 e PSH, obtendo valores de 0,305 e 0,301 $\mathrm{W} \mathrm{cm}^{-2}$, respectivamente. Para os catalisadores $P$ e P300, estes valores correspondem a 0,301 e 0,273 $\mathrm{W} \mathrm{cm}^{-2}$; com isto é possível observar uma melhor eficiência para os catalisadores tratados a $600^{\circ} \mathrm{C}$ e preparado com superhidreto, corroborando com a hipótese que a maior quantidade superficial de $\mathrm{Ru}$ e Mo na forma metálica favorece a $\mathrm{ROH}$ na presença de $\mathrm{CO}$. 
Figura 10. (a) Curva de polarização em estado estacionário e (b) curvas de densidade de potência e (c) Curva de sobrepotencial $\left(\eta \mathrm{H}_{2} / \mathrm{CO}=\mathrm{E} \mathrm{H}_{2}-\mathrm{E} \mathrm{H}_{2} / \mathrm{CO}\right)$ vs. densidade de corrente j $\left(\mathrm{A} \mathrm{cm}^{-2}\right)$. Para os catalisadores trimetálicos (ânodos) de PtRutMo/C. e cátodo de $\mathrm{Pt} / \mathrm{C}$ ao $20 \%$. Nafion $\Theta 115, \mathrm{~T}$. cátodo $=95^{\circ} \mathrm{C}, \mathrm{T}$. ânodo $=105^{\circ} \mathrm{C}, \mathrm{T}$. Célula $85^{\circ} \mathrm{C}$. Alimentados no ânodo com $\mathrm{H}_{2}$ e $\mathrm{H}_{2}+100$ ppm de CO.
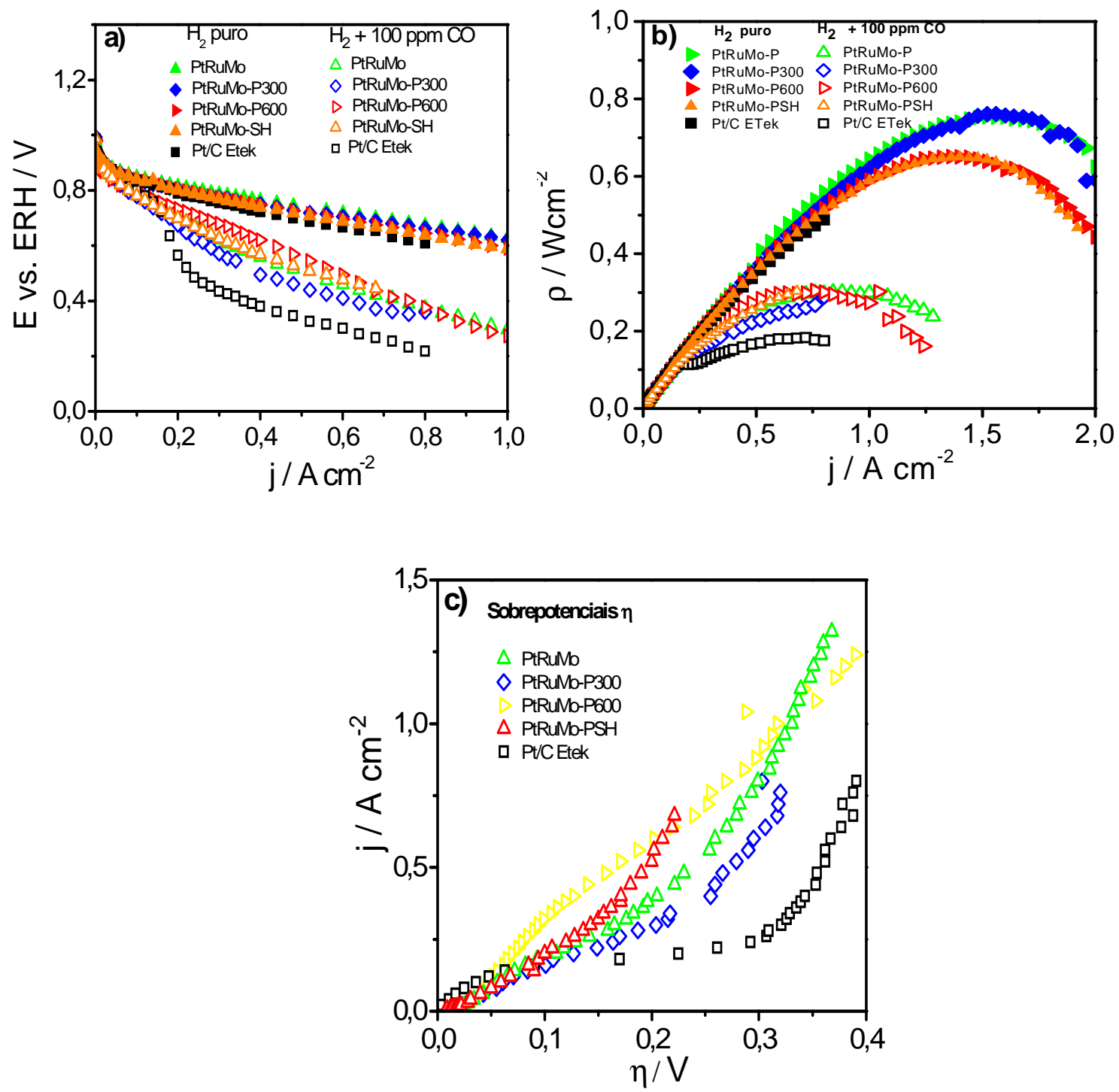

A Figura 10 (c) apresenta as curvas de sobrepotencial para os catalisadores de PtRuMo. Os catalisadores tratados termicamente apresentam maiores densidades de corrente, o catalisador tratado a $600{ }^{\circ} \mathrm{C}$, sendo superior do que o catalisador tratado a $300{ }^{\circ} \mathrm{C}$, e sem tratamento. No catalisador sem tratamento térmico, se observa uma menor atividade catalítica, mas superior à obtida no catalisador de $\mathrm{Pt} / \mathrm{C}$. Finalmente, 
para PtRuMo-PSH, as densidades de corrente foram comparáveis ao catalisador tratado a $600^{\circ} \mathrm{C}$.

Trabalhos da literatura apresentam estudos comparáveis, conforme à pressão, temperatura e quantidade de CO [20,38], e indicam uma tendência próxima da atividade catalítica no ânodo contaminado com 100 ppm de CO comparado aos catalisadores trimetálicos preparados. Entretanto, alguns trabalhos da literatura apresentam valores inferiores a 0,5 V para correntes de $0,7 \mathrm{~A} \mathrm{~cm}^{-2}[20,21]$.

\subsubsection{Testes de Envelhecimento Acelerado (TEA)}

Para este trabalho, é importante conhecer os fenômenos que explicam além do desempenho dos catalisadores trimetálicos de PtRuMo/C, sua estabilidade e relacioná-las de acordo com as propriedades físicas e químicas. Para este fim, cada catalisador foi submetido a 1000 ciclos a $50 \mathrm{mV} \mathrm{s}^{-1}$ entre $0,1 \mathrm{~V}$ e $0,7 \mathrm{~V}$ para simular o envelhecimento acelerado de cada catalisador e, posteriormente, comparar suas atividades catalíticas para $\mathrm{ROH}$ na presença e na ausência de $\mathrm{CO}$ na estação de teste. Na Figura 11 foi comparada a atividade catalítica para $\mathrm{H}_{2}$ e tolerância ao $\mathrm{CO}$ antes e após de 1000 ciclos no ânodo, para os catalisadores trimetálicos de $\mathrm{PtRuMo/C}$ tratados a $300^{\circ} \mathrm{C}, 600^{\circ} \mathrm{C}$ e o sintetizado com super hidreto.

Para os catalisadores trimetálicos é possível observar para $\mathrm{ROH}$ uma leve queda para os catalisadores tratados a $300{ }^{\circ} \mathrm{C}$ e $600{ }^{\circ} \mathrm{C}$, apresentando uma perda de 98 e $88 \mathrm{mV}$, respectivamente, em correntes de $0,7 \mathrm{~A} \mathrm{~cm}^{-2}$, respectivamente. Para o catalisador sintetizado com superhidreto a perda foi de $299 \mathrm{mV}$ a 0,7 A cm${ }^{-2}$, sendo esta diferença muito maior do que nos primeiros catalisadores. Entretanto, este catalisador apresentou maior oscilação de potencial em maiores densidades de corrente, razão pela qual não foi possível conseguir valores fixos e definidos de potencial [76].

Com relação à tolerância ao $\mathrm{CO}$, a perda de potencial para os catalisadores trimetálicos é maior do que em $\mathrm{H}_{2}$ puro. Estas quedas de potencial correspondem a 
219, 142 e $224 \mathrm{mV}$ para os catalisadores tratados a $300{ }^{\circ} \mathrm{C}, 600^{\circ} \mathrm{C}$ e $\mathrm{PSH}$, respectivamente $\left(0,5 \mathrm{~A} \mathrm{~cm}^{-2}\right)$. Com isto, observamos uma maior estabilidade para o catalisador PtRuMo-P600, que tem uma menor diferença de potencial tanto para $\mathrm{H}_{2}$ como para $\mathrm{H}_{2}$ contaminado com $\mathrm{CO}$, conseguindo como consequência um melhor desempenho após 1000 ciclagens.

Nas Figuras 11 (b), (d) e (f) observa-se o desempenho em termos de densidade de potência, onde o catalisador tratado a $600^{\circ} \mathrm{C}$ apresenta a menor queda de potência máxima após o TEA, de $33 \%$ para $\mathrm{H}_{2}$ puro e $23 \%$ frente a $\mathrm{CO}$. Estes resultados podem ser melhor visualizados nas Figura 12(a), na qual foi determinada a queda de densidade de potência máxima para cada catalisador antes e após 1000 ciclagens.

Na Figura 12 (b), observam-se as mudanças nos sobrepotenciais para cada catalisador antes e após de 1000 ciclos na densidade de corrente de $0,5 \mathrm{~A} \mathrm{~cm}^{-2}$. Na figura observa-se para cada composto trimetálico um aumento de sobrepotencial após o TEA, com isto, é possível determinar uma maior estabilidade para o catalisador tratado a $600{ }^{\circ} \mathrm{C}$, onde a diferença de sobrepotencial corresponde a $69 \mathrm{mV}$, seguido pelo catalisador tratado a $300^{\circ} \mathrm{C}$, que tem uma diferença de potencial de $123 \mathrm{mV}$. No caso do catalisador PtRuMo-PSH apesar de apresentar a menor diferença entre os sobrepotenciais após 1000 ciclos, que se deve à queda de potencial após de 1000 ciclos, resultado das oscilações que este catalisador apresentou, como descrito anteriormente [76]. 
Figura 11 . Curvas de polarização em estado estacionário e curvas de densidade de potência para catalisadores trimetálicos de PtRuMo/C antes e depois de 1000 ciclos, com $\mathrm{H}_{2}$ puro e 100 ppm de CO (a-b) PtRuMo-P300, (c-d) PtRuMo-P600 e (e-f) PtRuMo-PSH.
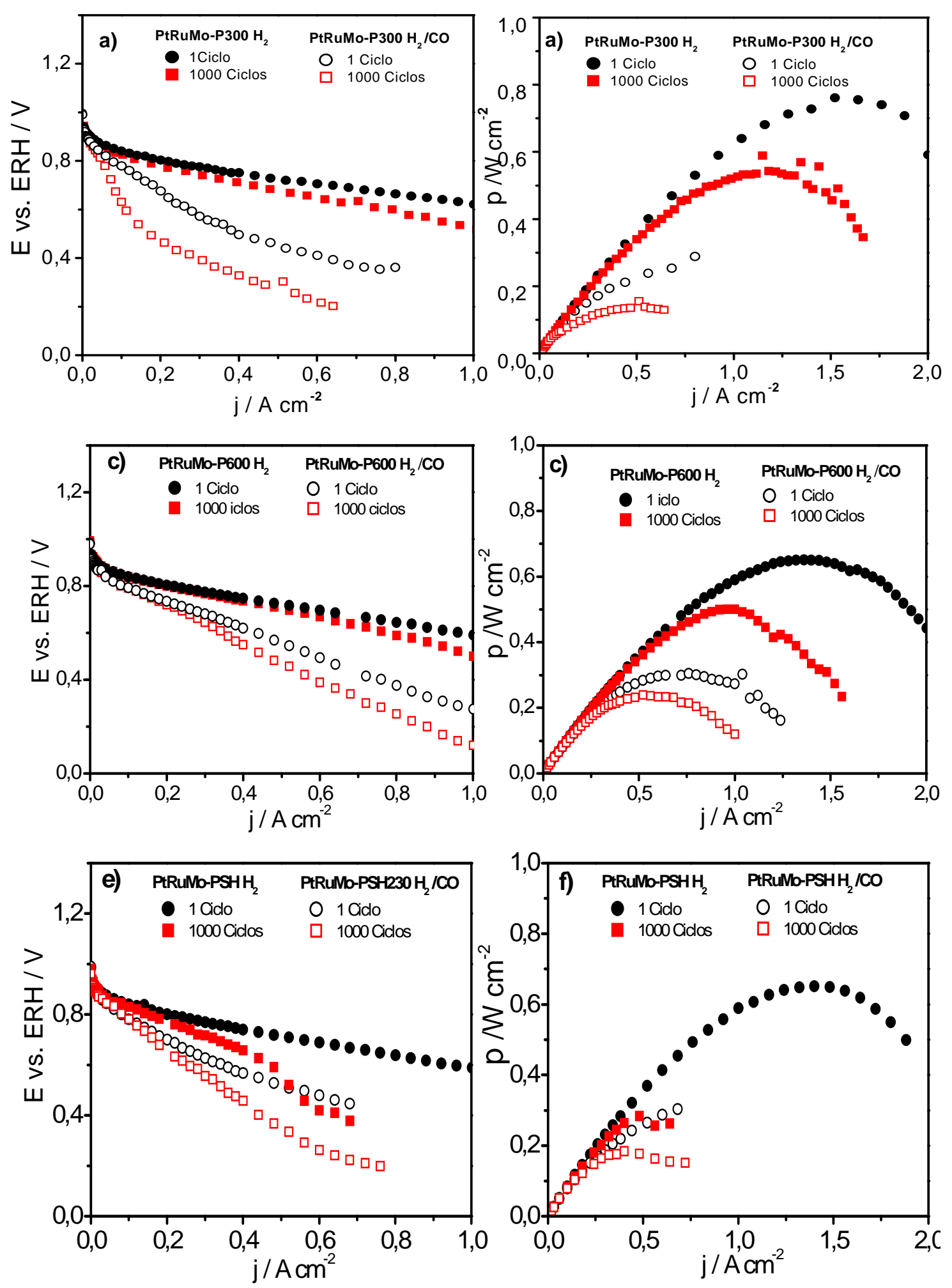
Estudos prévios mostram que o tratamento térmico permite estabelecer modificações na superfície do eletrodo através das mudanças na área superficial. Os tratamentos térmicos feitos por Ticianelli et al [77] mostraram que quando realizados em atmosfera redutora podem melhorar o desempenho dos catalisadores em maiores temperaturas como foi demonstrado a $600{ }^{\circ} \mathrm{C}$ em catalisadores de PtRu/C. Além disso, foram obtidos tamanho de partícula maiores. O desempenho na oxidação pode melhorar com relação à temperatura, devido a maior inclusão do segundo (ou terceiro metal) na rede cristalina da Pt. No caso dos resultados obtidos neste trabalho, esta inclusão acontece pela redução na superfície da Pt, como apontam Wieckowsky e colaboradores [78].

Figura 12. (a) Densidade de potência máxima para catalisadores trimetálicos de PtRuMo/C antes e depois de 1000 ciclos e (b) Sobrepotenciais da célula unitária em $0,5 \mathrm{~A} \mathrm{~cm}^{-2}$ para catalisadores trimetálicos de PtRuMo/C antes e depois de 1000 ciclos, com $\mathrm{H}_{2}$ puro e 100 ppm de $\mathrm{CO}$.
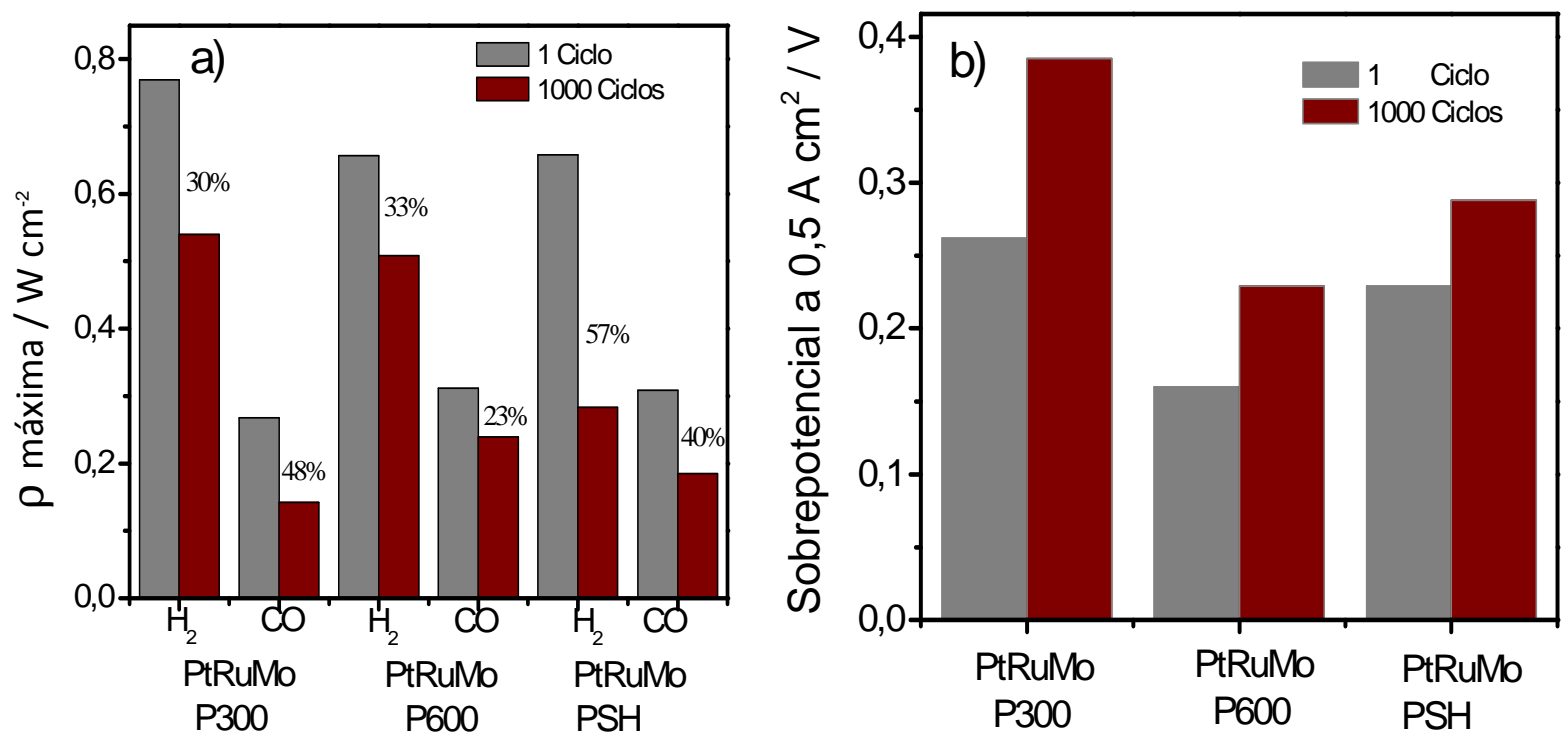


\subsubsection{Voltametria cíclica e stripping de CO}

Os voltamogramas cíclicos dos catalisadores ternários PtRuMo estão apresentados na Figura 13, antes e depois do TEA. Os voltamogramas cíclicos obtidos na configuração de célula, alimentando o ânodo com argônio e o cátodo com $\mathrm{H}_{2}$, e utilizando o cátodo como eletrodo referência $(E R H)$. Todos os materiais apresentam uma região relativa em processos de adsorção e dessorção de hidrogênio entre 0,05-0,4 V, a chamada região de hidrogênio. As cargas associadas a esses dois processos são dependentes do teor de Pt superficial do material, e do tamanho médio de partícula dos catalisadores PtRuMo. O aumento de tamanho contribui para a diminuição da área superficial de Pt desses materiais e, consequentemente, em uma menor região de $\mathrm{H}_{2}$.

A quantidade de $\mathrm{Ru}$ e Mo no catalisador tem influência direta na região de adsorção/dessorção de $\mathrm{H}_{2}$. Em catalisadores bimetálicos de $\mathrm{PtRu} / \mathrm{C}$ a região de dessorção de hidrogênio ocorre entre $0,075-0,350$ V vs. ERH [10, 25], já para catalisadores de PtMo a região está entre 050 - 0,40 V vs. ERH acompanhado de um pico de oxidação do Mo entre $0,3-0,5 \mathrm{~V}$ vs. ERH [58], não observado nos resultados obtidos com catalisadores ternários. Para catalisadores trimetálicos de PtRuMo/C, os perfis voltamétricos obtidos foram comparáveis com a literatura para este tipo de catalisadores $[40,79]$.

Para os catalisadores PtRuMo, tratados a diferentes temperaturas observa-se uma diminuição na região de adsorção de hidrogênio com aumento da temperatura, o que está diretamente relacionado ao aumento no tamanho de partícula destes materiais, determinados por TEM.

A Figura 13 também apresenta as voltametrias cíclicas após o TEA (1000 ciclos). Pela comparação dos resultados é possível observar que não ocorre variações significativas de área da região de adsorção/dessorção de hidrogênio. 
Figura 13. Voltametria cíclica para os catalisadores PtRuMo (P300, P600 e PSH), entre $0,1 \mathrm{~V}-0,7 \mathrm{~V}$ a $20 \mathrm{mV} \mathrm{s}^{-1}$ vs. $\mathrm{ERH}, \mathrm{T}=25^{\circ} \mathrm{C}$, ante e após 1000 ciclos.

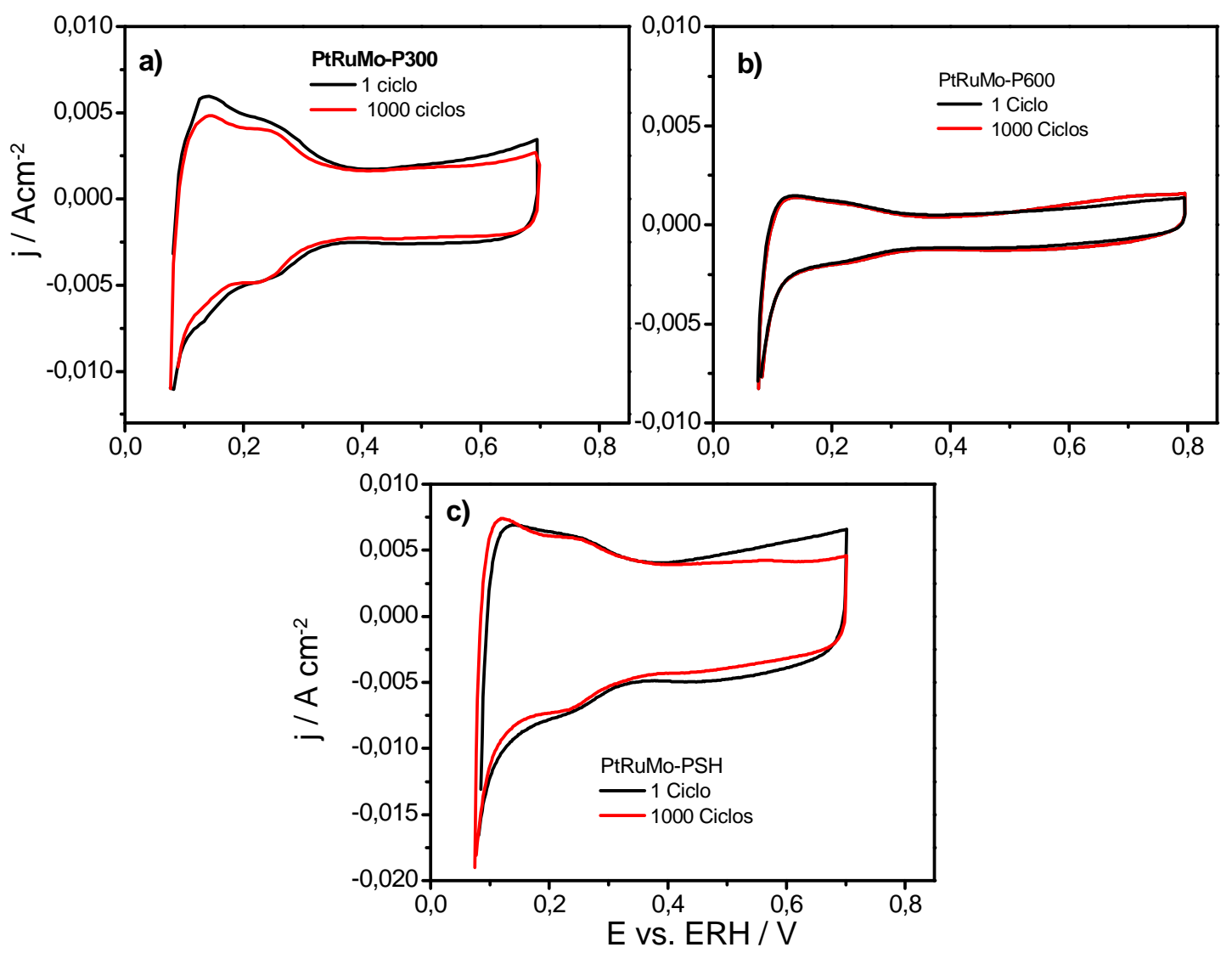

A técnica de stripping de $\mathrm{CO}$ corresponde a um procedimento para determinar a área ativa nas reações superficiais, avaliando o desempenho catalítico em cada catalisador frente à oxidação de $\mathrm{CO}$, estabelecendo se a melhora na atividade catalítica deve-se ao incremento da área ou a atividade catalítica superior do catalisador. $O$ cálculo de área consiste em determinar a quantidade de sítios ativos utilizados na adsorção de $\mathrm{CO}$ na superfície do eletrodo, saturando a superfície catalítica com CO para depois ser oxidada com o potencial aplicado, obtendo a resposta do $\mathrm{CO}$ dessorvido relacionada à quantidade de corrente como sinal de resposta. Devido a adsorção estável que o CO apresenta com os orbitais $d$ dos metais, considera-se confiável a determinação das áreas eletroativas. Normalizando as áreas obtidas pela subtração do primeiro ciclo voltamétrico correspondente, obtém-se os valores necessários na oxidação de uma monocamada de $\mathrm{CO}$. Com isto, se integram os valores de $i$ vs. $E$ obtendo as áreas para cada catalisador em termos de corrente 
vs. tempo (Coulombs). Estes valores de carga são relacionados pela constante estabelecida, em termos de carga - área $\left(420 \mu \mathrm{C}=1 \mathrm{~cm}^{-2}\right)$, na oxidação de uma monocamada de $\mathrm{CO}_{a d s}$ sobre a superfície de platina, obtendo a área eletroativa do eletrodo para cada catalisador. $\mathrm{Na}$ adsorção e dessorção de $\mathrm{CO}$ são produzidos 2 elétrons por molécula de $\mathrm{CO}$ oxidada, como é representado pela reação 1 , incluindo a carga utilizada para a determinação da área eletroativa.

$$
\mathrm{Pt}-\mathrm{CO} \text { ads }+\mathrm{H}_{2} \mathrm{O} \rightarrow \mathrm{Pt}+\mathrm{CO}_{2}+2 \mathrm{H}^{+}+2 \mathrm{e}^{-}
$$

A Figura 14(a) apresenta o stripping de CO para os catalisadores trimetálicos, A Figura 14(b) representa a subtração do primeiro ciclo de CO de uma linha de base para o cálculo da área, apresentadas na Tabela 6.

Figura 14. Stripping de CO para os catalisadores trimetálicos PtRuMo/C , v $=10 \mathrm{mV}$ $\mathrm{s}^{-1}$, atmosfera de argônio (a) e Curvas obtidas da subtração do $1^{\circ}$ ciclo (b).
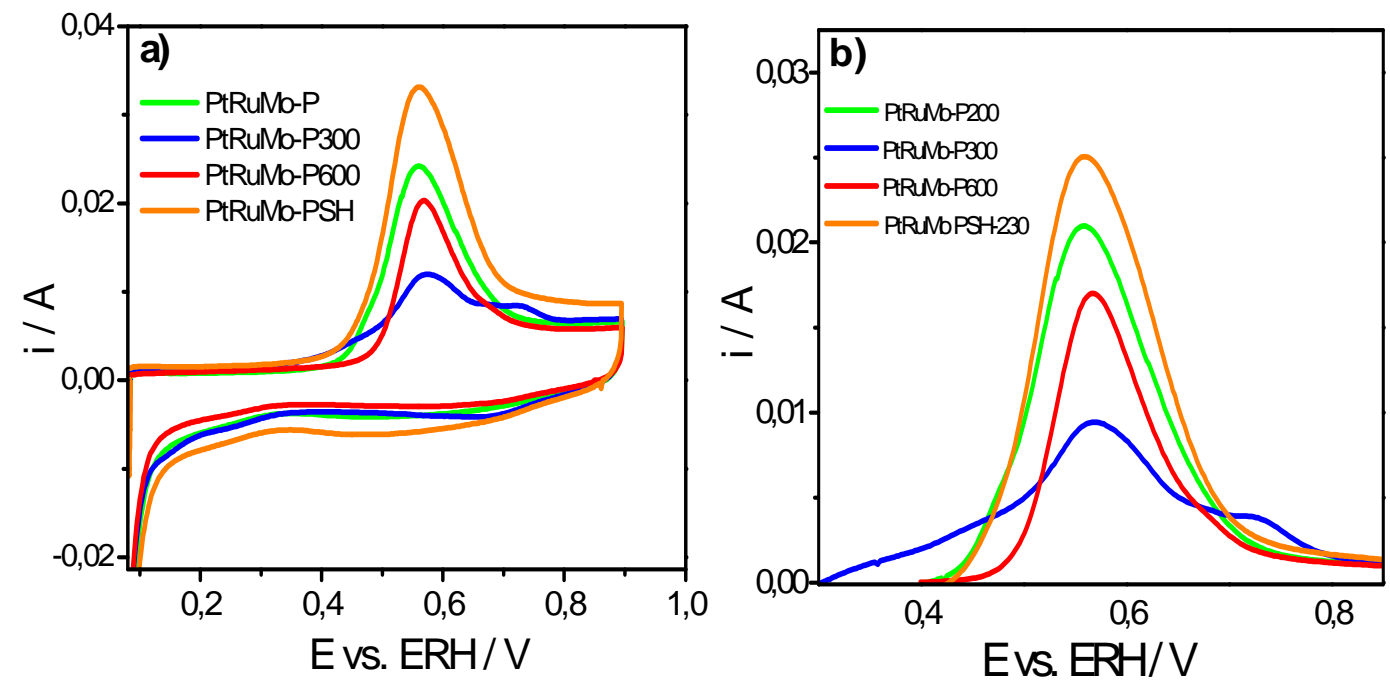
Tabela 6. Áreas eletroativas dos catalisadores trimetálicos de PtRuMo antes e após o TEA.

\begin{tabular}{c|cccc}
\hline Catalisador & $\begin{array}{c}\text { PtRuMo- } \\
\text { P }\end{array}$ & PtRuMo-P300 & PtRuMo-P600 & PtRuMo-PSH \\
& 773 & 520 & 528 & \\
\hline Área $/ \mathbf{~ c m}^{2}$ & 773 & 466 & 865 \\
\hline Área $/ \mathbf{c m}^{2}$ & & 402 & $12 \%$ & $6 \%$ \\
\% perda após TEA & & $23 \%$ & & \\
\hline
\end{tabular}

O objetivo principal é determinar o perfil voltamétrico de dessorção do CO e avaliar a eficiência de cada catalisador para promover a oxidação de $\mathrm{CO}$ com relação ao potencial aplicado. Os potenciais de oxidação de $\mathrm{CO}$ começam em $0,32 \mathrm{~V}$ vs. ERH para os catalisadores PtRuMo-P300 e PtRuMo-PSH, 0,41 V para o catalisador PtRuMo-P e finalmente $0,46 \mathrm{~V}$ para o catalisador tratado a $600^{\circ} \mathrm{C}$. Estes potenciais de início têm relação com a energia de adsorção sobre a banda $d$ da $\mathrm{Pt}$, mostrando maior susceptibilidade da oxidação de $\mathrm{CO}$ para os catalisadores tratados a $300^{\circ} \mathrm{C}$, e preparado com super hidreto.

A Figura 15 apresenta o stripping de CO para os catalisadores trimetálicos, antes e após o TEA , onde observa-se uma diminuição da área ativa após o envelhecimento. A Tabela 6 apresenta a comparação das áreas ativas dos catalisadores determinadas pela técnica de stripping de $\mathrm{CO}$ antes e após TEA. Para determinar a estabilidade de cada catalisador, o stripping de $\mathrm{CO}$ fornece um complemento para avaliar mudanças na área ativa do catalisador.

A Figura 16 apresenta a relação entre as área antes e após o TEA dos catalisadores PtRuMo. A porcentagem de perda de área eletroativa seguiu a sequência: PtRuMo-300 $>$ PtRuMo-600 $>$ PtRuMo-PSH, 22\%, $13 \%$ e $7 \%$, respectivamente. As porcentagens de perda de área foram relativamente pequenas, podendo estar associadas à dissolução de Ru e/ou Mo. Medidas de EDX foram realizadas após os TEA, mas infelizmente devido a influência do flúor, proveniente do Nafion, no pico do molibdênio não foi possível determinar a porcentagem atômica dos metais. 
Figura 15. Comparação das curvas obtidas da subtração do $1^{\circ}$ ciclo do stripping de CO para os catalisadores trimetálicos PtRuMo/C, antes e após o TEA , v $=10 \mathrm{mV} \mathrm{s}^{-1}$, atmosfera de argônio: (a) PtRuMo-P300, (b) PtRuMoP-600 e (c) PtRuMo-PSH.
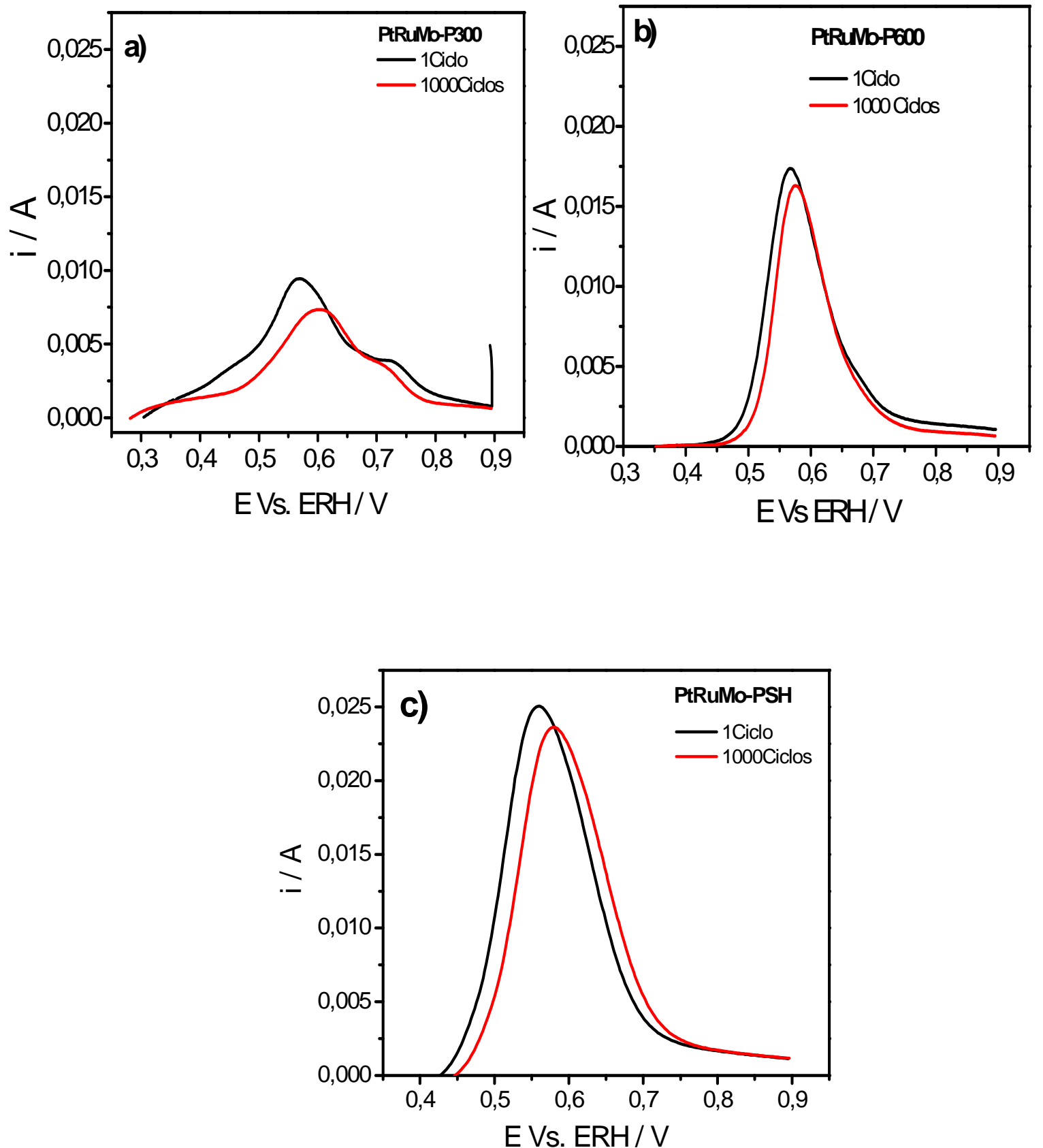
Figura 16. Áreas ativas dos catalisadores PtRuMo antes e após o TEA.

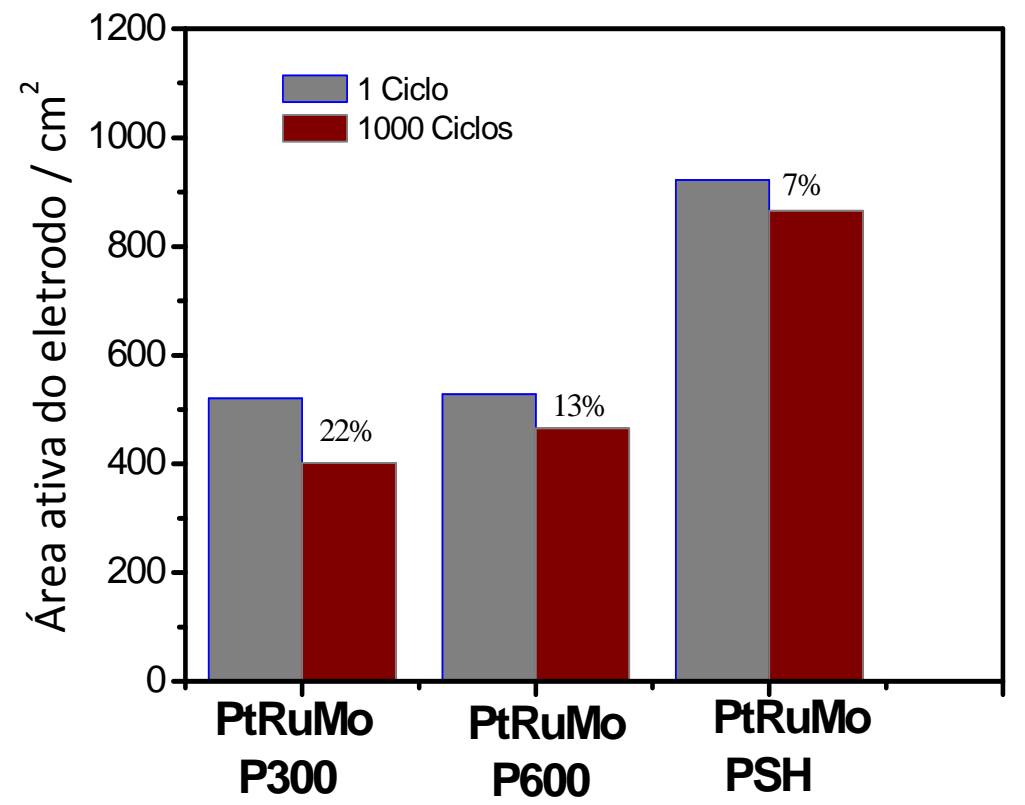

\subsection{Espectroscopia de Massa on line}

Os experimentos de espectrometria de massa on line foram feitos para avaliar a produção de $\mathrm{CO}_{2}$ com relação à oxidação de $\mathrm{CO}$ para os catalisadores anódicos de PtRuMo. Estes estudos foram realizados analisando o ganho de corrente iônica que que é produzido mediante os sinais de $\mathrm{CO}_{2}(\mathrm{~m} / \mathrm{z}=44)$, com relação as variações de potencial, desde $0,9 \mathrm{~V}$ e diminuindo $0,1 \mathrm{~V}$ a cada 200 ciclos. Desta maneira, os resultados de produção de $\mathrm{CO}_{2}$ são relacionados com as correntes iônicas $(\Delta \mathrm{l})$ a um potencial fixo, como se observa na Figura 17. 
Figura 17 (a) Produção de $\mathrm{CO}_{2}$ em termos de corrente relativa $(\Delta \mathrm{I})$ vs. sobrepotencial $\eta$ para os catalisadores PtRuMO-P e (b) Densidade de corrente $\left(\mathrm{Acm}^{-2}\right)$ vs. sobrepotencial ( $\eta$ ).

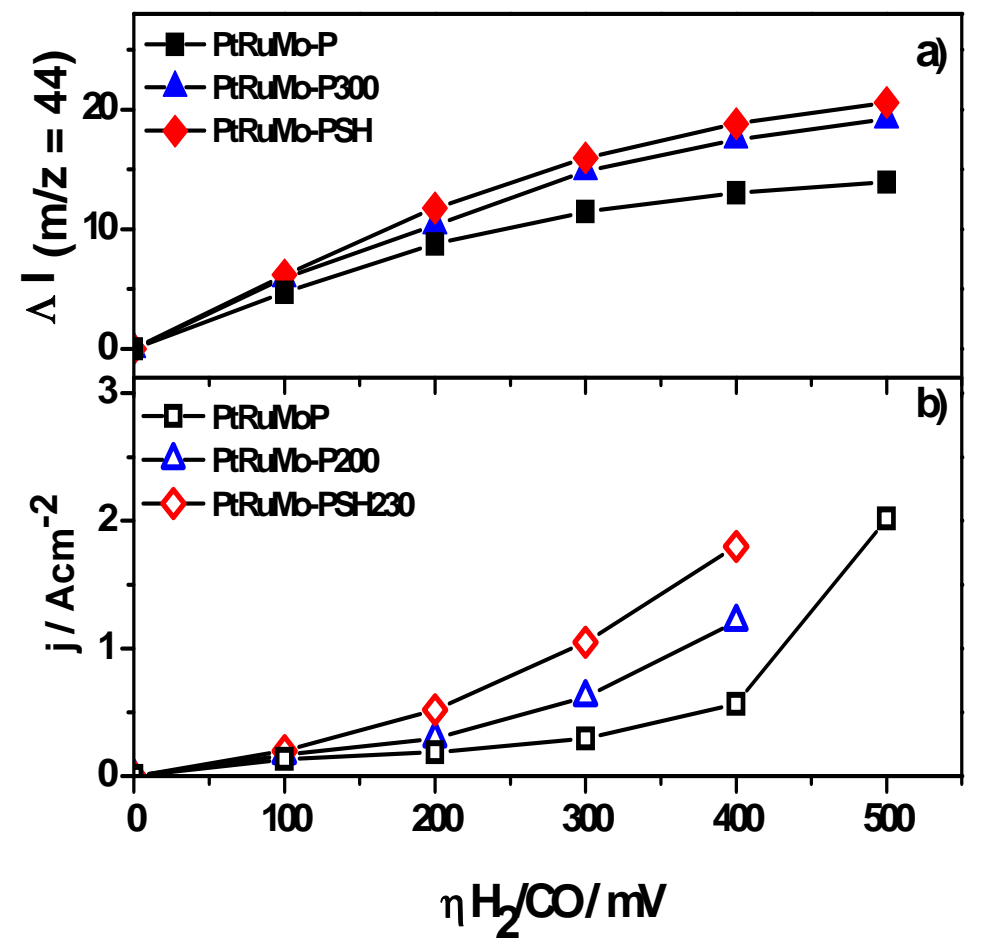

Os sobrepotenciais obtidos com relação à corrente representam a tolerância relativa de cada catalisador, com relação ao potencial de oxidação para $\mathrm{H}_{2}$ puro, obtendo uma maior tolerância quando são obtidos maiores potenciais ao ser contaminado com 100 ppm de CO. Esta relação de tolerância pode ser estabelecida em função da quantidade de $\mathrm{CO}_{2}$ produzido, que representa a quantidade de $\mathrm{CO}$ dessorvido do catalisador, como pode se observar pela equação 6. Para cada catalisador foi determinada a quantidade de corrente para $\mathrm{CO}_{2}$, obtendo para o catalisador PtRuMo$\mathrm{P}$ menores cargas, correspondentes a $\mathrm{m} / \mathrm{z}=44$ (Figura $17 \mathrm{a}$ ), indicando menor tolerância. O catalisador preparado com super hidreto apresenta uma produção superior de $\mathrm{CO}_{2}$ e maiores valores de densidades de corrente, seguido do catalisador tratado a $300{ }^{\circ} \mathrm{C}$. Estes resultados indicam a produção de $\mathrm{CO}_{2}$ em baixos sobrepotenciais, corroborando com a proposta do mecanismo bifuncional que correspondente à dessorção de $\mathrm{CO}$ adsorvido na liga trimetálica, descrita pelo mecanismo de Eley-Rideal e representados pela reação 2: 


$$
\mathrm{CO}+\mathrm{H}_{2} \mathrm{O}_{a d s} \rightleftharpoons \mathrm{CO}_{2}+2 \mathrm{H}^{+}+2 \mathrm{e}^{-}
$$

As Figuras 18 e 19 apresentam a produção de $\mathrm{CO}, \mathrm{CO}_{2}$ e $\mathrm{CH}_{4}$ em forma de $\mathrm{CH}_{3}{ }^{+}$ de acordo com a troca de gases aplicado na estação de teste para o catalisador PtRuMo-P e PtRuMo-PSH, respectivamente. Troca de $\mathrm{H}_{2}$ puro para $\mathrm{H}_{2}$ com 100 ppm de CO.

Figura 18. Intensidade iônica via $\mathrm{EM}$, obtida para a produção de $\mathrm{CH}_{4}(\mathrm{~m} / \mathrm{z}=15)$ e $\mathrm{CO}_{2}(\mathrm{~m} / \mathrm{z}=44)$ com relação a troca de $\mathrm{H}_{2}$ por $\mathrm{H}_{2}+100 \mathrm{ppm}$ de $\mathrm{CO}$ alimentando o cátodo com $\mathrm{O}_{2}$ para o catalisador de PtRuMo-P, nas condições estabelecidas para as curvas de polarização em função do tempo. Trocas indicadas na figura.

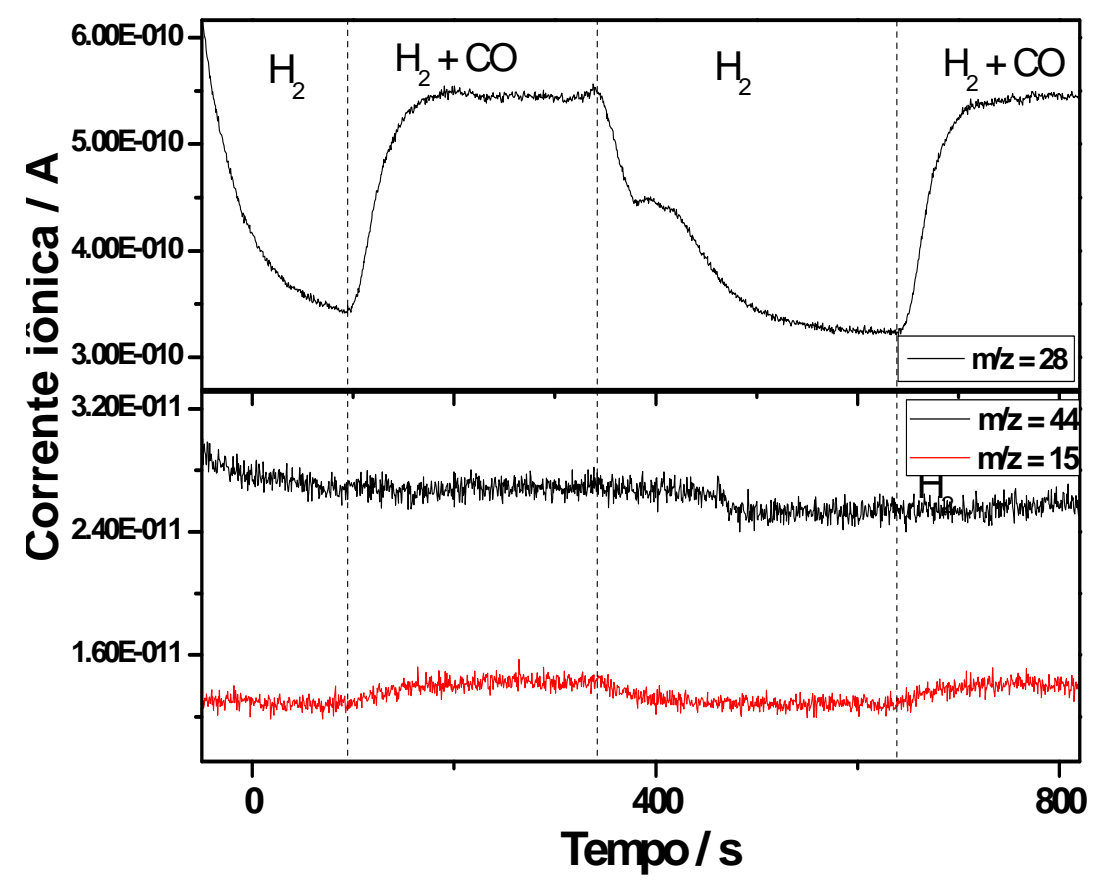


Figura 19. Intensidade iônica Via EM, obtida para a produção de $\mathrm{CH}_{4}(\mathrm{~m} / \mathrm{z}=15)$, $\mathrm{CO}$ $(\mathrm{m} / \mathrm{z}=28)$ e $\mathrm{CO}_{2}(\mathrm{~m} / \mathrm{z}=44)$ com relação a troca de $\mathrm{H}_{2}$ por $\mathrm{H}_{2}+100 \mathrm{ppm}$ de $\mathrm{CO}$ alimentando o cátodo com $\mathrm{O}_{2}$ para o catalisador de PtRuMo-PSH, nas condições estabelecidas para as curvas de polarização. Trocas indicadas na figura

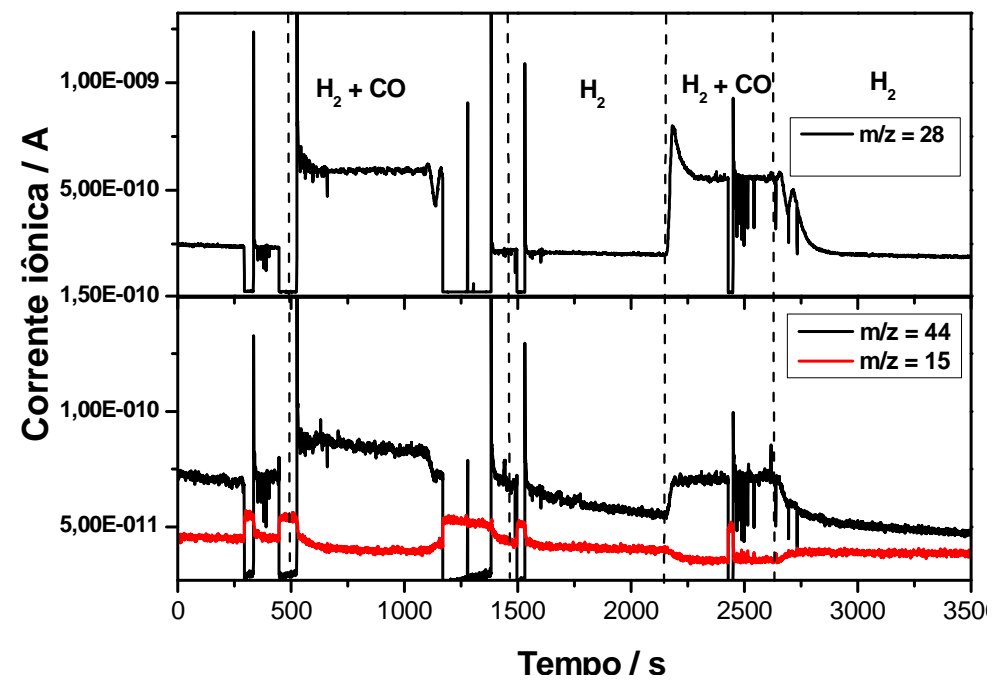

A produção de $\mathrm{CO}_{2}$ depende dos gases que ingressam no ânodo, sendo esta produção dependente da quantidade de $\mathrm{CO}$ a ser oxidado, permitindo observar a transformação de $\mathrm{CO}$ a $\mathrm{CO}_{2}$ via $\mathrm{EM}$, mantendo o circuito aberto e trocando conforme o tempo, a quantidade de $\mathrm{H}_{2}$ e $\mathrm{H}_{2}+\mathrm{CO}$, determinando as correntes $\mathrm{m} / \mathrm{z}=28$ (CO), $\mathrm{m} / \mathrm{z}=44\left(\mathrm{CO}_{2}\right)$ e $\mathrm{CH}_{4} \mathrm{~m} / \mathrm{z}=15$, que pode ser gerada sobre a superfície metálica do catalisador de acordo com a reação 3 :

$$
\mathrm{CO}_{\mathrm{ads}}+6 \mathrm{H}_{\mathrm{ads}} \rightleftharpoons \mathrm{CH}_{4}+\mathrm{H}_{2} \mathrm{O}
$$

A produção de metano pode acontecer devido à influência de Ru na liga como apontam alguns estudos [80], que explicam as respostas de corrente obtidas nas figuras 18-19, obtendo as sinais da troca de gases com relação as mudanças entre a produção de $\mathrm{CO}_{2}$ e $\mathrm{CH}_{4}$.

Nas Figuras 18-19 é possível observar que para a produção de $\mathrm{CO}_{2}$ e $\mathrm{CH}_{4}$ durante o tempo que com a mudança dos gases de $\mathrm{H}_{2}+\mathrm{CO}$ para $\mathrm{H}_{2}$ puro observa-se uma diminuição na quantidade de corrente para $\mathrm{m} / \mathrm{z}=44\left(\mathrm{CO}_{2}\right)$ e aumento em $\mathrm{m} / \mathrm{z}=15$ 
$\left(\mathrm{CH}_{4}\right)$ para o catalisadores PtRuMo-P e PSH. A produção de $\mathrm{CH}_{4}$ está determinada pela quantidade de hidrogênio no compartimento anódico, o qual é necessário para promover a dessorção de $\mathrm{CO}$ e produção de $\mathrm{CH}_{4}$.

A intensidade atingida para $\mathrm{CO}_{2}$ e $\mathrm{CH}_{4}$ depende da quantidade de $\mathrm{CO}$ e $\mathrm{H}_{2}$ que estava adsorvido na superfície do catalisador. A troca de gases permite determinar de forma qualitativa a dependência que precede cada reação com relação aos gases alimentados, obtendo-se uma diferença pouco significativa na produção das correntes dos gases devido ao pouco tempo que tem para adsorver e dessorver os gases produzidos. 


\section{CONCLUSÃO}

A síntese dos eletrocatalisadores $\mathrm{PtRu} / \mathrm{C}, \mathrm{PtMo} / \mathrm{C}$ e $\mathrm{PtRuMo} / \mathrm{C}$ pelos métodos de impregnação e poliol mostrou-se eficiente. Os resultados de EDX confirmaram a incorporação dos metais aos materiais, de acordo com os valores nominais, enquanto que pela análise dos dados de XRD obteve-se deslocamentos dos parâmetros de rede indicando que houve formação de liga. As análises de TEM mostraram uma distribuição de partícula uniforme para os catalisadores sintetizados e tratados, e o tamanho médio de partícula entre 2,4 e 4,9 nm, menor do que comparado com a literatura. Os dados de XPS, mostraram que o catalisador PtRuMo-PSH apresentou maior proporção dos metais no seu estado metálico em comparação com o catalisador PtRuMo-P, sem necessidade de tratamentos térmicos, devido ao superhidreto como agente redutor. Para os demais catalisadores com aumento da temperatura de tratamento térmico em atmosfera redutora também ocorre maior proporção dos metais no estado metálico. O tratamento térmico em atmosfera redutora contribuiu a um aumento do tamanho médio de cristalito, assim como a proporção dos metais no estado metálico.

Neste trabalho, os catalisadores trimetálicos mostraram superior desempenho comparado aos catalisadores bimetálicos para a $\mathrm{ROH}$ na presença de $\mathrm{CO}$, sendo estas comparáveis com a literatura. Esta atividade foi maior para os catalisadores tratados a maior temperatura, obtendo-se a melhor atividade para o catalisador PtRuMo-P600. De mesma maneira, o catalisador PtRuMo-P600 mostrou uma melhora na estabilidade com relação aos catalisadores trimetálicos frente ao teste de envelhecimento acelerado. $\mathrm{O}$ tratamento térmico contribuiu na melhora da tolerância ao $\mathrm{CO}$ e da estabilidade para os catalisadores trimetálicos. Entretanto o catalisador PtRuMo-PSH também apresentou boa atividade e estabilidade, indicando que os materiais com maior proporção de metais na forma metálica, e provavelmente, maior grau de liga, favorecem a $\mathrm{ROH}$ e a $\mathrm{ROH}$ na presença de $\mathrm{CO}$. A diferença principal destes catalisadores está no tamanho de partícula, 4,9 e 2,4, para PtRuMo-P600 e PtRuMo-PSH, respectivamente. 
As caracterizações eletroquímicas permitiram obter os perfis voltamétricos dos catalisadores trimetálicos, mostrando uma diminuição das áreas eletroativas com o aumento da temperatura de tratamento térmico, diretamente relacionado ao aumento de tamanho de partícula. A técnica de stripping de CO foi utilizada para avaliar as mudanças de área antes e após o TEA observando perdas de área eletroativa de 22 , 13 e $7 \%$ para os catalisadoresPtRuMo-300>PtRuMo-600>PtRuMo-PSH. respectivamente. As porcentagens de perda de área foram relativamente pequenas, podendo estar associadas à dissolução de Ru e/ou Mo.

A espectrometria de massas on-line determinou a produção de $\mathrm{CO}_{2}$, a partir da injeção de $\mathrm{H}_{2} / \mathrm{CO}$ a 100 ppm, obtendo relação direita com a atividade catalítica para os catalisadores em termos de corrente relativa, sendo maior para os catalisadores mais tolerantes. Além disso, foi possível observar a produção de $\mathrm{CH}_{4}$ para os catalisadores PtRuMo-P e PtRuMo-PSH. 


\section{REFERÊNCIAS BIBLIOGRÁFICAS}

1. DIAS, M.S.C. Shell Solar: eletrificação e desenvolvimento sustentátel. Scielo procedings: engenharía e meio rural. 2003. Disponível em: <http://www.proceedings.scielo.br/scielo.php?pid=MSC0000000022000000100048\& script=sci_arttext/>. Acesso em: 3 abr. 2014.

2. Pinheiro, A.L.N.; Oliveira-Neto, A.; De Souza, E.C.; Perez, J.; Paganin, V.A.; TICIANELLI, E.A.; GONZALEZ, E.R. Electrocatalysis on noble metal and noble metal alloys dispersed on high surface area carbon. Journal of New Materials for Electrochemical Systems, v. 6, n. 1, p. 1-8, 2003.

3. AlONSO-VANTE, N. Electroquímica y electrocatálisis. Buenos aires, Argentina: elibro.net, 2003. v. 1 a.

4. LARMINIE, J.D. A. Fuel cell systems explained. Chichester: Wiley, 2003. v. 2.

5. GONZÁLEZ, E.R. Electrocatálise e poluição ambiental. Química Nova, v. 23, n. 2, p. 262-266, 1999.

6. KUNZE, J.; STIMMING, U. Electrochemical versus heat-engine energy technology: tribute to Wilhelm Ostwald's visionary statements. Angewandte ChemieInternational Edition, v. 48, n. 49, p. 9230-9237, 2009.

7. Mercedes, V.H.T.; Ticianelli, E. A.; GonzÁLez, E. R. Células a combustível: energia limpa a partir de fontes renováveis. Atualidades em Química, v. 15, 2002. Disponível em: <http://qnesc.sbq.org.br/online/qnesc15/v15a06.pdf>. Aceso em: 4 mar. 2013.

8. BIODISOL. Hidrógeno: ¿Qué es el hidrógeno?. 2005. Disponível em: $<$ http://www.biodisol.com/hidrogeno-que-es-el-hidrogeno-energias-limpias-elcombustible-del-futuro-energia-infinita/>. Acesso em: 3 fev. 2014.

9. PERLES, C.E. Physicochemical properties related to the development of nafion (R) membranes for application in fuel cells. Polimeros-Ciencia E Tecnologia, v. 18, $\mathrm{n}$. 4, p. 281-288, 2008.

10. Mcbreen, J.; MuKeRJee, S. In-situ X-ray-absorption studies of a Pt-Ru electrocatalyst. Journal of the Electrochemical Society, v. 142, n. 10, p. 33993404, 1995.

11. LOPES, P.P. Estudos da reação de oxidação de hidrogênio na presença de CO no sistema eletrocatalítico Pt-Ru/C. 2004. 91 f. Dissertação (Mestrado) Instituto de Química de São Carlos, Universidade de São Paulo, São Carlos, 2009. 
12. IGARASHI, H.; FUJINO, T.; WATANABE, M. Hydrogen electrooxidation on platinum catalysts in the presence of trace carbon-monoxide. Journal of Electroanalytical Chemistry, v. 391, n. 1-2, p. 119-123, 1995.

13. IgARASHI, H.; FUJINO, T.; WatANABE, M. Hydrogen electro-oxidation on platinum catalysts in the presence of trace carbon monoxide. Journal of Electroanalytical Chemistry, v. 391, n. 1-2, p. 119-123, 1995.

14. LIU, P.; LOGADOTTIR, A.; NorSKOV, J.K. Modeling the electro-oxidation of $C O$ and $\mathrm{H}-2 / \mathrm{CO}$ on Pt, Ru, PtRu and Pt3Sn. Electrochimica Acta, v. 48, n. 25-26, p. 37313742, 2003.

15. Christoffersen, E.; LiU, P.; Ruban, A.; Skriver, H.L.; Norskov, J.K. Anode materials for low-temperature fuel cells: A density functional theory study. Journal of Catalysis, v. 199, n. 1, p. 123-131, 2001.

16. ObRadovic, M.D.; GoJkovic, S.L. Electrochemical instability of Pt nanoparticles probed by formic acid oxidation. Journal of Electroanalytical Chemistry, v. 664, p. 152-155, 2012.

17. IGARASHI, H.; FuJINo, T.; ZhU, Y.M.; UCHIDA, H.; WatANABE, M. CO Tolerance of Pt alloy electrocatalysts for polymer electrolyte fuel cells and the detoxification mechanism. Physical Chemistry Chemical Physics, v. 3, n. 3, p. 306-314, 2001.

18. MukeRJee, S.; URian, R.C.; LeE, S.J.; TicianelLI, E.A.; McBreen, J. Electrocatalysis of $\mathrm{CO}$ tolerance by carbon-supported PtMo electrocatalysts in PEMFCs. Journal of the Electrochemical Society, v. 151, n. 7, p. A1094-A1103, 2004.

19. Martínez-Huerta, M.V.; Rojas, S.; Gómez de la Fuente, J.L.; TerReros, P.; PeÑA, M.A.; FIERRO, J.L.G. Effect of Ni addition over PtRu/C based electrocatalysts for fuel cell applications. Applied Catalysis B: Environmental, v. 69, n. 1-2, p. 7584, 2006.

20. EhTESHAMI, S.M.M.; JIA, Q.; HALDER, A.; Chan, S.H.; MuKERJEe, S. The role of electronic properties of $\mathrm{Pt}$ and $\mathrm{Pt}$ alloys for enhanced reformate electro-oxidation in polymer electrolyte membrane fuel cells. Electrochimica Acta, v. 107, p. 155-163, 2013.

21. EHTESHAMI, S.M.M.; CHAN, S.H. A review of electrocatalysts with enhanced CO tolerance and stability for polymer electrolyte membarane fuel cells. Electrochimica Acta, v. 93, p. 334-345, 2013.

22. Obradovic, M.D.; TRIPKOVIC, A.V.; GoJKOVIC, S.L. Oxidation of carbon monoxide and formic acid on bulk and nanosized Pt-Co alloys. Journal of Solid State Electrochemistry, v. 16, n. 2, p. 587-595, 2012. 
23. LIU, Z.F.; JACKSON, G.S.; EICHHORN, B.W. Tuning the CO-tolerance of Pt-Fe bimetallic nanoparticle electrocatalysts through architectural control. Energy \& Environmental Science, v. 4, n. 5, p. 1900-1903, 2011.

24. LIN, R.; CAO, C.H.; ZHANG, H.Y.; HUANG, H.B.; MA, J.X. Electro-catalytic activity of enhanced $\mathrm{CO}$ tolerant cerium-promoted $\mathrm{Pt} / \mathrm{C}$ catalyst for PEM fuel cell anode. International Journal of Hydrogen Energy, v. 37, n. 5, p. 4648-4656, 2012.

25. Carmo, M.; Paganin, V.A.; Rosolen, J.M.; Gonzalez, E.R. Alternative supports for the preparation of catalysts for low-temperature fuel cells: the use of carbon nanotubes. Journal of Power Sources, v. 142, n. 1-2, p. 169-176, 2005.

26. Camara, G.A.; Giz, M.J.; Paganin, V.A.; Ticianelli, E.A. Correlation of electrochemical and physical properties of PtRu alloy electrocatalysts for PEM fuel cells. Journal of Electroanalytical Chemistry, v. 537, n. 1-2, p. 21-29, 2002.

27. Watanabe, M.; Motoo, S. Electrocatalysis by ad-atoms: Part I. Enhancement of the oxidation of methanol on platinum and palladium by gold ad-atoms. Journal of Electroanalytical Chemistry and Interfacial Electrochemistry, v. 60, n. 3, p. 259266, 1975.

28. Watanabe, M.; Mотоo, S. Electrocatalysis by ad-atoms: Part II. Enhancement of the oxidation of methanol on platinum by ruthenium ad-atoms. Journal of

Electroanalytical Chemistry and Interfacial Electrochemistry, v. 60, n. 3, p. 267273, 1975.

29. ANTOLINI, E. The problem of Ru dissolution from Pt-Ru catalysts during fuel cell operation: analysis and solutions. Journal of Solid State Electrochemistry, v. 15, n. 3, p. 455-472, 2011.

30. URIAN, R.C.; GULLA, A.F.; MUKERJEE, S. Electrocatalysis of reformate tolerance in proton exchange membranes fuel cells: Part I. Journal of Electroanalytical

Chemistry, v. 554, p. 307-324, 2003.

31. Santiago, E.I.; Camara, G.A.; Ticianelli, E.A. CO tolerance on PtMo/C electrocatalysts prepared by the formic acid method. Electrochimica Acta, v. 48, n. 23, p. 3527-3534, 2003.

32. GotZ, M.; WENDT, H. Binary and ternary anode catalyst formulations including the elements W, Sn and Mo for PEMFCs operated on methanol or reformate gas.

Electrochimica Acta, v. 43, n. 24, p. 3637-3644, 1998.

33. MaillaRd, F.; LU, G.Q.; WiEckowski, A.; Stimming, U. Ru-decorated Pt surfaces as model fuel cell electrocatalysts for $\mathrm{CO}$ electrooxidation. Journal of Physical Chemistry B, v. 109, n. 34, p. 16230-16243, 2005. 
34. LEBEDEVA, N.P.; JANSSEN, G.J.M. On the preparation and stability of bimetallic $\mathrm{PtMo} / \mathrm{C}$ anodes for proton-exchange membrane fuel cells. Electrochimica Acta, v. 51, n. 1, p. 29-40, 2005.

35. Martinez-Huerta, M.V.; Rojas, S.; de la Fuente, J.L.G.; Terreros, P.; Pena, M.A.; FIERRO, J.L.G. Effect of Ni addition over PtRu/C based electrocatalysts for fuel cell applications. Applied Catalysis B-Environmental, v. 69, n. 1-2, p. 75-84, 2006.

36. LIANG, Y.M.; ZHANG, H.M.; ZHONG, H.X.; ZHU, X.B.; TIAN, Z.Q.; XU, D.Y.; YI, B.L. Preparation and characterization of carbon-supported PtRulr catalyst with excellent CO-tolerant performance for proton-exchange membrane fuel cells. Journal of Catalysis, v. 238, n. 2, p. 468-476, 2006.

37. CHEN, S.; YE, F.; LIN, W. Effect of operating conditions on the performance of a direct methanol fuel cell with PtRuMo/CNTs as anode catalyst. International Journal of Hydrogen Energy, v. 35, n. 15, p. 8225-8233, 2010.

38. Alcaide, F.; Álvarez, G.; Tsiouvaras, N.; Peña, M.A.; Fierro, J.L.G.; MartínezHUERTA, M.V. Electrooxidation of H2/CO on carbon-supported PtRu-MoOx nanoparticles for polymer electrolyte fuel cells. International Journal of Hydrogen Energy, v. 36, n. 22, p. 14590-14598, 2011.

39. SteVens, D.A.; Rouleau, J.M.; MaR, R.E.; Atanasoski, R.T.; SchmoeCKel, A.K.; DEBE, M.K.; DAHN, J.R. Enhanced CO-tolerance of Pt-Ru-Mo hydrogen oxidation catalysts. Journal of the Electrochemical Society, v. 154, n. 12, p. B1211-B1219, 2007.

40. Martinez-Huerta, M.V.; Tsiouvaras, N.; Pena, M.A.; Fierro, J.L.G.; Rodriguez, J.L.; PASTOR, E. Electrochemical activation of nanostructured carbon-supported PtRuMo electrocatalyst for methanol oxidation. Electrochimica Acta, v. 55, n. 26, p. 7634-7642, 2010.

41. PETRII, O.A. Pt-Ru electrocatalysts for fuel cells: a representative review. Journal of Solid State Electrochemistry, v. 12, n. 5, p. 609-642, 2008.

42. Russell, A.E.; Ball, S.C.; Maniguet, S.; Thompsett, D. Unravelling the complexities of $\mathrm{CO} 2$ tolerance at PtRu/C and PtMo/C. Journal of Power Sources, v. 171, n. 1, p. 72-78, 2007.

43. Ball, S.; Hodgkinson, A.; HoOgers, G.; Maniguet, S.; ThOMPSetT, D.; Wong, B. The proton exchange membrane fuel cell performance of a carbon supported PtMo catalyst operating on reformate. Electrochemical and Solid State Letters, v. 5, n. 2, p. A31-A34, 2002.

44. Antolini, E. Platinum-based ternary catalysts for low temperature fuel cells Part II. Electrochemical properties. Applied Catalysis B-Environmental, v. 74, n. 3-4, p. 337-350, 2007. 
45. Obradovic, M.D.; Gojkovic, S.L.; Elezovic, N.R.; ERcIUS, P.; Radmilovic, V.R.; VRACAR, L.D.; KRSTAJIC, N.V. The kinetics of the hydrogen oxidation reaction on WC/Pt catalyst with low content of Pt nano-particles. Journal of Electroanalytical Chemistry, v. 671, p. 24-32, 2012.

46. SHEN, P.K.; TSEUNG, A.C.C. Anodic-oxidation of methanol on Pt/Wo3 in acidic media. Journal of the Electrochemical Society, v. 141, n. 11, p. 3082-3090, 1994.

47. Coutanceau, C.; Brimaud, S.; Lamy, C.; Leger, J.M.; Dubau, L.; Rousseau, S.; VIGIER, F. Review of different methods for developing nanoelectrocatalysts for the oxidation of organic compounds. Electrochimica Acta, v. 53, n. 23, p. 6865-6880, 2008.

48. Hogarth, M.P.; RALPh, T.R. Catalysis for Low Temperature Fuel Cells PART III: challenges for the direct methanol fuel cell. Platinum Metals Review, v. 46, n. 4, p. 146-164, 2002.

49. De-los-Santos-Álvarez, N.; Alden, L.R.; Rus, E.; Wang, H.; DiSalvo, F.J.; ABRUÑA, H.D. CO tolerance of ordered intermetallic phases. Journal of Electroanalytical Chemistry, v. 626, n. 1-2, p. 14-22, 2009.

50. Ranjan, C.; Hoffmann, R.; DiSalvo, F.J.; AbRuna, H.A. Electronic effects in CO chemisorption on pt-pb intermetallic surfaces: a theoretical study. Journal of Physical Chemistry C, v. 111, n. 46, p. 17357-17369, 2007.

51. Papageorgopoulos, D.C.; KelJzer, M.; de Bruljn, F.A. The inclusion of Mo, Nb and $\mathrm{Ta}$ in $\mathrm{Pt}$ and PtRu carbon supported 3electrocatalysts in the quest for improved CO tolerant PEMFC anodes. Electrochimica Acta, v. 48, n. 2, p. 197-204, 2002.

52. LUO, J.; KARIUKI, N.; HAN, L.; WANG, L.Y.; ZHONG, C.J.; HE, T. Preparation and characterization of carbon-supported PtVFe electrocatalysts. Electrochimica Acta, v. 51, n. 23, p. 4821-4827, 2006.

53. HE, C.Z.; KUNZ, H.R.; FENTON, J.M. Evaluation of platinum-based catalysts for methanol electro-oxidation in phosphoric acid electrolyte. Journal of the Electrochemical Society, v. 144, n. 3, p. 970-979, 1997.

54. KIM, H.T.; YoO, J.S.; JoH, H.I.; KIM, H.; MoON, S.H. Properties of Pt-based electrocatalysts containing selectively deposited $\mathrm{Sn}$ as the anode for polymer electrolyte membrane fuel cells. International Journal of Hydrogen Energy, v. 36, n. 2, p. 1606-1612, 2011.

55. Malheiro, A.R.; Perez, J.; Villullas, H.M. Well-alloyed PtFe/C nanocatalysts of controlled composition and same particle size: oxygen reduction and methanol tolerance. Journal of the Electrochemical Society, v. 156, n. 1, p. B51-B58, 2009. 
56. Godol, D.R.M.; PeREZ, J.; VILLULLAS, H.M. Influence of particle size on the properties of $\mathrm{Pt}-\mathrm{Ru} / \mathrm{C}$ catalysts prepared by a microemulsion method. Journal of the Electrochemical Society, v. 154, n. 5, p. B474-B479, 2007.

57. KEMBALL,C.; DOWDEN, D.A.; ACRES, G.J.K.; BIRD, J.A.; JENKINS, J.W. Catalisys. In: ACRES, G.J.K.; BIRD, A.J.; JENKINS, J.W.; KING, F. The Design and preparation of supported catalysts. Cambridge: Royal society of chemistry, 1981. cap. 1. Disponível em: <http://pubs.rsc.org/en/content/chapter/cl978085186554600001/978-0-85186-554-6\#!divabstract>. Acesso em: 5 maio. 2014.

58. NePEL, T.C.M.; LOPES, P.P.; PAganin, V.A.; TICIANELLI, E.A. CO tolerance of proton exchange membrane fuel cells with $\mathrm{Pt} / \mathrm{C}$ and $\mathrm{PtMo} / \mathrm{C}$ anodes operating at high temperatures: A mass spectrometry investigation. Electrochimica Acta, v. 88, n., p. 217-224, 2013.

59. ZHANG, X.; ZHANG, F.; CHAN, K.Y. Synthesis of Pt-Ru-Mo ternary metal nanoparticles by microemulsions, their characterization and electrocatalytic properties. Journal of Materials Science, v. 39, n. 18, p. 5845-5848, 2004.

60. FIEVET F, L.J.P.; FIGLARZ M. Preparing monodisperse metal powders in micrometer and submicrometer sizes by poliol process. MRS Bulletin, v. n., p. 5, 1989.

61. ANTOLINI, E. Platinum-based ternary catalysts for low temperature fuel cells Part I. Preparation methods and structural characteristics. Applied Catalysis BEnvironmental, v. 74, n. 3-4, p. 324-336, 2007.

62. WANG, G.; TAKEGUCHI, T.; MUHAMAD, E.N.; YAMANAKA, T.; UEDA, W. Investigation of grain boundary formation in $\mathrm{PtRu} / \mathrm{C}$ catalyst obtained in a polyol process with posttreatment. International Journal of Hydrogen Energy, v. 36, n. 5, p. 3322-3332, 2011.

63. STIMMING, J.K.U. Electrochemical heat engine energy technology a tribute of wilhelm ostwalds visionary statements chemie international edition. Agenwandte Chemie Internatinal Edition, v. 48, n. 5, p. 9230-9237, 2009.

64. ZHOU, W.J.; LI, W.Z.; SONG, S.Q.; ZHOU, Z.H.; JIANG, L.H.; SUN, G.Q.; XIN, Q.; POULIANITIS, K.; KONTOU, S.; TSIAKARAS, P. Bi- and tri-metallic Pt-based anode catalysts for direct ethanol fuel cells. Journal of Power Sources, v. 131, n. 1-2, p. 217-223, 2004.

65. LEE, K.-S.; PARK, H.-Y.; CHO, Y.-H.; PARK, I.-S.; YOO, S.J.; SUNG, Y.-E. Modified polyol synthesis of PtRu/C for high metal loading and effect of post-treatment. Journal of Power Sources, v. 195, n. 4, p. 1031-1037, 2010. 
66. Castro Luna, A.M.; Bonesi, A.R.; Moreno, M.S.; Zampieri, G.; Bengió, S.; TRIACA, W.E. Influence of metallic oxides on ethanol oxidation. International Journal of Hydrogen Energy, v. 39, n. 16, p. 8690-8696, 2014.

67. Paganin, V.A.; Ticianelli, E.A.; GonZalez, E.R. Development and electrochemical studies of gas diffusion electrodes for polymer electrolyte fuel cells. Journal of Applied Electrochemistry, v. 26, n. 3, p. 297-304, 1996.

68. CiAPINA, E.G.; TICIANELLI, E.A. The effect of electrochemical CO annealing on platinum-cobalt nanoparticles in acid medium and their correlation to the oxygen reduction reaction. Electrochimica Acta, v. 58, n., p. 172-178, 2011.

69. Bonnet, C.; Franck-Lacaze, L.; Ronasi, S.; Besse, S.; LAPICQUe, F. PEM fuel cell Pt anode inhibition by carbon monoxide: Non-uniform behaviour of the cell caused by the finite hydrogen excess. Chemical Engineering Science, v. 65, n. 10, p. 30503058, 2010.

70. Godol, D.R.M.; PereZ, J.; VILLULlas, H.M. Effects of alloyed and oxide phases on methanol Oxidation of Pt-Ru/C nanocatalysts of the same particle size. Journal of Physical Chemistry C, v. 113, n. 19, p. 8518-8525, 2009.

71. VilLARS, P.; CALVERT, L.D. Pearson's handbook of crystallographic data for intermetallic phases. Metals Park, Ohio: ASM International. 1991. v. 2

72. MOULDER, J.F.; STICKLE, W.F.; SOBOL, P.E.; BOMBEN, K.D. Handbook of X-ray photoelectron spectroscopy: a reference book of standard spectra for identification and interpretation of XPS data. Eden Prairie, Minn: Perkin-Elmer, 1992. p. $180-181$.

73. PereiRA, L.G.S.; Paganin, V.A.; Ticianelli, E.A. Investigation of the CO tolerance mechanism at several Pt-based bimetallic anode electrocatalysts in a PEM fuel cell. Electrochimica Acta, v. 54, n. 7, p. 1992-1998, 2009.

74. IOROI, T.; AKITA, T.; YAMAZAKI, S.-I.; SIROMA, Z.; FuJIWARA, N.; YASUdA, K. Comparative study of carbon-supported Pt/Mo-oxide and PtRu for use as CO-tolerant anode catalysts. Electrochimica Acta, v. 52, n. 2, p. 491-498, 2006.

75. HU, J.E.; LIU, Z.F.; EICHHORN, B.W.; JACKSON, G.S. CO tolerance of nanoarchitectured Pt-Mo anode electrocatalysts for PEM fuel cells. International Journal of Hydrogen Energy, v. 37, n. 15, p. 11268-11275, 2012.

76. Hassan, A.; Paganin, V.A.; Carreras, A.; Ticianelli, E.A. Molybdenum carbidebased electrocatalysts for $\mathrm{CO}$ tolerance in proton exchange membrane fuel cell anodes. Electrochimica Acta, v. 142, p. 307-316, 2014. 
77. Hassan, A.; Carreras, A.; Trincavelli, J.; Ticianelli, E.A. Effect of heat treatment on the activity and stability of carbon supported PtMo alloy electrocatalysts for hydrogen oxidation in proton exchange membrane fuel cells. Journal of Power Sources, v. 247, p. 712-720, 2014.

78. BABU, P.K.; KIM, H.S.; KUK, S.T.; CHUNG, J.H.; OldFIELD, E.; WIECKOWSKI, A.; SMOTKIN, E.S. Activation of nanoparticle Pt-Ru fuel cell catalysts by heat treatment: A 195Pt NMR and electrochemical study. The Journal of Physical Chemistry B, v. 109, n. 36, p. 17192-17196, 2005.

79. García, G.; Tsiouvaras, N.; Pastor, E.; Peña, M.A.; Fierro, J.L.G.; MartínezHUERTA, M.V. Ethanol oxidation on PtRuMo/C catalysts: In situ FTIR spectroscopy and DEMS studies. International Journal of Hydrogen Energy, v. 37, n. 8, p. 71317140, 2012.

80. Panagiotopoulou, P.; Kondarides, D.I.; Verykios, X.E. Selective methanation of CO over supported Ru catalysts. Applied Catalysis B: Environmental, v. 88, n. 34, p. 470-478, 2009. 